UNIVERSIDADE DE SÃO PAULO

ESCOLA DE ENGENHARIA DE SÃO CARLOS

DEPARTAMENTO DE ENGENHARIA ELÉTRICA

\title{
Algoritmo de Alocação Dinâmica de Largura de Faixa para Redes de Comunicação Móvel Celular
}

\author{
Eduardo Martinelli Galvão de Queiroz
}

\author{
Dissertação apresentada à Escola de \\ Engenharia de São Carlos da Universidade de São \\ Paulo para obtenção do título de Mestre em \\ Engenharia Elétrica.
}

São Carlos, SP. 



\title{
Algoritmo de Alocação Dinâmica de Largura de Faixa para Redes de Comunicação Móvel Celular
}

\author{
Eduardo Martinelli Galvão de Queiroz \\ Dissertação apresentada à Escola de \\ Engenharia de São Carlos da Universidade de São \\ Paulo para obtenção do título de Mestre em \\ Engenharia Elétrica.
}

Área de Concentração: Telecomunicações

Orientador: Prof. Dr. Amílcar Careli César

São Carlos, SP. 2008 

Aos meus pais,

Paulo e Dinorah. 

"A ciência é uma aventura de toda a raça humana para aprender a viver e talvez a amar o Universo onde se encontra. Ser uma parte dele é compreender, é conhecer-se a si próprio, é começar a sentir que existe dentro do Homem uma capacidade muito superior a que ele pensava ter e uma quantidade infinita de possibilidades humanas".

Isidor Isaac Rabi 



\section{Agradecimentos}

A vida é a principal escola da vida, onde os principais professores são as pessoas com quem convivemos. Agradeço a todos que fazem parte da minha vida e que fazem com que a jornada seja o âmago do meu ser.

Agradeço a Deus, pela minha vida.

Aos meus pais, Paulo e Dinorah, pelo carinho, dedicação e atenção sem os quais não conquistaria meus anseios.

Ao meu orientador, Prof. Dr. Amílcar Careli César, pela amizade, confiança, atenção e conhecimentos passados ao longo do trabalho e que o tornaram possível.

A toda minha família, meus avós, tios, tias, primas, por participarem tão positivamente de minha vida: Eugênio, Carmelina, Ulisses Queiroz, Leonilde, Marina, Regina, Luiz André, Patrícia, Fernanda, Gabriel, Maria Regina, Durval, Juca, Ulisses, Sandra, Natália, Juliana, Adriano, Adilene e Adriele.

A todos os amigos do Laboratório de Telecomunicações do Departamento de Engenharia Elétrica da USP de São Carlos pela amizade, confiança e conhecimentos que foram essenciais para a realização deste trabalho: Helvécio, Luizir, Anderson Betiol, Eduardo Aloi, Belini, Leandro, Denis, Danilo, Ricardo, Andrey, Anderson, Emiliano, Carmem, Clenilson, Valdemir, Pedro.

A todos os meus amigos aos quais meu respeito e amizade são eternos, dentre eles Adelaide, Alessandro, Antonio Carlos, Breno, Chico, Cláudia, Diego, Edílson, Gustavo, João Bruno, Lucas, Luiz, Luiz Cláudio, Mattheus, Mônica, Ricardo, Sarita.

A todos os professores de minha vida.

A todos os funcionários e professores da SEL-EESC e a USP, pela estrutura que oferecem para os estudos de pós-graduação. 



\section{Resumo}

QUEIROZ, E. M. G. Algoritmo de alocação dinâmica de largura de faixa para redes de comunicação móvel. 2008. 108 f. Dissertação (Mestrado) - Escola de Engenharia de São Carlos, Universidade de São Paulo, 2008

O crescente aumento da demanda de tráfego nas redes celulares vem aumentando a necessidade de uma melhor utilização dos recursos do sistema, já que sua expansão é custosa. Nas estações rádio base (ERB), a disponibilidade de largura de faixa de frequiências é limitada e desta maneira, em uma rede de comunicação móvel celular, o controle de admissão de chamadas exerce grande influência no desempenho do sistema, pois determina a utilização de banda das ERBs e se uma determinada quantidade de recursos (banda) será alocado ou não para uma determinada chamada. O desempenho da rede pode ser atrelado a determinados parâmetros, como a probabilidade de bloqueio de novas chamadas, probabilidade de bloqueio de chamadas handoff e a utilização de banda da rede.

Este trabalho propõe um controle de admissão de chamadas que, no atendimento de uma chamada, faz o empréstimo de banda de chamadas em andamento na célula no caso de banda insuficiente. O sistema adota um mecanismo heurístico que determina a banda disponível para novas chamadas conforme os valores de certos parâmetros do sistema. O empréstimo de banda é realizado em chamadas em andamento nas células até níveis mínimos estabelecidos para cada tipo de chamada, que se diferenciam pelas necessidades de banda de cada uma. $\mathrm{O}$ algoritmo foi aplicado às bandas e características de uma rede de terceira geração (3G), que possui chamadas de voz, videoconferência, interação multimídia, e-mail, downloads e transferência de arquivos e a uma rede GSM/GPRS (global system for mobile communications/ general packet radio service), que possui chamadas de voz e de dados.

Os resultados mostram melhorias na probabilidade de bloqueio de novas chamadas, probabilidade de bloqueio de handoff e na utilização de banda do sistema.

Palavras-chave: 1. Redes de comunicação móvel celular. 2. Algoritmos de alocação de banda. 3. Controle de admissão de chamadas. 4. Redes de terceira geração (3G). 5. Redes GSM/GPRS. 



\section{Abstract}

QUEIROZ, E. M. G. Dynamic bandwidth allocation algorithm for mobile communication networks. 2008. 108 f. Master's Dissertation - Escola de Engenharia de São Carlos, Universidade de São Paulo, 2008

The recent growth in traffic loads in cellular networks has seen the need for a better use of system resources as its expansion is expensive. In the base transceiver station (BTS), the bandwidth availability is limited. Thus, in cellular networks the call admission control greatly influences the system performance because it determines the bandwidth use of the BTSs and if an amount of resources will or will not be allocated to a call. The network performance can be evaluated by parameters such as blocking probability of new calls, dropping probability of handoff calls and bandwidth use.

This work proposes a call admission control that carries out the bandwidth borrowing when a call arrives and there is not enough bandwidth. The system makes use of a heuristic mechanism that determines the available bandwidth for the new calls according to some parameter values of the system. The bandwidth borrowing is applied to the cell ongoing calls until the minimum levels for each type are met. The algorithm was applied to the bandwidths and characteristics of a third generation cellular network, which supports voice calls, videoconference, multimedia interaction, e-mails, downloads and file transfers. It was also applied to a GSM/GPRS (global system for mobile communications/ general packet radio service), which supports voice and data calls.

The results show improvements in the blocking probability of new calls, dropping probability of handoff calls and in the bandwidth use of the system.

Keywords: 1. Mobile cellular communication networks. 2. Bandwidth allocation algorithms. 3. Call admission control. 4. Third generation cellular networks (3G) 5. GSM/GPRS Networks. 

Sumário

INDICE DE FIGURAS XVII

ÍNDICE DE TABELAS $X I X$

LISTA DE SIGLAS $X X I$

LISTA DE SÍMBOLOS XXIII

\section{CAPÍTULO 1}

INTRODUCÃO AO SISTEMA DE COMUNICACÃO

MÓVEL CELULAR 1

1.1. INTRODUÇÃO

1.2. REDES DE TERCEIRA GERAÇÃo $3 G$ 3

1.3. TECNOLOGIA GSM 5

1.4. Trabalhos Relacionados 7

1.5. ESCOPO DO TRABALHO 10

1.6. OrganizaÇão do Trabalho

\section{CAPÍTULO 2}

\section{PROPOSTA DE ALOCACÃO DE BANDA}

2.1. O Problema de AlocaÇão de ReCursos

2.2. MODELO DE PROPAGAÇÃo IMPLEMENTAdO 15

2.3. ESQUEMA PROPOSTO PARA REDE 3G 17

2.4. ESQUEMA PROPOSTO PARA REDE GSM/GPRS 25

2.4.1. Voz 25

2.4.2. DADOS PARA GPRS 26

2.4.3. Algoritmo PRoposto - REDE GSM/GPRS

2.5. PARÂMETROS do CAC 37

2.6. SimulaÇÃ̃o 
CAPÍTULO 3

RESULTADOS PARA O SISTEMA 3G 43

CAPÍTULO 4

RESULTADOS GSM/GPRS 61

CAPÍTULO 5

CONCLUSÕES 77 81 


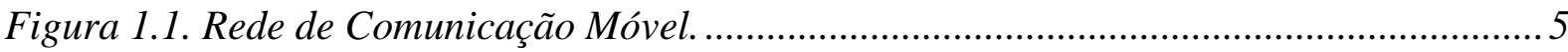

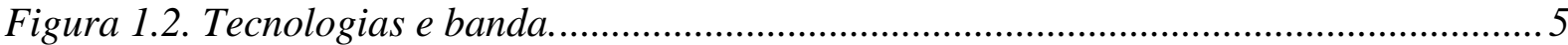

Figura 2.1. Direções possíveis de uma estação móvel............................................................. 16

Figura 2.2. Esquema de divisão de níveis de conexão.......................................................... 18

Figura 2.3. Níveis de conexão das classes de tráfego............................................................ 19

Figura 2.4. Fluxograma do sistema de empréstimo de banda .............................................. 20

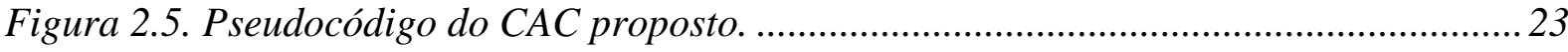

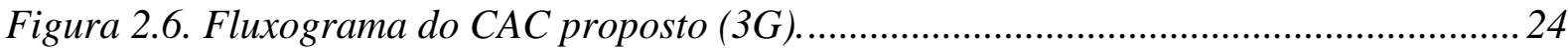

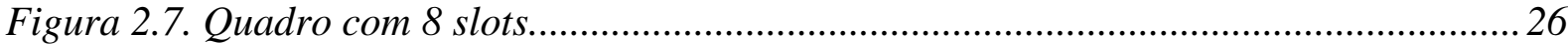

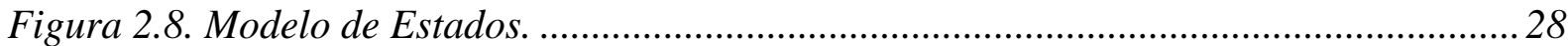

Figura 2.9. Pseudocódigo do algoritmo do sistema GSM/GPRS. ........................................... 33

Figura 2.10. Exemplo dos níveis mínimos para o empréstimo de banda..................................35

Figura 2.11. Fluxograma do CAC Proposto (GSM/GPRS). ...................................................... 36

Figura 2.12. Células Hexagonais da Rede Celular................................................................. 40

Figura 3.1. Probabilidade de Bloqueio de Novas Chamadas................................................ 44

Figura 3.2. Probabilidade de Bloqueio de Handoff................................................................ 45

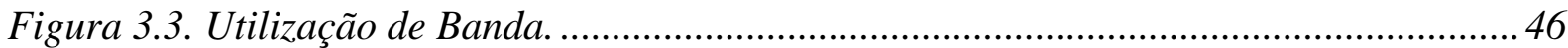

Figura 3.4. Probabilidade de Bloqueio de Novas Chamadas (Classe 1)................................ 47

Figura 3.5. Probabilidade de Bloqueio de Novas Chamadas (Classe 2)................................. 48

Figura 3.6. Probabilidade de Bloqueio de Novas Chamadas (Classe 3)................................ 48

Figura 3.7. Probabilidade de Bloqueio de Novas Chamadas (Classe 4)................................ 49

Figura 3.8. Probabilidade de Bloqueio de Novas Chamadas (Classe 5)............................... 49

Figura 3.9. Probabilidade de Bloqueio de Novas Chamadas (Classe 6)................................50

Figura 3.10. Probabilidade de Bloqueio de Handoff (Classe 1).............................................52

Figura 3.12. Probabilidade de Bloqueio de Handoff (Classe 3).............................................53

Figura 3.13. Probabilidade de Bloqueio de Handoff (Classe 4)............................................. 54

Figura 3.14. Probabilidade de Bloqueio de Handoff (Classe 5)............................................54

Figura 3.15. Probabilidade de Bloqueio de Handoff (Classe 6)............................................55

Figura 3.16. Throughput médio para a classe 3................................................................ 58

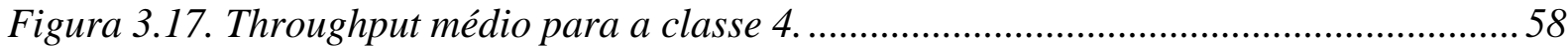

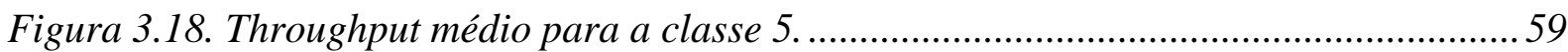




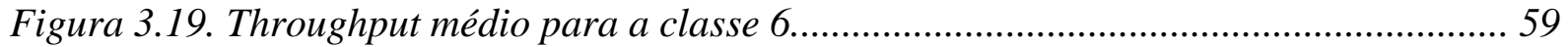

Figura 4.1. Probabilidade de Bloqueio de Novas Chamadas. ................................................ 63

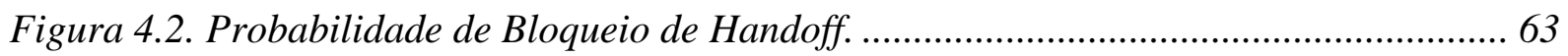

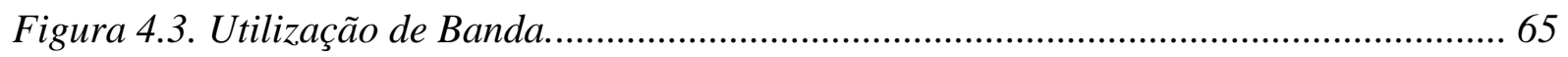

Figura 4.4. Probabilidade de Bloqueio de Novas Chamadas (Voz)......................................66 66

Figura 4.5. Probabilidade de Bloqueio de Novas Chamadas (Chamadas CS1).................... 66

Figura 4.6. Probabilidade de Bloqueio de Novas Chamadas (Chamadas CS2)................... 67

Figura 4.7. Probabilidade de Bloqueio de Novas Chamadas (Chamadas CS3).................... 67

Figura 4.8. Probabilidade de Bloqueio de Novas Chamadas (Chamadas CS4).................... 68

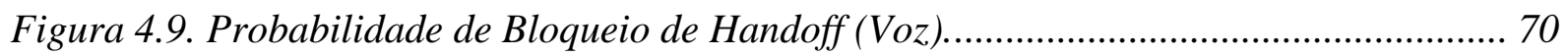

Figura 4.10. Probabilidade de Bloqueio de Handoff (Chamadas CS1)................................ 70

Figura 4.11. Probabilidade de Bloqueio de Handoff (Chamadas CS2)................................ 71

Figura 4.12. Probabilidade de Bloqueio de Handoff (Chamadas CS3)................................. 71

Figura 4.13. Probabilidade de Bloqueio de Handoff (Chamadas CS4)................................ 72

Figura 4.14. Throughput médio (Chamadas CS1). ............................................................. 74

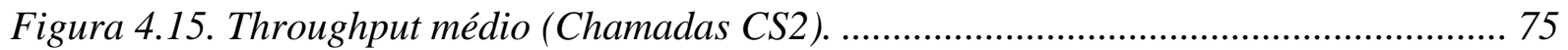

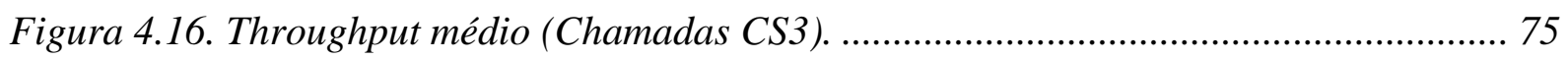

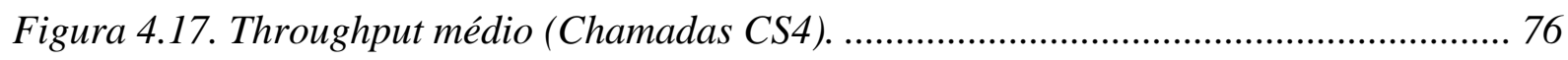


Tabela 2.1. Classes de Chamadas. 18

Tabela 2.2. Limiares para as mudanças dos níveis de conexão. 25

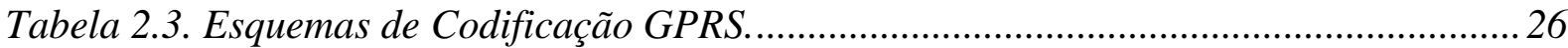

Tabela 2.4. Níveis de Conexão e número de slots do sistema GSM/GPRS.............................. 27

Tabela 2.5. Esquemas de codificação e seus limiares.................................................................2 29

Tabela 2.6. Percentagem das chamadas geradas para a rede $3 G$....................................... 41

Tabela 2.7. Percentagem das chamadas geradas para a rede GSM/GPRS........................... 41

Tabela 3.1. Parâmetros Utilizados na Rede $3 G$.................................................................... 43

Tabela 3.2. Comparação de Valores entre os Esquemas para novas chamadas..................... 45

Tabela 3.3. Comparação de Valores entre os Esquemas para chamadas Handoff................. 46

Tabela 3.4. Comparação de utilização de banda entre os esquemas. ..................................... 47

Tabela 3.5. Comparação de Valores da Classe 1 (Novas Chamadas). .................................... 50

Tabela 3.6. Comparação de Valores da Classe 2 (Novas Chamadas). ....................................50

Tabela 3.7. Comparação de Valores da Classe 3 (Novas Chamadas). ...................................51

Tabela 3.8. Comparação de Valores da Classe 4 (Novas Chamadas). ...................................51

Tabela 3.9. Comparação de Valores da Classe 5 (Novas Chamadas). .................................. 51

Tabela 3.10. Comparação de Valores da Classe 6 (Novas Chamadas)..................................51

Tabela 3.11. Comparação de Valores da Classe 1 (Chamadas Handoff). ............................... 55

Tabela 3.12. Comparação de Valores da Classe 2 (Chamadas Handoff). ............................... 55

Tabela 3.13. Comparação de Valores da Classe 3 (Chamadas Handoff). .............................. 56

Tabela 3.14. Comparação de Valores da Classe 4 (Chamadas Handoff). ...............................56

Tabela 3.15. Comparação de Valores da Classe 5 (Chamadas Handoff). .............................. 56

Tabela 3.16. Comparação de Valores da Classe 6 (Chamadas Handoff). ............................... 56

Tabela 4.1. Parâmetros Utilizados na Rede GSM/GPRS......................................................... 61

Tabela 4.2. Comparação valores entre os esquemas para novas chamadas........................... 64

Tabela 4.3. Comparação de valores entre os esquemas para chamadas Handoff. ................. 64

Tabela 4.4. Comparação da utilização de banda entre os esquemas. ..................................... 65

Tabela 4.5. Comparação de probabilidade de bloqueio (Voz). ............................................... 68

Tabela 4.6. Comparação de probabilidade de bloqueio (Chamadas CS1)............................. 68

Tabela 4.7. Comparação de probabilidade de bloqueio (Chamadas CS2).............................. 69

Tabela 4.8. Comparação de probabilidade de bloqueio (Chamadas CS3)..............................69 
Tabela 4.9. Comparação de probabilidade de bloqueio (Chamadas CS4). 69

Tabela 4.10. Comparação de probabilidade de bloqueio (Handoff - Voz). 72

Tabela 4.11. Comparação de probabilidade de bloqueio (Chamadas handoff CS1). 72

Tabela 4.12. Comparação de probabilidade de bloqueio (Chamadas handoff CS2). 73

Tabela 4.13. Comparação de probabilidade de bloqueio (Chamadas handoff CS3). 73

Tabela 4.14. Comparação de probabilidade de bloqueio (Chamadas handoff CS4). 73 


\begin{tabular}{|c|c|}
\hline AMR & adaptive multi-rate \\
\hline CAC & call admission control (controle de admissão de chamadas) \\
\hline $\mathbf{C} / \mathbf{I}$ & carrier-to-interference ratio \\
\hline CS1 & coding scheme 1 \\
\hline CS2 & coding scheme 2 \\
\hline CS3 & coding scheme 3 \\
\hline CS4 & coding scheme 4 \\
\hline CBR & constant bit rate \\
\hline CDMA2000 & code division multiple access 2000 \\
\hline dB & decibel \\
\hline EDGE & enhanced data rates for GSM evolution \\
\hline ERB & estação rádio base \\
\hline FDMA & frequency division multiple access \\
\hline HSDPA & high-speed downlink packet access \\
\hline FTP & file transfer protocol \\
\hline GPRS & general packet radio service \\
\hline GSM & global system for mobile communications \\
\hline IMT-2000 & International Mobile Telecommunications 2000 \\
\hline ITU & International Telecommunication Union \\
\hline MTSO & mobile telephone switching office \\
\hline PBH & probabilidade de bloqueio de handoff \\
\hline PBNC & probabilidade de bloqueio de novas chamadas \\
\hline PSTN & public switched telephone network \\
\hline QoS & quality of service \\
\hline
\end{tabular}


RSS received signal strength

SMS short message service

TDMA time division multiple access

UMTS Universal Mobile Telecommunications System

VBR variable bit rate

W-CDMA wideband CDMA 


\section{Lista de Símbolos}

$\alpha \quad$ total de chamadas de classes diferentes

$\Re j(t) \quad$ total de recursos de uma atividade $j$

$x_{i, j}(t) \quad$ total de recursos requisitados pela atividade $j$

$d_{i} \quad$ distância da estação móvel à ERB

$\lambda \quad$ taxa de chegada de chamadas nas células

$E_{\text {min }} \quad$ níveis mínimos de empréstimo de banda de chamadas em andamento (3G)

$E_{G m i n} \quad$ níveis mínimos de empréstimo de banda de chamadas em andamento (GPRS)

$C_{1} \quad$ conjunto 1 de níveis mínimos de empréstimo de banda (3G) na simulação

$C_{2} \quad$ conjunto 2 de níveis mínimos de empréstimo de banda (3G) na simulação

$C_{G 1} \quad$ conjunto 1 de níveis mínimos de empréstimo de banda (GPRS) na simulação

$C_{G 2}$ conjunto 2 de níveis mínimos de empréstimo de banda (GPRS) na simulação

$T_{n} \quad$ limiar da probabilidade de bloqueio de novas chamadas

$T_{h} \quad$ limiar da probabilidade de bloqueio de chamadas handoff

$T_{v} \quad$ limiar para o uso da variação da probabilidade de bloqueio de handoff

$\mathrm{PB}_{n} \quad$ expectativa de probabilidade de bloqueio de novas chamadas

$\mathrm{PB}_{h} \quad$ expectativa de probabilidade de bloqueio de chamadas handoff

$\triangle P B_{h} \quad$ variação da probabilidade de bloqueio de handoff

AD adaptabilidade

RP razão de perda

NC nível de conexão

L nível L de conexão

$X_{n b} \quad$ total de novas chamadas bloqueadas

$x(t) \quad$ posição no eixo $x$ da estação móvel 
$y(t) \quad$ posição no eixo y da estação móvel

a(i) posição no eixo $x$ da ERB $i$

b(i) posição no eixo y da ERB $i$

$N_{n} \quad$ total de novas chamadas

$X_{h b} \quad$ total de chamadas handoff bloqueadas

$N_{h} \quad$ total de chamadas handoff

$N_{\min } \quad$ banda mínima de conexão

$N_{\text {med }} \quad$ nível médio de conexão

$N_{\max } \quad$ banda máximo de conexão

$\beta_{i} \quad$ níveis de conexão para as chamadas da classe $i$

IB $\quad$ tamanho dos intervalos de banda 


\section{Capítulo 1}

\section{Introdução ao Sistema de Comunicação}

\section{Móvel Celular}

\subsection{Introdução}

O crescimento das redes de comunicação móvel celular teve grande avanço a partir do início dos anos 90 e conta agora com quase 3 bilhões de usuários em todo o planeta, com projeções que estimam em mais de 4 bilhões o número de assinantes de comunicação móvel no ano de 2010 [1]. No Brasil, o avanço também é grande. Em setembro de 2007, o país contava com mais de 120 milhões de usuários de telefones celulares [2], enquanto que em 1999 este número era de quase 8 milhões [3].

O perfil de uso da comunicação móvel celular vem apresentando mudanças durante os últimos anos. Com o avanço da infra-estrutura de comunicação celular como a de terceira geração (3G), os serviços de faixa larga apresentam rápido crescimento entre os usuários. Estes serviços incluem diferentes tipos de tráfego, como voz, vídeo e dados [4]. Os usuários destes serviços esperam uma qualidade de serviço (QoS) específica que depende de cada aplicação e também do serviço contratado da operadora para uma determinada finalidade como, por exemplo, videoconferência. Desta maneira, a rede de comunicação móvel celular deve garantir a qualidade de serviço de cada usuário e, ao mesmo tempo, maximizar o número de usuários que podem ser atendidos [5], utilizando de maneira ótima os recursos. 
As redes de terceira geração ainda estão em grande expansão em muitos países e em março de 2008 havia 293 redes 3G totalizando mais de 180 milhões de usuários [6]. No Brasil há a expectativa de maior oferecimento de serviços $3 \mathrm{G}$ em 2008, sendo que no país existe apenas uma operadora oferecendo serviços de terceira geração em alguns municípios [7]. Desta maneira, a utilização da tecnologia GSM/GPRS ainda predomina em grande parte do mundo e assim este trabalho também aborda esta tecnologia.

A cobertura de uma rede celular é dividida em áreas, chamadas células, servidas cada uma por estação rádio base (ERB). As estações convencionais são fixas e são conectadas com os MTSO's (mobile telephone switching office), que por sua vez são ligadas à PSTN (public switched telephone network). No sistema de uma rede celular, o controle de admissão de chamadas (CAC - call admission control) exerce papel fundamental no desempenho da rede de comunicação móvel e o seu funcionamento leva em conta vários fatores de decisão, como utilização de faixa de frequiências (banda) e QoS [8]. Este controle toma a decisão de aceitar ou não uma chamada tendo como base o tipo de serviço requisitado e suas características específicas de banda. Essas decisões precisam ser tomadas em tempo real e, desta maneira, o algoritmo de admissão de chamadas deve ser implementado nos recursos de computação das ERBs [8].

Em uma rede celular, a geração de uma chamada pode ocorrer em qualquer célula do sistema. Esta chamada, por sua vez, pode ficar sob a responsabilidade desta única célula ou, então, se houver movimentação do usuário, ficar sob a responsabilidade de uma célula vizinha. O procedimento de mudança de célula de uma chamada é o handoff [4].

No estudo deste sistema, alguns parâmetros podem ser expressos de uma maneira probabilística como a probabilidade de bloqueio de novas chamadas (PBNC) e a probabilidade de bloqueio de handoff $(\mathrm{PBH})$. A PBNC estabelece a probabilidade de uma nova solicitação de conexão ser bloqueada em uma célula, enquanto a $\mathrm{PBH}$ estabelece a 
probabilidade de uma chamada em curso ser finalizada quando deveria ocorrer a mudança para outra célula. O bloqueio de uma chamada devido ao handoff é considerado mais problemático para o usuário do que o bloqueio de uma nova chamada e, desta maneira, é desejável que a rede dê maior prioridade às chamadas handoff [5].

Um outro parâmetro importante é a utilização de banda, ou seja, como uma rede de comunicação móvel celular consegue gerenciar sua capacidade. Uma baixa utilização significa que parte dos recursos da infra-estrutura está sendo subutilizado e poderia estar beneficiando o desempenho global da rede.

O estudo do controle de admissão de chamadas foi realizado em vários trabalhos, como em [5], [8]-[23] e o estudo de adaptação de link em redes GSM/GPRS é realizado em muitos trabalhos, como em [25]-[32].

Neste projeto foram estudadas diversas formas de procedimentos que podem ser utilizadas para controle de admissão de chamadas (CAC) e foi proposto um mecanismo que beneficia as novas chamadas e também as chamadas handoff. Este mecanismo é analisado em uma rede de terceira geração (3G) e também em uma rede GSM/GPRS tradicional, onde foram consideradas as bandas típicas utilizadas pela tecnologia.

\subsection{Redes de Terceira Geração 3G}

As redes de comunicação móvel celular de terceira geração vêm ao encontro do anseio de usuários de acessar serviços disponíveis que são usuais em um computador convencional por meio do telefone celular. Operando em altas taxas de transmissão como, por exemplo, 6 Mbps, as redes de terceira geração têm o objetivo de oferecer transmissão de voz de alta qualidade, mensagens SMS, videoconferência, transferência de dados e outros serviços, cujo propósito é o oferecimento de altas taxas de transmissão.

A definição desta geração de telefone celular foi realizada em 1992 pela ITU (International 
Telecommunication Union), que lançou o IMT-2000 (International Mobile Telecommunications). A ITU iniciou o desenvolvimento de apenas uma tecnologia para que as operadoras não tivessem que lidar com muitas especificações ao implementar a rede [24]. Muitas propostas foram feitas para o IMT-2000, mas elas se reduziram a duas: W-CDMA (Wideband CDMA) e CDMA2000. A tecnologia W-CDMA foi proposta pela Ericsson e permite integração com redes GSM, enquanto que a tecnologia CDMA2000, proposta pela Qualcomm, não oferece tal disponibilidade. O primeiro W-CDMA foi adotado pela União Européia, que o chamou de UMTS (Universal Mobile Telecommunications System). Apesar de muitas disputas, a partir de 1999 as duas empresas proponentes começaram a entrar em acordo sobre um único padrão $3 \mathrm{G}$.

Enquanto as redes $3 \mathrm{G}$ ainda enfrentavam dificuldades em relação a definições de padrões técnicos e de operação, algumas operadoras de comunicação móvel celular começaram a implantar sistemas de transferência de dados em faixa larga, criando a chamada rede $2.5 \mathrm{G}$. O sistema EDGE (enhanced data rates for GSM evolution) e o GPRS (general packet radio service), que são serviços de dados com bandas maiores [21], são exemplos desta implementação [24].

Pelo aumento do número de usuários apresentado recentemente [6], o futuro das redes de comunicações móveis 3G tende a agregar a convergência de serviços nos aparelhos celulares. Esta convergência depende exclusivamente da padronização das tecnologias e dos investimentos das empresas de comunicação móvel para a efetivação da nova geração das redes celulares, que agrega diversas funcionalidades, conforme ilustrado na Figura 1.1. 


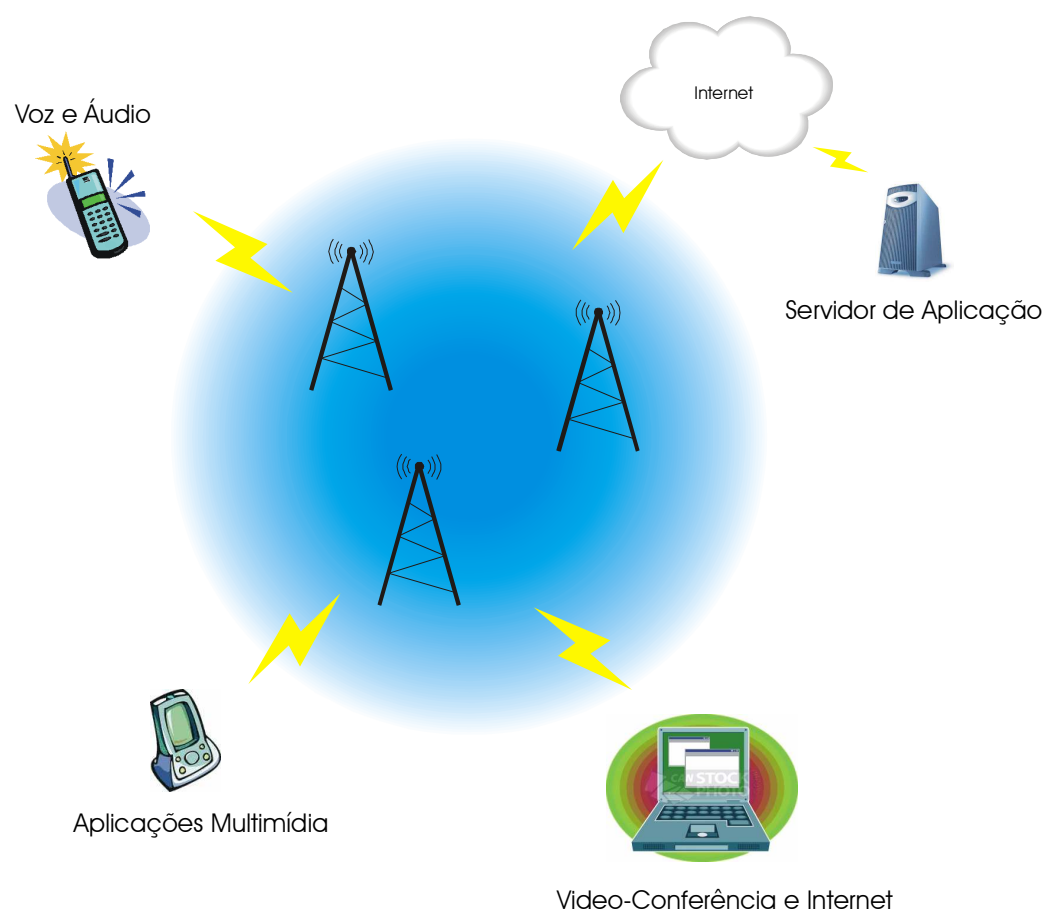

Figura 1.1. Rede de Comunicação Móvel.

A evolução das tecnologias quanto à banda oferecida para os usuários pode ser visualizada na Figura 1.2, onde está incluída a tecnologia 3G HSDPA (high-speed downlink packet access).

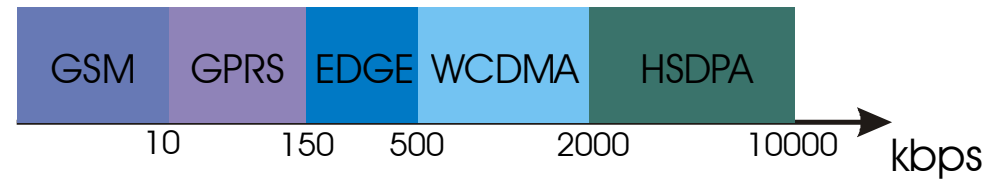

Figura 1.2. Tecnologias e banda.

\subsection{Tecnologia GSM}

A tecnologia GSM começou a ser amplamente utilizada no começo dos anos 90, quando o oferecimento de serviços de telefonia móvel de segunda geração (2G) apresentou grande crescimento em várias regiões do mundo [33]. O grupo responsável pela especificação do 
GSM foi criado em 1989 e a introdução comercial do padrão ocorreu em 1992. A proposta do grupo de criação era que a tecnologia oferecesse uma arquitetura aberta para que permitisse a combinação de equipamentos de diferentes fabricantes, reduzindo assim os custos de aquisição e manutenção dos sistemas.

Aproximadamente $80 \%$ dos celulares ativados no mundo utilizam a tecnologia GSM [6]. No Brasil este índice é de aproximadamente 70\% de acordo com dados recentes de 2007 [34]. Com a crescente oferta de serviços e demanda de tráfego, as operadoras tendem a buscar um padrão que ofereça serviços mais eficientes e que tenham uma maior banda para o suporte de aplicações multimídia, que são cada vez mais freqüentes em aparelhos celulares modernos. Uma das características que pode ser entendida como vantajosa é o fato de que o sistema GSM permite ao usuário ter seu número de celular e dados guardados em um pequeno chip, o que facilita a troca de aparelhos. E como o padrão GSM é o maior em utilização no mundo [6], o sistema oferece vantagens de compatibilidade de uso em muitos lugares do planeta.

A tecnologia GSM apresenta algumas características de transmissão de voz e dados que são analisados neste trabalho. O sistema utiliza o esquema AMR (adaptive multi-rate codec) que fornece diferentes codificações, oferecendo diferentes bandas para o tráfego de voz. Para a transmissão de dados, a tecnologia GPRS possui quatro esquemas de codificação (CS1, CS2, CS3 e CS4) que são utilizados em cada time slot (canais de dados PDCH - packet data channel) e que possui níveis de capacidade de correção de erros diferentes.

As operadoras globais investem agora na melhora de suas arquiteturas de rede para poder suportar o crescente aumento de tráfego provocado pelo rápido crescimento do uso de aplicações multimídia. Para atingir este objetivo baseiam-se na tecnologia 3G, que fornecem acesso em banda larga. 


\subsection{Trabalhos Relacionados}

Na literatura há vários trabalhos que tratam do controle de admissão de chamadas e também diversos tipos de abordagem [5], [12], [15]-[17], [19], [22], [25]-[32]. Os métodos envolvem programação linear [13], [14], redes neurais [8] e métodos heurísticos [5], [15] - [17].

Em [5] é proposto um controle de admissão de chamadas que trata seis diferentes tipos de tráfego com prioridades diferentes e divide a banda utilizada por cada tipo de chamada em $N$ níveis. O algoritmo realiza o empréstimo de banda de chamadas em andamento das células para atingir níveis mínimos de banda aceitáveis para novas chamadas e chamadas handoff. O algoritmo repõe a banda emprestada de cada chamada assim que o tráfego de chamadas em cada célula permitir.

Em [12] é proposto um esquema baseado na característica apresentada pelo tráfego web (WWW). Como este tipo de tráfego apresenta períodos em que não há transferência de dados, algumas conexões são agrupadas e compartilham a mesma banda utilizando uma política round robin.

Seguindo a mesma proposta de divisão de banda, [15] estabelece um algoritmo para o controle de admissão de chamadas que tenta primeiramente alocar a banda desejada para cada chamada, que por sua vez é discretizada em $N$ níveis, tendo um nível máximo $M$ e nível mínimo $m$. Quando não há banda suficiente na célula, o esquema realiza o empréstimo temporário de banda de algumas chamadas em andamento na célula. $\mathrm{O}$ esquema garante que a banda emprestada será condizente com o tipo de tráfego de cada chamada.

Em [16] a discretização de banda em $N$ níveis também é realizada, assim como o empréstimo de banda de chamadas em andamento para a alocação de novas chamadas e chamadas handoff. A distribuição de banda entre as chamadas em andamento é realizada baseada no esquema Max-Min, mas não utiliza nenhum esquema de adaptação do tamanho da banda reservada às chamadas handoff. 
Em [17] um controle de admissão de chamadas estabelece prioridades para chamadas em andamento e para novas chamadas. Não é realizado o estudo específico de chamadas handoff, que segundo os autores podem ser representadas por chamadas de alta prioridade. A banda necessária para cada chamada, que é dividida em $N$ níveis, é especificada em nível mínimo $\left(B_{\min }\right)$ e nível máximo $\left(B_{\text {máx }}\right)$. A diferença $\left(B_{\text {máx }}-B_{\min }\right)$ é o decréscimo máximo de banda que um certo tipo de chamada pode suportar. O trabalho também realiza o empréstimo de banda de chamadas em andamento para alocar novas chamadas.

Em [19] um esquema de empréstimo de banda é realizado para a alocação de chamadas quando a banda disponível na célula não é suficiente para atender o nível de banda máximo de uma chamada. $\mathrm{O}$ algoritmo possui um critério pelo qual as novas chamadas originadas em uma célula são bloqueadas se o número de chamadas correntes for maior ou igual a um determinado valor.

Em [22] é implementado um algoritmo que busca automaticamente o número ideal de canais que são alocados para as chamadas handoff em cada ERB. Esta busca é realizada com o monitoramento da probabilidade de bloqueio de chamadas handoff e com a introdução de um valor limiar (threshold) para este parâmetro.

Em [25] é proposto um esquema de adaptação de link em uma rede GPRS que modifica os esquemas de codificação utilizados nas conexões GPRS (CS1, CS2, CS3 ou CS4) conforme a BLER (block error rate) estimada do sinal.

Em [26] é proposto um controle de admissão de chamadas que aloca canais guarda de voz às conexões GPRS que tem como objetivo o aumento da utilização de canais.

Em [27] é realizado um estudo de desempenho em termos de throughput e delay para diferentes tipos de tráfego em relação aos quatro esquemas de codificação GPRS em uma rede GSM convencional.

Em [28] é analisado um algoritmo que realiza a alocação de time slots para conexões GPRS 
de maneira fixa e sob demanda. Estas duas abordagens são analisadas para tráfego web (WWW) e e-mail.

Em [29] é realizado um estudo sobre dois algoritmos de adaptação de link GPRS, ou seja, sobre a mudança do esquema de codificação. O primeiro é baseado na mudança da relação de C/I (carrier-to-interference ratio) e o segundo é baseado na estimativa de BLER.

Em [30] um estudo sobre os limiares de alteração de codificação de voz (AMR) é realizado. O trabalho faz uma análise sobre a mudança adaptativa dos limiares de modificação da codificação de voz utilizada pela conexão.

Em [31] é feito um estudo sobre o desempenho do esquema AMR em redes GSM e WCDMA (wideband CDMA) e mostra o aumento da eficiência de recursos no caso de uma rede GSM. O trabalho também apresenta a evolução do sistema AMR para melhoria na qualidade de voz.

Em [32] é realizado um trabalho sobre alternativas para lidar com congestionamento nas redes GSM e GSM/GPRS. O estudo aborda técnicas de custos de chamadas que variam conforme o tráfego da rede e que podem custar mais ou menos conforme a situação atual do sistema, como um aumento de preços durante um congestionamento na rede e preços muito baixos durante um período em que a rede encontra-se subutilizada.

Os trabalhos relacionados estudam a alocação de banda em redes de comunicação móvel celular em relação à capacidade total de recursos (banda) da rede e para isso adotam técnicas diferentes com o objetivo de um melhor desempenho do sistema. Em alguns trabalhos relacionados à tecnologia GSM/GPRS, são realizados estudos que abordam a adaptação de link do sistema de esquemas de codificação CS1, CS2, CS3 e CS4 e também do sistema AMR. 


\subsection{Escopo do Trabalho}

Este trabalho propõe um controle de admissão de chamadas (CAC) que inclui o empréstimo de banda de chamadas correntes nas células. O sistema implementado tem como foco a alocação de recursos em termos de banda disponível no sistema, no qual cada ERB tem uma capacidade de transmissão de dados de $30 \mathrm{Mbps}$, no caso de uma rede $3 \mathrm{G}$, independentemente da técnica de acesso utilizada, como WCDMA, HSDPA ou CDMA2000, assim como realizado em [5], [9], [12], [13], [15] - [17], [19], [21]. O trabalho também utiliza o CAC proposto em uma rede GSM/GPRS, na qual para cada ERB é considerada uma capacidade de transmissão de dados de 2 Mbps, onde as características de codificação de sinais no esquema AMR e GPRS são modeladas como bandas diferentes e então consideradas para a análise.

O algoritmo proposto realiza o empréstimo de banda de chamadas em andamento para atender às solicitações de novas chamadas e chamadas handoff. O algoritmo executa o empréstimo de banda de chamadas em andamento até um nível mínimo previamente especificado para cada classe de chamada e adapta esses níveis conforme a situação da rede.

O esquema também agrega o monitoramento de probabilidade de bloqueio de novas chamadas e de chamadas handoff para o ajuste da banda a ser disponibilizada para as novas chamadas. Como o sistema reserva $20 \%$ da banda de cada célula para as chamadas handoff, assim como realizado em [13], para cada empréstimo de banda realizado é verificada a possibilidade de agregar parte da banda reservada às chamadas handoff para as novas chamadas pelo acompanhamento das expectativas de probabilidades de bloqueio em relação a limiares previamente estabelecidos.

\subsection{Organização do Trabalho}

O trabalho apresentado divide-se em cinco capítulos. No Capítulo 2 é apresentado o problema de alocação de recursos em uma rede celular e o esquema proposto pelo projeto, 
além dos parâmetros do sistema e da simulação implementada para os sistemas 3G e GSM/GPRS. No Capítulo 3 são apresentados os resultados do esquema proposto para o sistema 3G e no Capítulo 4 são apresentados os resultados do esquema proposto para o sistema GSM/GPRS. Finalmente, no Capítulo 5, são apresentadas as conclusões do trabalho. 



\section{Capítulo 2}

\section{Proposta de Alocação de Banda}

\section{em Redes de Comunicação Móvel Celular}

\subsection{O Problema de Alocação de Recursos}

O aumento da demanda por serviços multimídia em comunicações móveis vem crescendo rapidamente nas últimas duas décadas. Desta maneira, a banda do sistema é um recurso que precisa ser otimizado para atender diferentes tipos de conexão com bandas diferentes como, por exemplo, serviços de multimídia que requerem até $6 \mathrm{Mbps}$ em uma rede $3 \mathrm{G}$. Um dos desafios da rede de comunicação móvel celular é oferecer os serviços requisitados pelos usuários e ao mesmo tempo lidar com a escassez de banda do sistema [19].

Neste sentido, a principal questão reside em como alocar recursos que melhoram o desempenho geral de rede, como a probabilidade de bloqueio de novas chamadas e de chamadas handoff. A alocação de recursos nas redes celulares pode ser entendida por meio de atividades (chamadas) que requerem recursos do sistema [20], que decide se cada solicitação será atendida ou não. Neste caso, seja $m$ o total de recursos disponíveis na rede celular para serem alocados em $n$ atividades. A atividade $j$ corresponde à requisição de uma célula por um recurso. $\mathfrak{R} j(t)$ é o total de recursos que a atividade $j$ requer no tempo $t$ no sistema e que varia dinamicamente com o tempo. O total de recursos requisitados pela atividade $j$ na célula $i$ no tempo $t$ é $x_{i, j}(t)$. A demanda total de uma atividade $j$ pode ser representada pela seguinte expressão 


$$
\sum_{i=1}^{m} x_{i, j}(t)=\Re j(t), \text { onde } 1 \leq j \leq n
$$

Estabelecendo $N_{i}$ o total de recursos de uma célula $i$ e considerando o total de requisições para um recurso na célula $i$ menor do que o total de recursos do sistema, $N$, então

$$
\sum_{i=1}^{m} \sum_{j=1}^{n} x_{i, j}(t) \leq N \text {, na qual } N \prec \sum_{i=1}^{m} N_{i}, 1 \leq i \leq m
$$

Da mesma forma, o total de recursos utilizados na célula $i$ será

$$
r_{i}(t)=\sum_{j=1}^{n} x_{i, j}(t), 1 \leq i \leq m
$$

O objetivo de um controle de admissão de chamadas é a maximização do uso dos recursos do sistema, o que se caracteriza por uma baixa probabilidade de bloqueio de novas chamadas e de chamadas handoff. Estes dois parâmetros são calculados por

$$
\begin{gathered}
P B_{n}=\frac{X_{n b}}{N_{n}} \\
P B_{h}=\frac{X_{h b}}{N_{h}}
\end{gathered}
$$

nas quais $P B_{n}$ é a expectativa de probabilidade de bloqueio de novas chamadas, $P B_{h}$ é a expectativa de probabilidade de bloqueio de chamadas handoff, $X_{n b}$ é o total de novas 
chamadas bloqueadas, $N_{n}$ é o total de novas chamadas, $X_{h b}$ é o total de chamadas handoff bloqueadas e $N_{h}$ é o total de chamadas handoff.

As abordagens para o problema de alocação de banda dividem-se em soluções baseadas em programação linear, como em [13] e [18], e soluções baseadas em métodos heurísticos, como em [15] - [17]. A abordagem que compreende a programação linear tem a vantagem de procurar por uma solução ótima e que beneficie vários parâmetros, porém seu tempo de computação é muitas vezes proibitivo para algumas arquiteturas de rede em que é empregado. Os métodos heurísticos não garantem a determinação de uma solução ótima de um problema, mas são capazes de retornar uma solução de qualidade em tempo adequado para as necessidades da aplicação [21].

Neste trabalho é proposto um método heurístico para o controle de admissão de chamadas em redes celulares.

\subsection{Modelo de Propagação Implementado}

No programa de simulação do sistema GSM/GPRS e do sistema 3G foi adotado um modelo de propagação como em [5]. O esquema considera três parâmetros: posição inicial dentro da célula, a direção e sua velocidade. Uma nova chamada gerada tem sua respectiva estação móvel em uma posição determinada de maneira aleatória e uniforme, ou seja, em qualquer posição dentro da célula. Há seis direções possíveis para a estação móvel, que são escolhidas uniformemente, conforme mostra a Figura 2.1. No instante $t$ em que o nível de sinal da célula vizinha é maior do que a da atual ocorre o handoff. Nesta nova célula, uma nova direção entre seis possíveis poderá ser determinada para o móvel. A velocidade considerada é constante e $50 \mathrm{~km} / \mathrm{h}$ e o raio da célula é $500 \mathrm{~m}$. Para o nível de sinal da estação móvel, é considerado o RSS (dBm) (received signal strength) utilizando o modelo log-normal em uma determinada posição $x(t), y(t)$ conforme [5] 


$$
\left.R S S\right|_{d B m}=-10 \gamma \log \left(d_{i}\right) \quad \text { para } d_{i}>1
$$

na qual $\gamma$ é o coeficiente de atenuação de percurso (geralmente $\gamma=2$ para ambientes como rodovias e $\gamma=4$ para microcélulas em uma cidade) e $d_{i}$ é a distância entre a estação móvel e a ERB da célula $i$, definido por

$$
d_{i}=\sqrt{(x(t)-a(i))^{2}+(y(t)-b(i))^{2}}
$$

na qual $(a(i), b(i))$ é a posição da ERB.

Utilizando a coordenada da estação móvel é possível determinar o instante $t$ da ocorrência do handoff pela verificação do nível de sinal RSS. Quando este procedimento de mudança é iniciado, uma requisição de banda é enviada para a nova célula para que a chamada seja alocada.

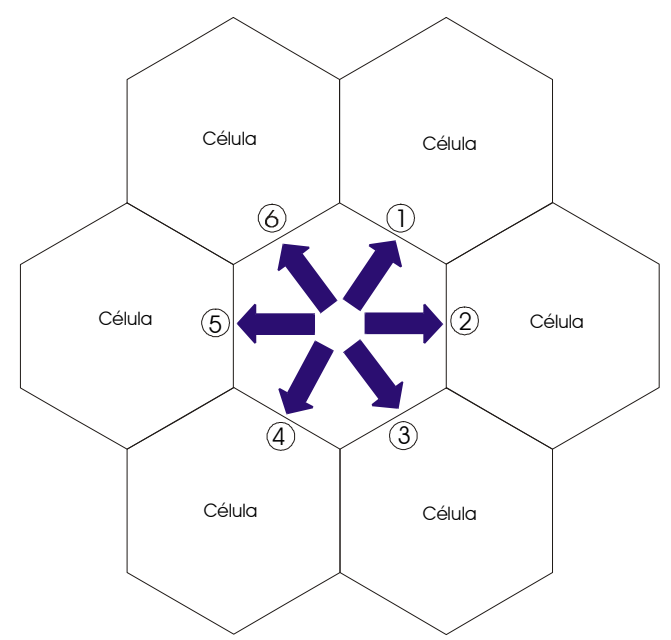

Figura 2.1. Direções possíveis de uma estação móvel.

No caso do sistema GSM/GPRS simulado, uma nova chamada pode ser bloqueada devido a valor de $\mathrm{C} / \mathrm{I}$ abaixo do limiar mínimo ou devido à indisponibilidade de banda na ERB. Uma chamada handoff também pode ser bloqueada devido a um valor de C/I abaixo de um limiar mínimo ou pela indisponibilidade de banda na célula de destino. 
No caso do sistema $3 \mathrm{G}$ simulado, uma nova chamada pode ser bloqueada devido à indisponibilidade de banda na ERB de origem e uma chamada handoff pode ser bloqueada devido à indisponibilidade de banda na célula de destino da chamada. Para este tipo de rede, o sinal recebido pelas estações móveis é considerado para a mudança de célula e não para o bloqueio de chamadas.

\subsection{Esquema Proposto para Rede 3G}

O esquema proposto neste trabalho considera a divisão da banda necessária para cada tipo de chamada em diferentes níveis possíveis de aceitação de conexão. Os níveis de conexão são as possíveis bandas que podem ser atribuídos ao tráfego. $\mathrm{O}$ esquema considera a existência de seis diferentes classes de chamadas, como sugerido em [5], [15] - [17], cada uma contendo uma banda máxima e uma banda mínima. Dentre os seis tipos de tráfego considerados, quatro deles são do tipo VBR (variable bit rate) e dois são CBR (constant bit rate), justamente as classes que não permitem variação em suas taxas de conexão. As classes de chamadas utilizadas estão representadas na Tabela 2.1.

As chamadas que pertencem às classes que permitem níveis diferentes de taxas de conexão são consideradas conforme sua tolerância à perda de banda. A tolerância à perda de banda é o quanto uma chamada em andamento pode ter sua banda diminuída. Desta maneira, quanto maior a tolerância, menor é a prioridade de um determinado tráfego porque mais banda pode ser emprestada. Cada classe de chamada possui uma banda mínima, $N_{\min }$ e uma banda máxima $N_{\max }$. A diferença entre estes dois níveis é dividida por outro parâmetro, $\beta_{i}$, que determina os níveis possíveis de conexão para a classe $i$ e o tamanho dos intervalos de banda $\left(I B_{i}\right)$ de cada classe, conforme

$$
I B_{i}=\frac{\mathrm{N}_{\max }-\mathrm{N}_{\min }}{\beta_{i}}
$$


Tabela 2.1. Classes de Chamadas.

\begin{tabular}{|c|c|c|c|c|c|}
\hline $\begin{array}{c}\text { Classes } \\
\text { Prioridade }\end{array}$ & $\begin{array}{c}\text { Banda Mínima } \\
\text { Banda máxima }\end{array}$ & $\begin{array}{c}\text { Média de } \\
\text { Duração (s) }\end{array}$ & \multicolumn{2}{|c|}{ Tipo } & $\beta$ \\
\hline 1 & $30-30 \mathrm{kbps}$ & 180 & Voz & CBR & 1 \\
\hline 2 & $256-256 \mathrm{kbps}$ & 300 & Videoconferência & CBR & 1 \\
\hline 3 & $1-6 \mathrm{Mbps}$ & 600 & Interação Multimídia & VBR & 6 \\
\hline 4 & $10-20 \mathrm{kbps}$ & 30 & E-mail & VBR & 5 \\
\hline 5 & $64-512 \mathrm{kbps}$ & 180 & Download, FTP & VBR & 4 \\
\hline 6 & $1-10 \mathrm{Mbps}$ & 120 & Transferência de Arquivos & VBR & 3 \\
\hline
\end{tabular}

Desta maneira, cada tipo de tráfego VBR permite um nível mínimo aceitável e também uma tolerância diferente de perda de banda, determinando assim as prioridades de cada chamada, devido aos diferentes valores de $\beta$ que são determinados para cada classe, conforme pode ser visualizado pela Figura 2.2.

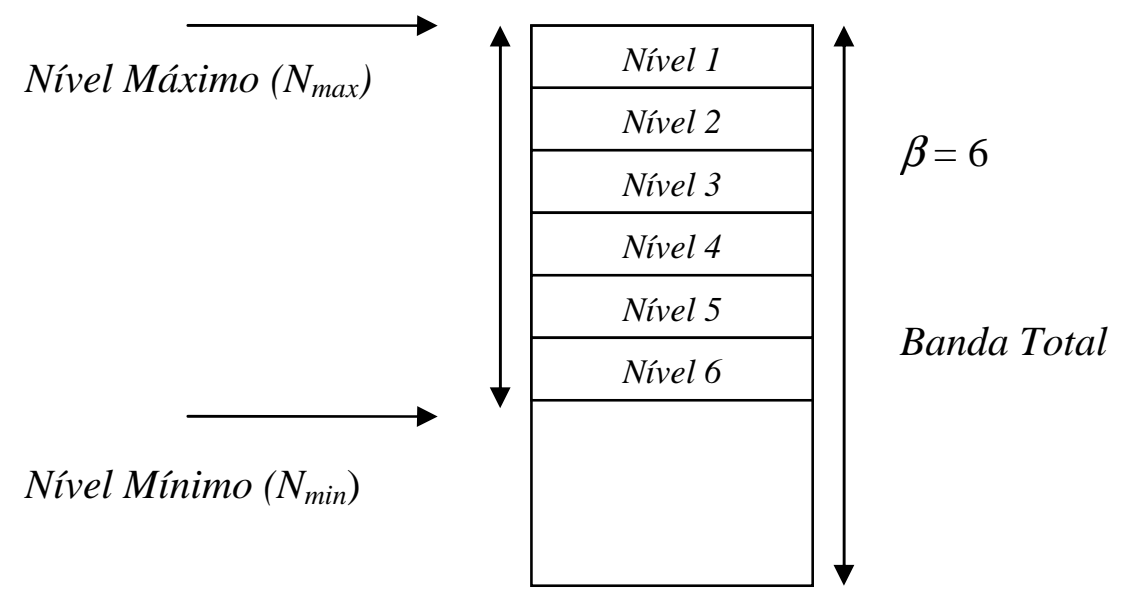

Figura 2.2. Esquema de divisão de níveis de conexão.

O parâmetro $\beta_{i}$ determina a "granularidade" da classe $i$ e, portanto, determina a prioridade do tipo de tráfego. Assim, o tráfego da classe 3 de uma rede $3 \mathrm{G}$, por possuir uma "granularidade" maior do que o de classe 6, tem uma maior prioridade. Desta maneira, terá 
um número maior de níveis nos quais sua conexão poderá ser estabelecida, conforme pode ser visualizado pela Figura 2.3.

\begin{tabular}{|l|}
\hline \multicolumn{1}{|l}{$\beta=6$} \\
\hline Nivel 1 \\
\hline Nivel 2 \\
\hline Nivel 3 \\
\hline Nivel 4 \\
\hline Nivel 5 \\
\hline Nivel 6 \\
\hline \\
\hline \\
\end{tabular}

Classe 3

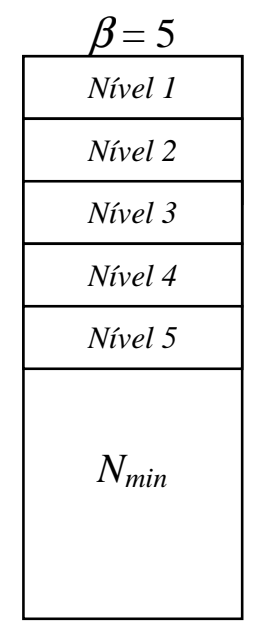

Classe 4

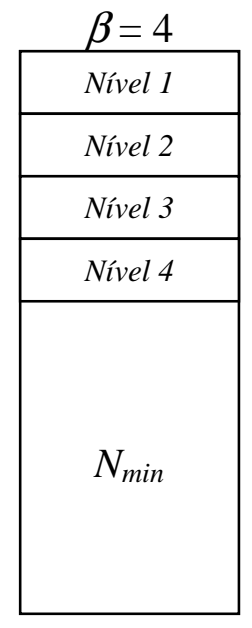

Classe 5

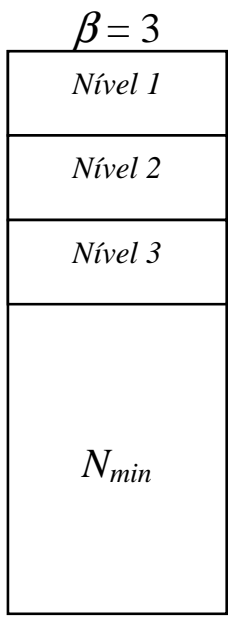

Classe 6

Figura 2.3. Níveis de conexão das classes de tráfego.

O controle de admissão de chamadas proposto foi configurado para uma rede de terceira geração (3G) e opera da seguinte maneira. Ele admite níveis de conexão aceitáveis para cada classe de chamada e reserva para as chamadas do tipo handoff uma banda de $20 \%$ da capacidade total (6 Mbps) de cada ERB, que é $30 \mathrm{Mbps}$. O uso da banda reservada será feito quando a banda disponível da célula não for suficiente para acomodar chamadas handoff. Para cada nova solicitação de conexão gerada, o CAC verifica a possibilidade de alocação do nível máximo de banda requisitado $\left(N_{\max }\right)$ pela chamada. No caso de não haver banda suficiente no sistema, é realizada uma verificação em ordem decrescente nos níveis de conexão permitidos para a chamada, até o nível mínimo $\left(N_{\min }\right)$. Se a banda disponível não for suficiente para a alocação de pelo menos o nível mínimo $\left(N_{\min }\right)$, é realizado um empréstimo de banda de chamadas que estão em andamento na célula. $\mathrm{O}$ algoritmo armazena as chamadas e inicia o procedimento de empréstimo de banda das chamadas em ordem crescente de prioridade (ou seja, da menor prioridade para a maior) e em ordem decrescente de tempo de permanência na célula. 
A diminuição dos níveis de conexão das chamadas em andamento ocorre da seguinte maneira. Considerando $\alpha$ como a quantidade de chamadas em andamento na célula, o algoritmo percorre-as rotativamente e diminui o nível de conexão em uma unidade cada chamada em andamento de maneira rotativa. Os níveis de banda das $\alpha$ chamadas são modificados, de maneira gradativa, até um nível mínimo de empréstimo de banda $\left(E_{\min }\right)$ especificado para cada classe de chamada. Este processo ocorre até que a banda emprestada seja suficiente para a alocação da chamada ou que todos os níveis das chamadas estejam nos níveis mínimos possíveis, especificados pelos conjuntos $C_{l}$ e $C_{2}$ e, neste caso, o empréstimo de banda é encerrado. O conjunto de níveis mínimos de empréstimo de banda estabelecido para as classes de chamadas é escolhido conforme dois parâmetros, $P B_{n}$ e $P B_{h}$, que indicam a expectativa de probabilidade de bloqueio de novas chamadas e de chamadas handoff, respectivamente, para cada célula. Caso $P B_{n}$ esteja acima de um certo limiar, $T_{n}$, e $P B_{h}$ abaixo de $T_{h}$, os níveis mínimos serão $C_{2}$. Caso um dos parâmetros não satisfaça os limiares, os níveis mínimos serão $C_{1}$, maiores do que os níveis $C_{2}$. O fluxograma da Figura 2.4 ilustra o procedimento.

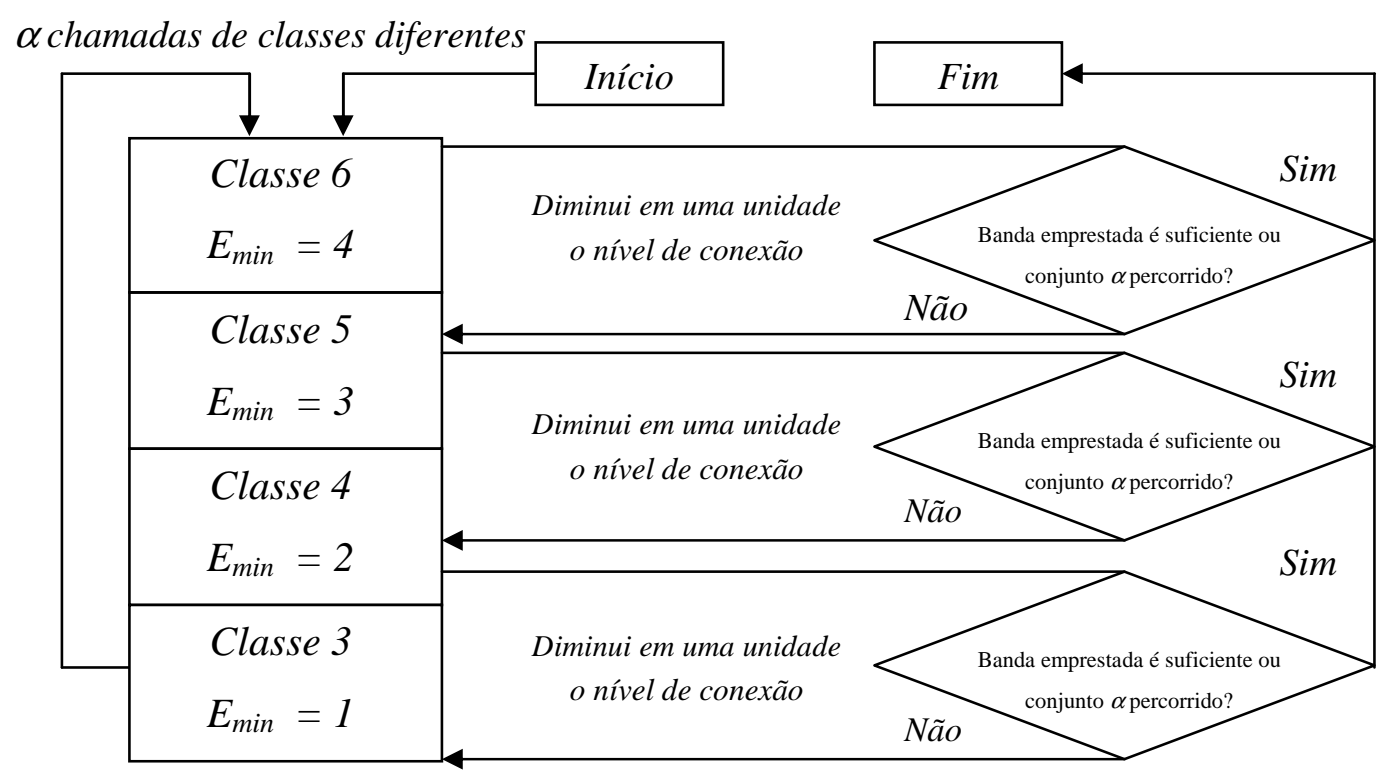

Figura 2.4. Fluxograma do sistema de empréstimo de banda. 
Adicionalmente a este mecanismo, outro tipo de verificação é realizado na ocorrência de empréstimo de banda. Neste caso, outro parâmetro $\left(\Delta P B_{h}\right)$ armazena a variação da expectativa de probabilidade de bloqueio de handoff e indica se a probabilidade aumentou ou diminui em relação a última computação. O módulo de $\Delta P B_{h}$ tem como limite o limiar $T_{v}$, que evita que o algoritmo agregue toda a banda reservada à handoff para novas chamadas. Quando há empréstimo de banda, o algoritmo verifica as variáveis de probabilidade $P B_{n}$ e $P B_{h}$. Caso estas duas variáveis satisfaçam seus respectivos limiares, $T_{n}$ e $T_{h}$, e $\Delta P B_{h}$ diminuiu $\left(\Delta P B_{h}<0\right)$ e seu módulo é menor que $T_{v}$, a banda considerada para a alocação de uma nova chamada contará com o aumento da mesma magnitude da banda reservada para as chamadas handoff.

Com este tipo de abordagem, o controle de admissão de chamadas apenas utiliza a banda reservada às chamadas handoff para as novas chamadas se os valores dos dois parâmetros $\left(P B_{n}\right.$ e $\left.P B_{h}\right)$ utilizados não são violados. Caso esse esquema não consiga atingir o nível mínimo de banda $\left(N_{\min }\right)$, então a chamada é bloqueada.

Para cada chamada handoff o controle de admissão verifica a possibilidade de alocar o nível máximo de banda para as classes de tráfego. Se não for possível devido à banda insuficiente disponível para a chamada na nova célula, o procedimento de empréstimo de banda de chamadas em andamento é iniciado seguindo o procedimento explicitado pela Figura 2.4. O conjunto de níveis mínimos de empréstimo de banda é estabelecido conforme o valor de $P B_{h}$. Caso seu valor esteja acima de $T_{h}$, o conjunto utilizado será $C_{2}$, caso contrário será $C_{1}$. A chamada será alocada apenas se a banda disponível for suficiente para acomodar pelo menos o nível médio de conexão $\left(N_{m e d}\right)$. Esta abordagem tenta minimizar a queda abrupta de taxa de conexão na ocorrência de handoff. O pseudocódigo do CAC proposto está na Figura 2.5 e seu fluxograma na Figura 2.6. 
se conexão é nova chamada

Se banda_disponível $\geq$ nível_máximo

Aloque o nível máximo para a chamada da classe $i$;

Senão

percorra os níveis $N_{i}$ da chamada da classe i em ordem decrescente;

Se banda_disponível $\geq N_{i}$

Aloque o nível $N_{i}$ para a chamada.

Senão

$$
\begin{aligned}
& \operatorname{Se}\left(P B_{h}<T_{h}\right) e\left(P B_{n}>T_{n}\right) \\
& E_{\min }(\text { Classe } 3)=C_{2}(\text { Classe } 3) \\
& E_{\min }(\text { Classe } 4)=C_{2}(\text { Classe } 4) \\
& E_{\min }(\text { Classe } 5)=C_{2}(\text { Classe } 5) \\
& E_{\text {min }}(\text { Classe } 6)=C_{2}(\text { Classe } 6)
\end{aligned}
$$$$
\operatorname{Se}\left(\Delta P B_{h}<0 \text { e }\left|\Delta P B_{h}\right|<T_{v}\right)
$$

Banda_disponível $=$ banda_disponível $+\left|\triangle P B_{h}\right|$. banda_reservada

Fim Se

Senão

$$
\begin{aligned}
& E_{\text {min }}(\text { Classe } 3)=C_{l}(\text { Classe } 3) \\
& E_{\text {min }}(\text { Classe } 4)=C_{l}(\text { Classe } 4) \\
& E_{\text {min }}(\text { Classe } 5)=C_{1}(\text { Classe } 5) \\
& E_{\text {min }}(\text { Classe } 6)=C_{1}(\text { Classe } 6)
\end{aligned}
$$

Banda_disponível $=$ banda_disponível

Fim Se

Enquanto Banda Disponível < Nível Mínimo $\left(N_{\min }\right)$ e todas as classes de chamadas não estão no nível mínimo correspondente $\left(E_{\min }\right)$ faça

$$
\text { Para } j=1 \text { até Número de Chamadas Disponíveis }(\alpha) \text { faça }
$$$$
\text { Nivel_Chamada[j] = Nivel_Chamada[j] }-1 \text {; }
$$

Fim para

Fim Enquanto

Banda Disponível Temporária $=$ Banda Disponível + Banda Emprestada Se Banda Disponível Temporária $\geq N_{\min }$

Aloque o nível mínimo $\left(N_{\min }\right)$ para a chamada

Fim Se

Fim Se 


$$
\begin{aligned}
& \text { senão handoff } \\
& \text { se (banda_disponível }+ \text { banda_reservada }) \geq \text { nível_máximo } \\
& \text { । } \quad \text { Aloque o nível máximo para a chamada da classe } i \text {; } \\
& \text { senão } \\
& \text { percorra os níveis } N_{i} \text { da chamada da classe i em ordem decrescente; } \\
& \text { se (banda_disponível }+ \text { banda_reservada }) \geq N_{i} \\
& \text { Aloque o nível } N_{i} \text { para a chamada. } \\
& \operatorname{Se}\left(P B_{h}>T_{h}\right) \\
& E_{\min }(\text { Classe } 3)=C_{2}(\text { Classe } 3) \\
& E_{\min }(\text { Classe } 4)=C_{2}(\text { Classe } 4) \\
& E_{\min }(\text { Classe } 5)=C_{2}(\text { Classe } 5) \\
& E_{\min }(\text { Classe } 6)=C_{2}(\text { Classe } 6)
\end{aligned}
$$

Senão

$$
\begin{aligned}
& E_{\min }(\text { Classe } 3)=C_{l}(\text { Classe } 3) \\
& E_{\min }(\text { Classe } 4)=C_{1}(\text { Classe } 4) \\
& E_{\min }(\text { Classe } 5)=C_{1}(\text { Classe } 5) \\
& E_{\min }(\text { Classe } 6)=C_{1}(\text { Classe } 6)
\end{aligned}
$$

Fim Se

Enquanto Banda Disponível < Nível Médio $\left(N_{\text {med }}\right)$ e todas as classes de chamadas não estão no nível mínimo correspondente $\left(E_{\min }\right)$ faça

$$
\begin{gathered}
\text { Para } j=1 \text { até Número de Chamadas Disponíveis }(\alpha) \text { faça } \\
\quad \text { Nível_Chamada[j] = Nível_Chamada[j] }-1 ;
\end{gathered}
$$

Fim para

Fim Enquanto

Banda Disponível Temporária $=$ Banda Disponível + Banda Emprestada

Se (Banda Disponível Temporária + banda_reservada $) \geq N_{\text {med }}$

Aloque o nível médio $\left(N_{\text {med }}\right)$ para a chamada

Fim Se

Fim Se

Fim Se

Fim Se

Figura 2.5. Pseudocódigo do CAC proposto. 


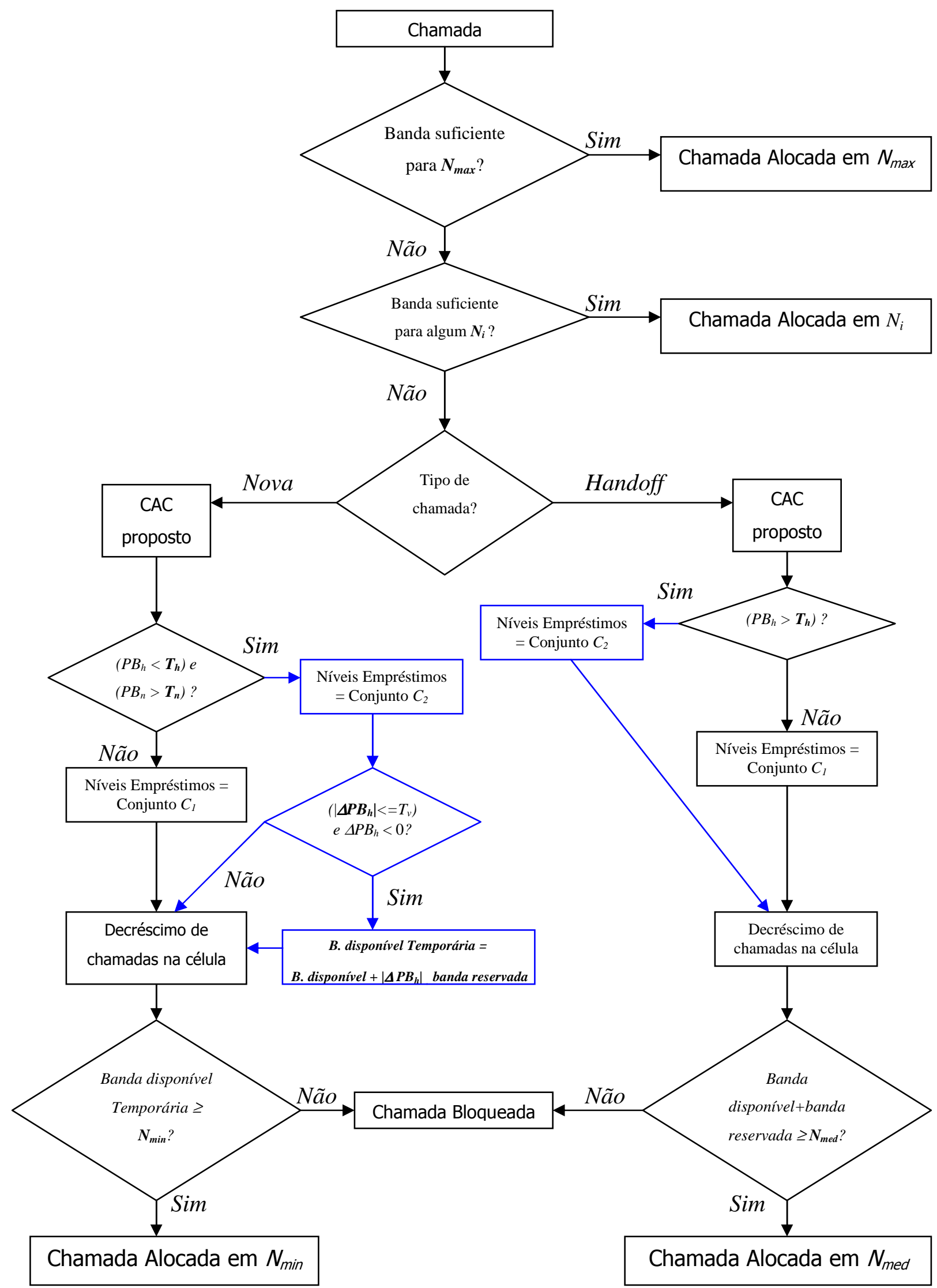

Figura 2.6. Fluxograma do CAC proposto (3G). 
Quando uma chamada deixa uma célula, a banda ocupada será adicionada à banda disponível da célula se a banda reservada para as chamadas handoff estiver completa. Caso contrário, a banda será adicionada à banda reservada. Com isso, a banda ocupada é utilizada para o aumento do nível de conexão de chamadas que foram utilizadas para o empréstimo de banda.

\subsection{Esquema Proposto para Rede GSM/GPRS}

O algoritmo de alocação de banda proposto também foi simulado para uma rede GSM/GPRS, considerando características de banda da rede quanto à voz (sistema AMR) e dados (número de slots). A descrição da simulação do sistema está nas próximas seções.

\subsubsection{Voz}

Especificamente para voz, o sistema GSM possui um mecanismo chamado AMR (adaptive multi-rate (AMR) voice coder) que determina, segundo a qualidade do canal, a banda a ser utilizada. Ao todo, são oito bandas: 12,2; 10,2; 7,95; 7,4; 6,7; 5,9; 5,15 e 4.75 kbps.

Na prática, conforme as especificações GSM [33], o sistema determina 4 larguras de faixa para serem utilizadas. Desta maneira, uma banda é utilizada segundo o nível C/I (carrier-tointerference ratio). No programa é utilizado o seguinte grupo: 4,75; 5,9; 7,4 e 12,2 kbps, conforme [33]. O grupo de limiares de C/I escolhido está na Tabela 2.2 [33].

Tabela 2.2. Limiares para as mudanças dos níveis de conexão.

\begin{tabular}{|c|c|}
\hline Mudança $($ kbps $)$ & Limiar $(d B)$ \\
\hline $12,2-7,4$ & 13 \\
\hline $7,4-5,9$ & 9 \\
\hline $5,9-4,75$ & 6 \\
\hline
\end{tabular}




\subsubsection{Dados para GPRS}

O sistema GSM/GPRS (general packet radio service) adota a divisão dos frames FDMA/TDMA em slots (Figura 2.7). Conforme a situação da rede pode-se alocar de um a oito slots para cada usuário [28]. Cada slot pode ser entendido como um canal lógico que transporta voz ou dados (no caso do GRPS). Os canais lógicos para dados são mapeados em canais físicos dedicados para dados, chamados PDCH (packet data channel).

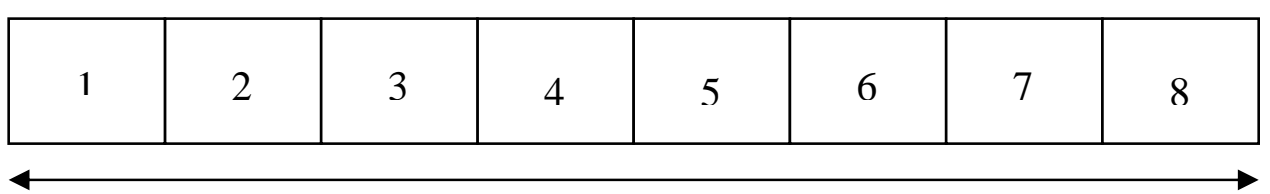

Figura 2.7. Quadro com 8 slots.

No sistema GPRS há a possibilidade de se utilizar quatro esquemas de codificação (CS1, CS2, CS3 e CS4), detalhados na Tabela 2.3.

Tabela 2.3. Esquemas de Codificação GPRS.

\begin{tabular}{|c|c|c|}
\hline $\begin{array}{c}\text { Esquema de } \\
\text { Codificação }\end{array}$ & Banda (kbps) & Sem RLC/MAC (kbps) \\
\hline CS1 & 9,05 & 8 \\
\hline CS2 & 13,4 & 12 \\
\hline CS3 & 15,6 & 14,4 \\
\hline CS4 & 21,4 & 20 \\
\hline
\end{tabular}

Desta maneira, a utilização de cada slot para uma conexão GPRS poderá ter quatro esquemas de codificação e, em relação às bandas possíveis, cada conexão poderá ter 8 níveis. Como exemplo, podemos imaginar uma conexão GPRS com o esquema de codificação CS4. Seus níveis poderão ser: 20 kbps (1 slot), 40 kbps (2 slost) , 60 kbps (3 slots), 80 kbps (4 
slots), $100 \mathrm{kbps}$ (5 slots), $120 \mathrm{kbps}$ (6 slots), $140 \mathrm{kbps}$ (7 slots), $160 \mathrm{kbps}$ (8 slots). A mesma esquematização pode ser atribuída para os esquemas de codificação CS1, CS2 e CS3. O esquema de divisão de níveis de conexão no sistema GSM/GPRS pode ser visualizado pela Tabela 2.4.

Tabela 2.4. Níveis de Conexão e número de slots do sistema GSM/GPRS.

\begin{tabular}{|c|c|c|c|c|}
\hline \multirow{2}{*}{$\begin{array}{c}\text { Codificação } \\
\text { Nivel } \\
\left(n^{\circ} \text { slots }\right) k\end{array}$} & CS1 & CS2 & CS3 & CS4 \\
\hline Nivel 8 & $(k b p s)$ & $(k b p s)$ & $(k b p s)$ & $(k b p s)$ \\
\hline Nivel 7 & 56 & 96 & 115,2 & 160 \\
\hline Nivel 6 & 48 & 84 & 100,8 & 140 \\
\hline Nivel 5 & 40 & 60 & 86,4 & 120 \\
\hline Nivel 4 & 32 & 48 & 72 & 80 \\
\hline Nivel 3 & 24 & 36 & 57,6 & 60 \\
\hline Nivel 2 & 16 & 24 & 28,8 & 40 \\
\hline Nivel 1 & 8 & 12 & 14,4 & 20 \\
\hline
\end{tabular}

\subsubsection{Algoritmo Proposto - Rede GSM/GPRS}

O programa de simulação para a rede GSM/GPRS adota os mecanismos de adaptação dos níveis mínimos de empréstimo de banda utilizados para a rede de terceira geração (3G) e considera as características da rede GSM/GPRS.

A variação do nível C/I é gerada utilizando um modelo de movimento de estados de Markov [35], que simula os estados possíveis que variáveis de um processo estocástico podem 
assumir. O modelo está na Figura 2.8.

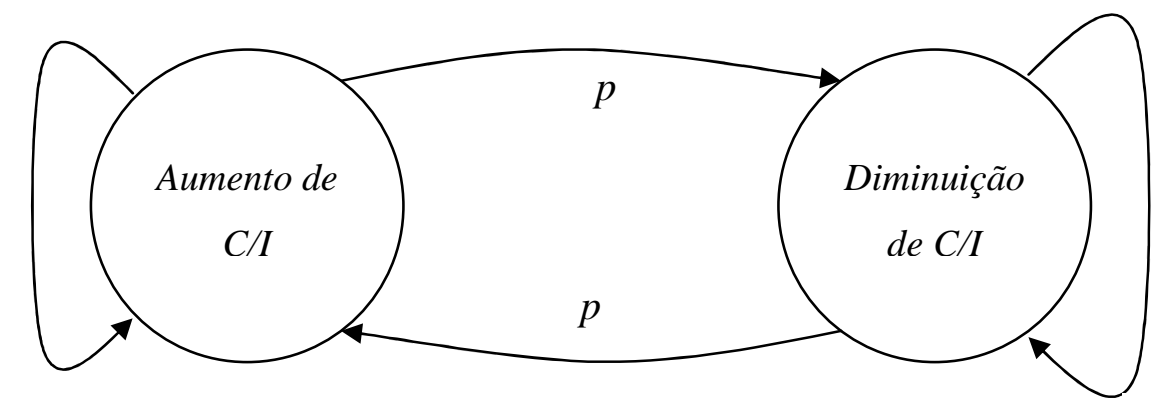

$(1-p)$

$(1-p)$

Figura 2.8. Modelo de Estados.

Uma estação móvel pode ter um aumento ou uma diminuição da relação C/I com probabilidade (1-p) e uma mudança da tendência de aumento ou diminuição com probabilidade $p$. O modelo segue a distribuição de C/I da Figura 17 de [35]. O valor $p$ utilizado na simulação é $p=0,1+\operatorname{random}[0,1] \times 0.2+a b s(26-(C / I)) \times 0.005$, na qual C/I é valor atual desta relação no intervalo $(0-52 \mathrm{~dB})$ e random[0,1] é um valor aleatório entre 0 e 1 . Este valor, $p$, é gerado para cada nova chamada ou handoff e comparado com um valor aleatório no intervalo 0 a 1 para determinar a tendência de aumento ou diminuição de C/I. O aumento ou diminuição ocorre em uma unidade (1dB).

$\mathrm{Na}$ geração de uma nova chamada, um determinado valor de $\mathrm{C} / \mathrm{I}$ é gerado (variando de $0 \mathrm{~dB}$ a $52 \mathrm{~dB}$ ) assim como sua tendência de aumento ou diminuição. No caso de uma chamada de voz, o algoritmo verifica em que nível de banda poderá alocar a chamada, conforme os limiares estabelecidos na Tabela 2.2. Depois, verifica a disponibilidade de banda da ERB e, no caso de insuficiência, os níveis inferiores são verificados.

No caso de uma chamada de dados (GPRS), o algoritmo também verifica o nível de sinal da chamada e determina o esquema de codificação possível conforme os limiares da Tabela 2.5 [32], para uma velocidade de $50 \mathrm{~km} / \mathrm{h}$. 
Tabela 2.5. Esquemas de codificação e seus limiares.

\begin{tabular}{|c|c|}
\hline Esquema de Codificação & Limiar (dB) \\
\hline CS1 & 9 \\
\hline$C S 2$ & 13 \\
\hline$C S 3$ & 15 \\
\hline$C S 4$ & 23 \\
\hline
\end{tabular}

Determinado o esquema de codificação, o programa verifica a possibilidade de alocar de 1 a 8 slots para a chamada. Caso a banda na ERB não seja suficiente para alocar a chamada no esquema de codificação escolhido, um esquema de codificação de menor banda será escolhido. Caso a banda seja insuficiente para alocar a menor banda possível do esquema de codificação CS1 (8 kbps) então o procedimento de empréstimo de banda é iniciado. Em termos de restrição física, a chamada é bloqueada se apresentar um nível de C/I menor do que $9 \mathrm{~dB}$. 


\section{Alocar chamada $i$ \\ Se conexão é nova ligação}

Se conexão é Voz

Verificar nível de $C / I \mathrm{~S}(i) \rightarrow$ nível de conexão de voz $j$ (Exemplo $=12,2$ kbps)

Se nível de $C / I S(i)<2 d B$

Chamada Bloqueada

\section{Senão}

Se nível de conexão $j>$ Banda Disponível ERB

Verificar níveis com menor banda (Exemplo: 7,4; 5,9 e 4,75 kbps)

Se banda suficiente $==$ TRUE

$$
\text { Alocação = TRUE; }
$$

Senão

$$
\text { Bloqueio da chamada }
$$

Fim Se

Senão

$$
\text { Alocação = TRUE; }
$$

Fim se

Fim Se

Senão (GPRS)

Verificar nível de $C / I \mathrm{~S}(i) \rightarrow$ Esquema de Codificação $j($ Exemplo $=$ CS4)

Se nível de $C / I S(i)<9 d B$

Chamada Bloqueada

Senão

Para Esquema de Codificação Escolhido (no caso, CS4) até CS1 faça

Para níveis de conexão $k$ de 8 a 1 faça (no caso de CS4: $160,140,120,100,80,60,40$ e 20 kbps - varia conforme o número de slots (1 1 a 8 ))

Se Nível Conexão $k \leq$ Banda Disponível

Alocar Chamada i em Nível Conexão $k$

Fim Se

Alocação = TRUE;

Fim Para

Fim Para

Fim se

Fim Se 
Se Alocação != TRUE

$$
\begin{aligned}
& \mathrm{Se}\left(P B_{h}<T_{h}\right) \text { e }\left(P B_{n}>T_{n}\right) \\
& \text { Se }\left(\Delta P B_{h}<0 \text { e }\left|\Delta P B_{h}\right|<T_{v}\right) \\
& \text { Banda_disponível }=\text { banda_disponível }+\left|\triangle P B_{h}\right| . \text { banda_reservada } \\
& E_{G \min }(C S 1)=C_{G 2}(\text { Classe } 3) \text {; } \\
& E_{G \min }(C S 2)=C_{G 2}(\text { Classe } 4) \text {; } \\
& E_{G \min }(C S 3)=C_{G 2}(\text { Classe } 5) \text {; } \\
& E_{\text {Gmin }}(\text { CS4 })=C_{G 2}(\text { Classe } 6) \text {; }
\end{aligned}
$$

Senão

$$
\begin{aligned}
& E_{G \min }(C S 1)=C_{G 1}(\text { Classe } 3) ; \\
& E_{G \min }(C S 2)=C_{G 1}(\text { Classe } 4) ; \\
& E_{G \min }(C S 3)=C_{G 1}(\text { Classe } 5) ; \\
& E_{G \min }(C S 4)=C_{G 1}(\text { Classe } 6) ;
\end{aligned}
$$

Banda_disponível $=$ banda_disponível

Fim Se

Enquanto Banda Emprestada < Nível Mínimo $\left(N_{\min }\right)$ e todas as classes de chamadas não estão no nível mínimo correspondente $\left(E_{G m i n}\right)$ faça

$$
\begin{array}{r}
\text { Para } j=1 \text { até Número de Chamadas Disponíveis faça } \\
\text { Nível_Chamada[j] = Nível_Chamada[j] }-1 \text {; }
\end{array}
$$

Fim para

Fim Enquanto

Banda Disponível Temporária $=$ Banda Disponível + Banda Emprestada

Se Banda Disponível Temporária $\geq N_{\min }$

Aloque o nível mínimo $\left(N_{\min }\right)$ para a ligação

Senão

Chamada Bloqueada

Fim Se

Fim Se 
Senão (é chamada Handoff)

Se conexão é Voz

Verificar nível de $C / I \mathrm{~S}(i) \rightarrow$ nível de conexão $j($ Exemplo $=12,2 \mathrm{kbps}$ )

Se nível de $C / I S(i)<2 d B$

Chamada Bloqueada

Senão

Se nível de conexão $j>$ Banda Disponível ERB

Verificar níveis com menor banda (Exemplo: 7,4; 5,9 e 4,75 kbps)

Se banda suficiente $==$ TRUE

Alocação = TRUE;

Senão

Bloqueio da chamada

Fim Se

Senão

Alocação $=$ TRUE;

Fim se

Fim Se

Senão (GPRS)

Verificar nível de $C / I \mathrm{~S}(i) \rightarrow$ Esquema de Codificação $j($ Exemplo $=C S 4)$

Se nível de $C / I S(i)<9 d B$

Chamada Bloqueada

Senão

Para Esquema de Codificação Escolhido (no caso, CS4) até CS1 faça

Para níveis de conexão $k$ de 8 a 1 faça (no caso de CS4: 160,140,120,100

80,60,40 e 20 kbps - varia conforme o número de slots (1 a 8))

Se Nível Conexão $k \leq$ Banda Disponível

Alocar Chamada i em Nível Conexão $k$

Alocação $=$ TRUE;

Fim Se

Fim Para

Fim Para

Fim Se

Fim Se 
Se Alocação ! = TRUE

$$
\begin{aligned}
S e\left(P B_{h}>T_{h}\right) & \\
E_{G \min }(C S 1) & =C_{G 2}(\text { Classe } 3) ; \\
E_{G \min }(C S 2) & =C_{G 2}(\text { Classe } 4) ; \\
E_{G \min }(C S 3) & =C_{G 2}(\text { Classe } 5) ; \\
E_{G \min }(C S 4) & =C_{G 2}(\text { Classe } 6) ;
\end{aligned}
$$

Senão

$$
\begin{aligned}
& E_{G \min }(C S 1)=C_{G 1}(\text { Classe } 3) ; \\
& E_{G \min }(C S 2)=C_{G 1}(\text { Classe } 4) ; \\
& E_{G \min }(C S 3)=C_{G 1}(\text { Classe } 5) ; \\
& E_{G \min }(C S 4)=C_{G 1}(\text { Classe } 6) ;
\end{aligned}
$$

Fim Se

Enquanto Banda Emprestada < Nível Médio $\left(N_{\text {med }}\right)$ e todas as classes de chamadas não estão no nível mínimo correspondente $\left(E_{G \min }\right)$ faça

$$
\begin{gathered}
\text { Para } j=1 \text { até Número de Chamadas Disponíveis faça } \\
\text { Nível_Chamada[j] = Nível_Chamada[j] }-1 ;
\end{gathered}
$$

Fim para

\section{Fim Enquanto}

Banda Disponível Temporária $=$ Banda Disponível + Banda Emprestada

Se (Banda Disponível Temporária + banda_reservada $) \geq N_{\text {med }}$

Aloque o nível médio $\left(N_{\text {med }}\right)$ para a ligação

Senão

\section{Chamada Bloqueada}

Fim Se

Fim Se

Fim Se

Figura 2.9. Pseudocódigo do algoritmo do sistema GSM/GPRS. 
No caso de $P B_{n}$ estar acima de um certo limiar $\left(T_{n}\right)$ e $P B_{h}$ abaixo de outro $\left(T_{h}\right)$, o algoritmo também determina alguns níveis mínimos de conexão para as chamadas que emprestam parte de suas bandas para a alocação de novas chamadas ou chamadas handoff na célula, da mesma maneira que é realizado para o modelo de redes de terceira geração (3G) na Seção 2.3. Desta maneira, caso $P B_{h}<T_{h}$ e $P B_{n}>T_{n}$, o empréstimo de cada tipo de tráfego, caracterizado pelo esquema de codificação que a chamada apresenta no momento, terá seu nível de conexão alterado até um nível mínimo $E_{G \min }\left(\right.$ Codificação) estabelecido pelo conjunto de níveis $C_{G 2}$. Caso contrário $\left(P B_{h}>T_{h}\right.$ e/ou $\left.P B_{n}<T_{n}\right)$, o conjunto de níveis mínimos determinados é $C_{G l}$. Este mecanismo também é aplicado caso a chamada seja uma conexão de voz. O pseudocódigo do algoritmo está na Figura 2.9.

Quando há empréstimo de banda, o algoritmo verifica as duas variáveis de probabilidade: $P B_{n}$ e $P B_{h}$. Caso estas duas variáveis satisfaçam seus respectivos limiares $\left(T_{n}\right.$ e $\left.T_{h}\right)$, a variação da probabilidade de bloqueio de handoff $\left(\triangle P B_{h}\right)$ for negativa, ou seja, se a probabilidade diminuiu em relação à última computação, e seu módulo estiver abaixo de um limiar $\left(T_{v}\right)$, a banda considerada para a alocação de uma nova chamada contará com o aumento da mesma magnitude da banda reservada para as chamadas handoff. Este mecanismo também é adotado para as redes de terceira geração (3G) na Seção 2.3. A adoção do limiar $T_{\nu}$ evita que o sistema agregue toda a banda reservada ao handoff para as novas ligações. A esquematização está na Figura 2.10 .

No caso das chamadas handoff, os valores dos níveis mínimos de conexão são escolhidos conforme o valor da expectativa de probabilidade de bloqueio de handoff $\left(P B_{h}\right)$. Caso $P B_{h}$ esteja com um valor maior que $T_{h}$, os valores mínimos escolhidos $\left(C_{G 2}\right)$ são diferentes daqueles que seriam $\left(C_{G 1}\right)$ caso $P B_{h}$ tenha um valor menor. 


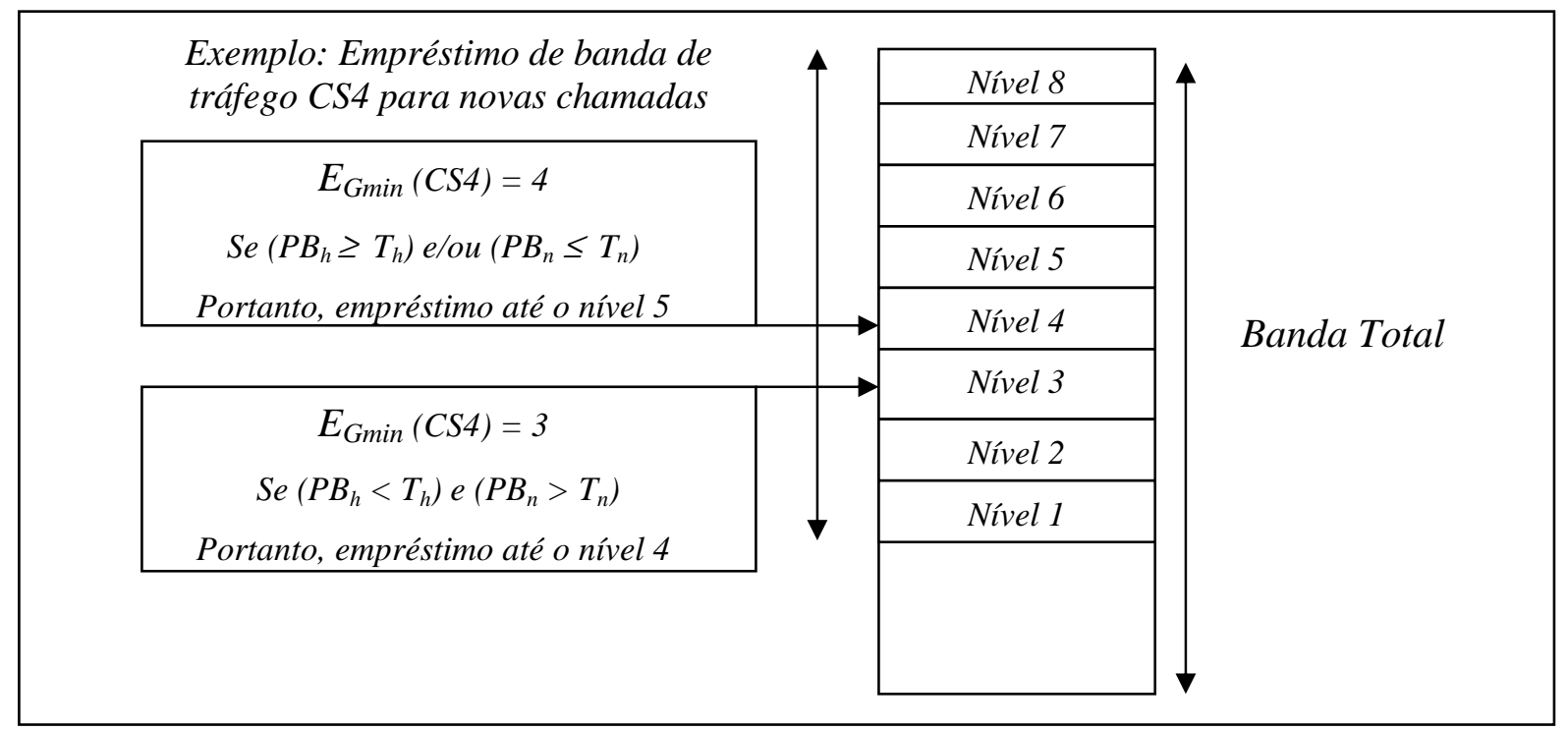

Figura 2.10. Exemplo dos níveis mínimos para o empréstimo de banda.

Com este tipo de mecanismo, o empréstimo de banda penaliza mais ou menos as chamadas em andamento na célula conforme a situação da rede. No caso do algoritmo, adotam-se diferentes tipos de prioridades para os diferentes esquemas de codificação (CS1, CS2, CS3 e CS4). O tráfego de voz apresenta a maior prioridade e não tem sua banda reduzida para o empréstimo de banda. No caso da rede GSM/GPRS as prioridades são determinadas conforme o nível mínimo atribuído $\left(E_{G \min }(\right.$ Codificação $\left.)\right)$ para cada uma e também pela ordem de procura das chamadas em andamento na célula, que se caracteriza primeiramente pelas chamadas com o esquema de codificação CS4 e sucessivamente até a CS1. O nível mínimo atribuído para o esquema de codificação CS4 $\left(E_{G \min }(\mathrm{CS} 4)\right)$ permite, no caso de empréstimo de banda de uma chamada com este esquema de codificação, uma diminuição maior nos níveis de conexão do que o nível atribuído para o esquema de codificação CS1. Desta maneira, a prioridade do esquema de codificação CS1 é maior do que a do esquema de codificação CS4. O fluxograma do algoritmo está na Figura 2.11. 


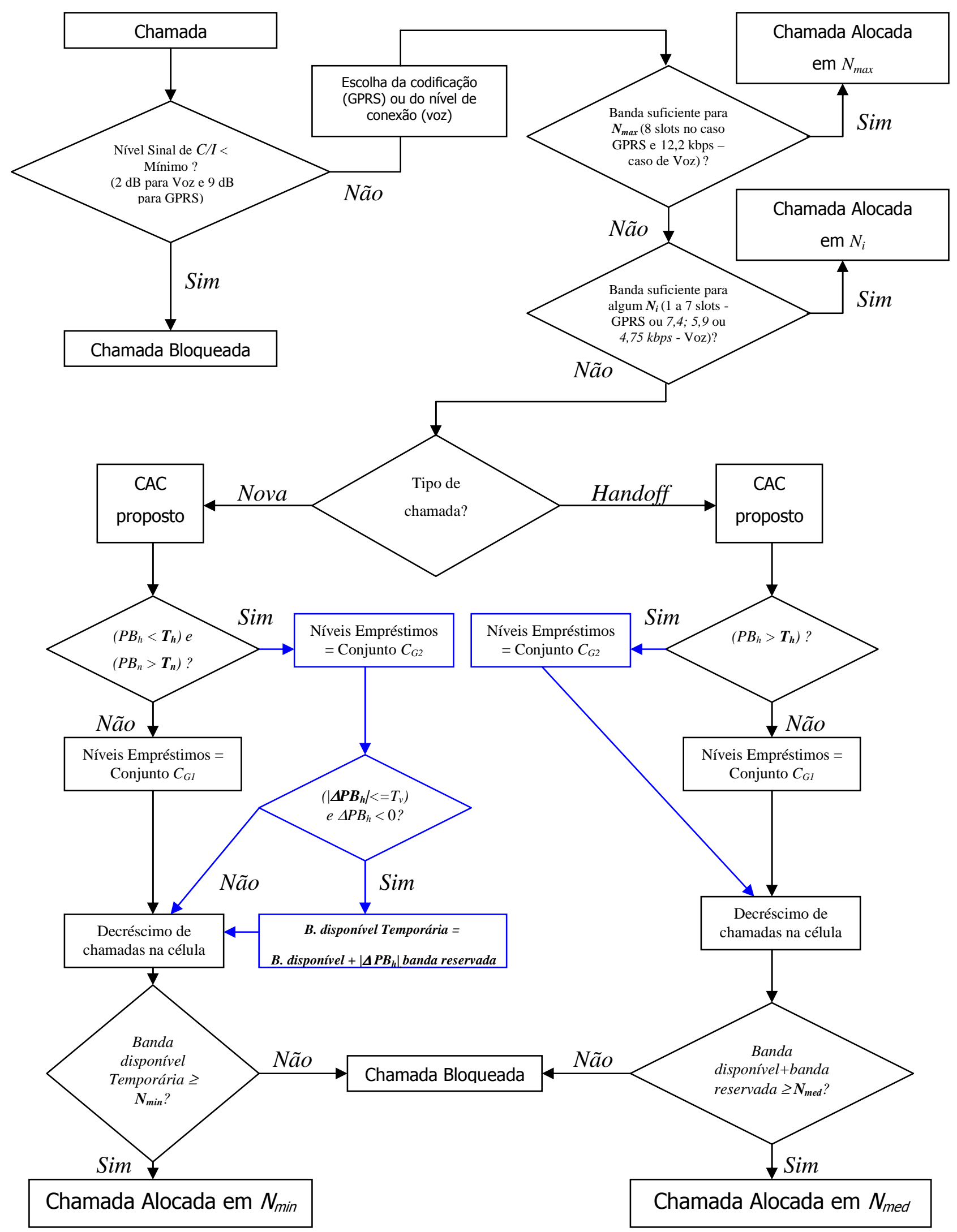

Figura 2.11. Fluxograma do CAC Proposto (GSM/GPRS). 


\subsection{Parâmetros do CAC}

O CAC é baseado em parâmetros para a divisão da banda de cada classe de conexão. Cada classe contém um nível máximo $\left(N_{\max }\right)$ e um nível mínimo $\left(N_{\min }\right)$ de banda e, assim, a tolerância de perda $(T P)$ possível pode ser expressa como [15]

$$
T P=N_{\max }-N_{\min }
$$

O sistema de empréstimo de banda pode ser entendido como um sistema justo de adaptação dos níveis de conexão conforme o tráfego de cada célula. Um outro parâmetro, chamado adaptabilidade $(A D)$, pode ser definido por [15]

$$
A D=\frac{T P}{N_{\max }}
$$

De acordo com (2.5.2), quanto maior sua tolerância de perda em relação a um mesmo nível máximo de conexão $\left(N_{\max }\right)$, o que significa uma maior adaptabilidade da conexão e conseqüentemente um menor $N_{\min }$, menor será a probabilidade de bloqueio, já que o intervalo possível para se estabelecer a conexão é maior.

Supondo que em uma célula do sistema uma conexão $C$ da classe $i$ esteja operando em um nível $L$ de conexão e tendo um parâmetro de divisão de banda $\beta_{i}$, como definido na Seção 2.3, o seu nível de conexão (NC) será [15]

$$
N C=N_{\max }-L \frac{T P}{\beta_{i}}
$$




$$
R P=\frac{L \frac{T P}{\beta_{i}}}{N_{\max }}
$$

Pela manipulação direta de (2.5.4) tem-se

$$
R P=\frac{L}{\beta_{i}} \frac{N_{\max }-N_{\min }}{N_{\max }}=\frac{L}{\beta_{i}} A D
$$

Desta maneira, para uma determinada célula o fator $L / \beta_{i}$ é constante e uma conexão da classe $i$ será estabelecida em um nível de conexão proporcional à sua adaptabilidade.

Considerando outra chamada $C^{\prime}$ na mesma célula e se $R P(C)$ e $R P\left(C^{\prime}\right)$ são as correspondentes razões de perda de tráfego da classe $i$ e da classe $j$, para $\beta_{i}=\beta_{j}$

$$
\frac{R P\left(C^{\prime}\right)}{R P(C)}=\frac{\frac{L}{\beta_{j}} A D\left(C^{\prime}\right)}{\frac{L}{\beta_{i}} A D(C)}=\frac{A D\left(C^{\prime}\right)}{A D(C)}
$$

A Equação (2.5.6) mostra que a relação entre as razões de perda das conexões é invariante em relação ao nível $L$. Mostra ainda que a adequação de uma conexão a um nível $L$ apresenta relação direta apenas com sua adaptabilidade e que sua razão de perda será tanto maior quanto maior for $A D$.

O CAC proposto opera utilizando estes conceitos de adaptabilidade das classes de chamadas para implementar as prioridades. $\mathrm{O}$ conceito destes parâmetros aplica-se mais diretamente à rede 3G, já que esta possui diferentes bandas para serviços diferentes. Na rede GSM/GPRS, as 
conexões de dados modificam-se somente em relação ao esquema de codificação utilizado (CS1, CS2, CS3 ou CS4). Os parâmetros estão relacionados diretamente com o conceito de divisão de banda em cada tipo de tráfego e com a dinâmica de alocação de banda do sistema e, desta maneira, não se relacionam com os aspectos físicos da rede.

\subsection{Simulação}

A simulação discreta de eventos foi implementada em linguagem ANSI C e a rede de comunicação móvel celular é formada por 100 células hexagonais, conforme exemplifica a Figura 2.12. Neste trabalho adota-se que cada ERB conta com uma banda de 30 Mbps para a rede $3 \mathrm{G}$ e de $2 \mathrm{Mbps}$ para a rede GSM/GPRS. A geração de novas chamadas ocorre seguindo uma distribuição de Poisson, tendo como média $\lambda$, que é o número de chamadas por segundo. Cada chamada gerada tem uma probabilidade $P_{h}$ de sofrer handoffs, que é comparada com valor aleatório gerado uniformemente no intervalo 0 a 1 . A classe da chamada $i$ é escolhida através de variável aleatória uniforme de 0 a 1, que é comparada com o percentual de tráfego da Tabela 2.6, no caso da rede 3G, e da Tabela 2.7, no caso da rede GSM/GPRS. O tempo de permanência em cada célula é proporcional à sua velocidade, que é definida como constante e cujo valor é $50 \mathrm{~km} / \mathrm{h}$.

A seqüência da simulação é a seguinte.

1. Geração de todos os eventos futuros das chamadas da simulação com distribuição de Poisson e média $\lambda$ :

Especificação da classe de tráfego de cada chamada;

Especificação do caminho a ser percorrido pela estação móvel caso a chamada seja alocada.

2. Análise das chamadas geradas na ordem que foram geradas Averiguação do tipo de cada chamada; 
Chamada do Controle de Admissão de Chamadas (CAC).

3. Contabilização dos parâmetros analisados

Probabilidade de bloqueio de novas chamadas;

Probabilidade de bloqueio de chamadas handoff;

Utilização de banda;

Throughput.

Os seis tipos de chamadas (Tabela 2.1) da rede de terceira geração (3G) são escolhidos segundo a percentagem determinada pela Tabela 2.6. Os tipos de chamadas da rede GSM/GPRS são exibidos na Tabela 2.7. As percentagens nas tabelas consideram uma possível distribuição de tráfego baseada nos trabalhos relacionados [15] e [16].

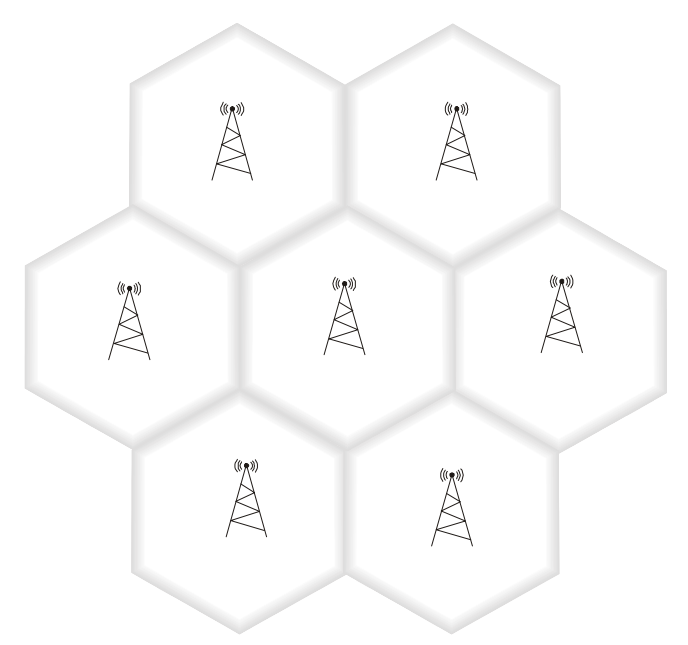

Figura 2.12. Células Hexagonais da Rede Celular. 
Tabela 2.6. Percentagem das chamadas geradas para a rede 3G.

\begin{tabular}{|c|c|c|c|c|c|}
\hline $\begin{array}{c}\text { Classes } \\
\text { Prioridade }\end{array}$ & $\begin{array}{c}\text { Banda Mínima } \\
\text { Banda máxima }\end{array}$ & $\begin{array}{c}\text { Duração Média } \\
(s)\end{array}$ & \multicolumn{2}{|c|}{ Tipo } & Percentual \\
\hline 1 & $30-30 \mathrm{kbps}$ & 180 & Voz & CBR & 40 \\
\hline 2 & $256-256 \mathrm{kbps}$ & 300 & Videoconferência & CBR & 15 \\
\hline 3 & $1-6 \mathrm{Mbps}$ & 600 & Interação Multimídia & VBR & 10 \\
\hline 4 & $10-20 \mathrm{kbps}$ & 30 & E-mail & VBR & 20 \\
\hline 5 & $64-512 \mathrm{kbps}$ & 180 & Download, FTP & VBR & 10 \\
\hline 6 & $1-10 \mathrm{Mbps}$ & 120 & $\begin{array}{c}\text { Transferência de } \\
\text { Arquivos }\end{array}$ & VBR & 5 \\
\hline
\end{tabular}

Tabela 2.7. Percentagem das chamadas geradas para a rede GSM/GPRS.

\begin{tabular}{|c|c|c|c|c|c|}
\hline $\begin{array}{c}\text { Tráfego } \\
\text { Prioridade }\end{array}$ & $\begin{array}{c}\text { Banda Mínima - } \\
\text { Banda máxima (kbps) }\end{array}$ & Muração & \multicolumn{2}{|c|}{ Tipo } & Percentual \\
\hline $1($ AMR $)$ & $4,75-12$ & 180 & Voz & CBR & 60 \\
\hline $2(C S 1)$ & $8-64$ & & & & \\
\hline $3(C S 2)$ & $12-96$ & 300 & Dados & VBR & 40 \\
\hline $4(C S 3)$ & $14,4-115,2$ & & & & \\
\hline $5(C S 4)$ & $20-160$ & & & & \\
\hline
\end{tabular}

A divisão das classes de chamadas segundo as Tabelas 2.6 e 2.7 tornam a geração das chamadas mais realista, já que o uso de uma rede celular é caracterizado principalmente por chamadas de voz. Este tipo de divisão foi encontrado em apenas um trabalho [5], mas os percentuais de cada classe de chamada não foram apresentados. 
Os eventos de cada chamada gerada são armazenados e tratados posteriormente pela simulação em ordem de chegada. Como exemplo, uma chamada $j$ da classe $i$ gerada no tempo $t$ com uma duração $\Delta t$ e que sofrerá $H$ handoffs conforme sua movimentação (velocidade $V$ ), terá a seguinte descrição de eventos:

Supondo $\Delta t=300 \mathrm{~s} ; V=50 \mathrm{~km} / \mathrm{h}(13,88 \mathrm{~m} / \mathrm{s})$ e distância a percorrer $=300 \times 13,88=4164 \mathrm{~m}$

Evento 1: $\quad$ Alocar $N_{\text {máx }}$ de j na célula 1 ou em algum nível L maior que $N_{\text {mín }}$;

Escolher direção de movimento e calcular distância percorrida na célula

Verificar nível de sinal RSS;

Atualizar distância total e verificar se é menor do que 4164 metros;

Evento 2: $\quad$ Alocar $N_{\text {máx }}$ de j na célula 2 ou em algum nível L maior que $N_{\text {med }}$;

Escolher direção de movimento e calcular distância percorrida na célula;

Verificar nível de sinal RSS;

Atualizar distância total e verificar se é menor do que 4164 metros;

Evento 3: Desocupar banda ocupada por j na célula 1;

Evento 4: $\quad$ Alocar $N_{\text {máx }}$ de j na célula 3 ou em algum nível L maior que $N_{\text {med }}$;

Escolher direção de movimento e calcular distância percorrida na célula;

Verificar nível de sinal RSS;

Atualizar distância total e verificar se é menor do que 4164 metros;

Evento 5: Desocupar banda ocupada por j na célula 2;

Evento 6: $\quad$ Alocar $N_{\text {máx }}$ de j na célula 4 ou em algum nível L maior que $N_{\text {med }}$;

Escolher direção de movimento e calcular distância percorrida na célula;

Verificar nível de sinal RSS;

Atualizar distância total e verificar se é menor do que 4164 metros;

Evento 7: Desocupar banda ocupada por j na célula 3;

Evento 8: $\quad$ Desocupar banda ocupada por j na célula 4, distância igual a 4164 metros. 


\section{Capítulo 3}

\section{Resultados para o Sistema 3G}

Neste capítulo são apresentados os resultados da simulação do algoritmo de alocação de banda para as redes de terceira geração $(3 \mathrm{G})$. Na simulação foram considerados os seguintes parâmetros mostrados na Tabela 1. Cada ponto dos gráficos corresponde à média aritmética de três simulações realizadas.

Tabela 3.1. Parâmetros Utilizados na Rede 3G.

\begin{tabular}{|c|c|}
\hline Chamadas por Segundo $(\lambda)$ & 0,$05 ; 0,1 ; 0,2 ; 0,3 ; 0,4 ; 0,5 ; 0,6 ; 0,7 ; 0,8 ; 0,9 ; 1,0$. \\
\hline Limiar $T_{h}$ & 0,05 \\
\hline Limiar $T_{n}$ & $0,05 \lambda$ \\
\hline Limiar $T_{v}$ & 0,85 \\
\hline Probabilidade de Handoff $\left(P_{h}\right)$ & $0,75(75 \%)$ \\
\hline Tempo Simulação $($ Sistema $)$ & 1 hora $(3600$ segundos $)$ \\
\hline Banda ERB & 30 Mbps \\
\hline
\end{tabular}

Foram simuladas quatro configurações diferentes. A primeira (A) refere-se ao esquema de alocação de banda sem o sistema de empréstimo de banda, ou seja, uma ligação de qualquer classe será aceita apenas se a banda disponível satisfizer algum nível de conexão. Outra simulação (B) refere-se ao esquema com empréstimo de banda, mas que não apresenta a funcionalidade de adaptação dos níveis mínimos de conexão para empréstimo de banda conforme parâmetros da rede (parte azul do fluxograma da Figura 2.6), que é base de [5], [15]- [17]. Adicionalmente, foi simulado o sistema de empréstimo de banda com outros níveis mínimos de adaptação de empréstimo para cada classe de chamada e também com o 
sistema de agregação da parte da banda reservada à handoff à banda considerada para alocação. Um conjunto de níveis $C_{2}$ de 4, 3, 2 e 1 (CN(1)), ou seja, o algoritmo pode emprestar banda das chamadas da classe 3 até o nível 5 (um nível acima do nível mínimo); da classe 4 até o nível 4; da classe 5 até o nível 3 e da classe 6 até o nível 2. Outro cenário simulado $(\mathrm{CN}(2))$ é com conjunto de níveis mínimos de empréstimo de banda $C_{2}$ de 3, 2, 2 e 1 (classes $3,4,5$ e 6). O valor do conjunto de níveis mínimos $C_{1}$ utilizado é 5 para a classe 3; 4 para a classe $4 ; 3$ para a classe 5 e 2 para a classe 6 .

A Figura 3.1 exibe a probabilidade de bloqueio de novas chamadas. Percebe-se que a adoção do sistema de empréstimo de banda melhora a probabilidade de bloqueio do sistema, e o uso do sistema adaptativo de níveis mínimos de empréstimo de banda melhoram a performance do sistema. A Tabela 3.2 mostra, para efeito de análise, os valores da probabilidade de bloqueio para três valores de $\lambda(0,1,0,5$ e 1,0$)$ e compara o algoritmo proposto neste trabalho $(\mathrm{CN})$ com o algoritmo $\mathrm{B}$.

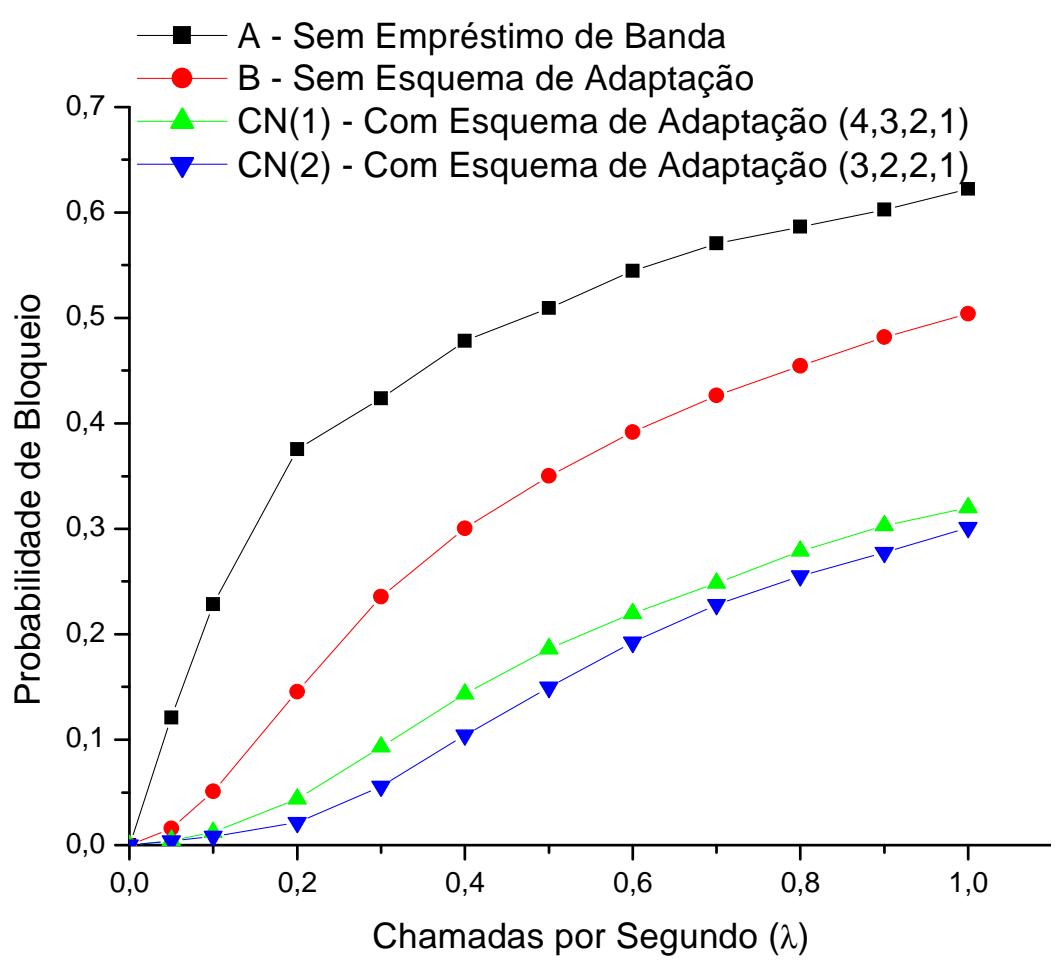

Figura 3.1. Probabilidade de Bloqueio de Novas Chamadas. 
A Figura 3.2 exibe a probabilidade de bloqueio de handoff. É possível perceber que com o sistema proposto há uma melhora de desempenho em relação ao algoritmo B. Este fato devese ao sistema adaptativo também empregado no caso de chamadas handoff, que considera outro conjunto de níveis mínimos de empréstimo de banda caso a expectativa de probabilidade de bloqueio de handoff $\left(P B_{h}\right)$ seja maior que $T_{h}$. A Tabela 3.3 exibe alguns valores da probabilidade de bloqueio para os diferentes algoritmos e há melhoria de até $23 \%$.

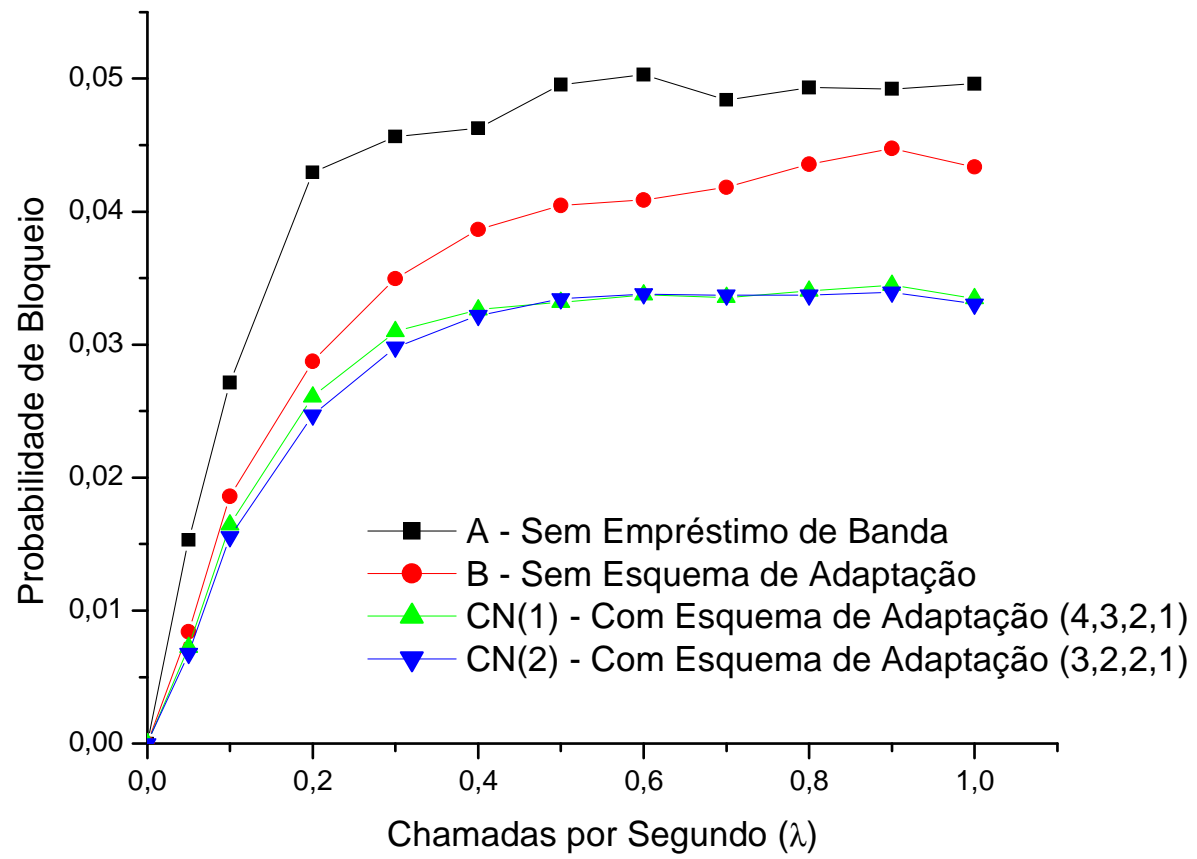

Figura 3.2. Probabilidade de Bloqueio de Handoff.

Tabela 3.2. Comparação de Valores entre os Esquemas para novas chamadas.

\begin{tabular}{|c|c|c|c|c|c|}
\hline$\lambda$ & Algoritmo B & Algoritmo CN(1) & Dif.(\%) & Algoritmo CN(2) & Dif.(\%) \\
\hline 0,1 & 0,05102 & 0,01215 & $-76,1$ & 0,00817 & $-83,9$ \\
\hline 0,5 & 0,35001 & 0,18619 & $-46,8$ & 0,14974 & $-57,2$ \\
\hline 1,0 & 0,50396 & 0,32005 & $-36,5$ & 0,30127 & $-40,2$ \\
\hline
\end{tabular}


Tabela 3.3. Comparação de Valores entre os Esquemas para chamadas Handoff.

\begin{tabular}{|c|c|c|c|c|c|}
\hline$\lambda$ & Algoritmo B & Algoritmo $C N(1)$ & Dif.(\%) & Algoritmo CN(2) & Dif.(\%) \\
\hline 0,1 & 0,0186 & 0,01646 & $-11,5$ & 0,01555 & $-16,3$ \\
\hline 0,5 & 0,04045 & 0,03319 & $-17,9$ & 0,03345 & $-17,3$ \\
\hline 1,0 & 0,04334 & 0,03346 & $-22,7$ & 0,03304 & $-23,7$ \\
\hline
\end{tabular}

Na Figura 3.3 e na Tabela 3.4 são exibidos a utilização de banda e alguns valores de utilização para diferentes cenários. Há uma melhoria na utilização de banda em relação ao algoritmo B devido ao melhor aproveitamento da banda proporcionado pelo sistema adaptativo dos níveis mínimos de empréstimo de banda.

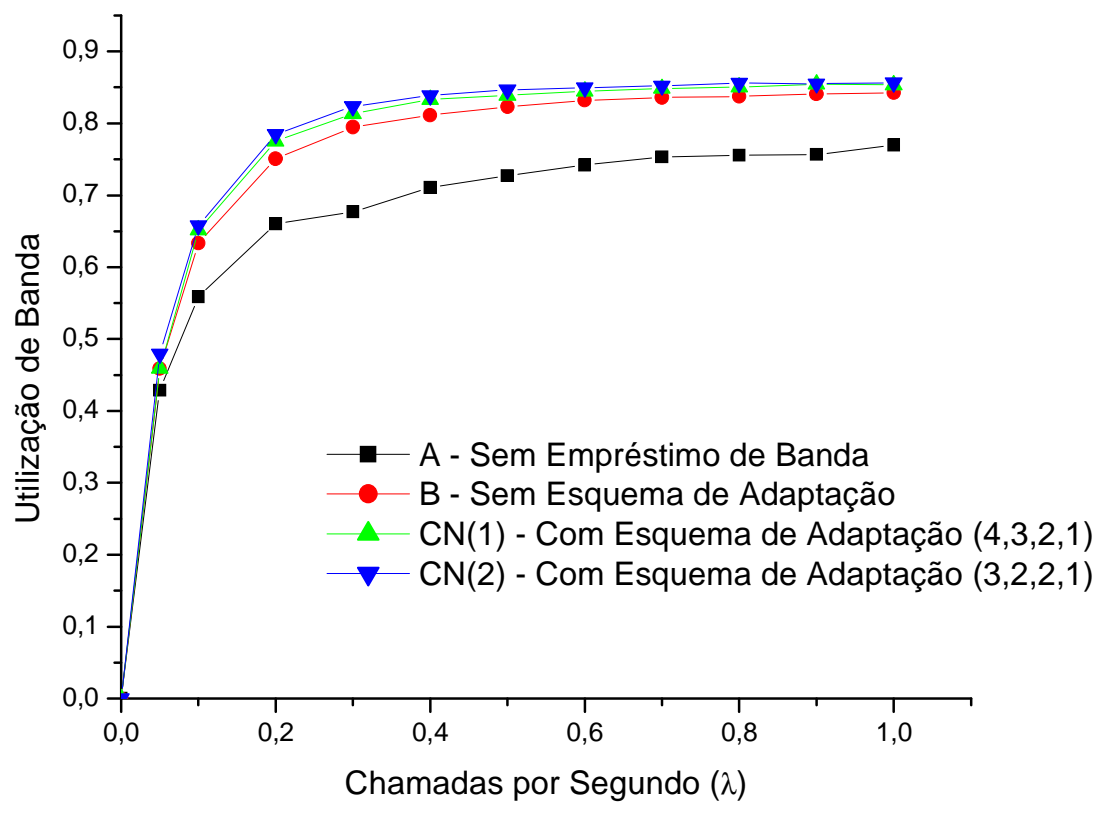

Figura 3.3. Utilização de Banda. 
Tabela 3.4. Comparação de utilização de banda entre os esquemas.

\begin{tabular}{|c|c|c|c|c|c|}
\hline$\lambda$ & Algoritmo B & Algoritmo CN(1) & Dif.(\%) & Algoritmo CN(2) & Dif.(\%) \\
\hline 0,1 & 0,63306 & 0,65149 & $+2,9$ & 0,65776 & $+3,9$ \\
\hline 0,5 & 0,82294 & 0,83879 & $+1,9$ & 0,84654 & $+2,8$ \\
\hline 1,0 & 0,8427 & 0,85323 & $+1,2$ & 0,85643 & $+1,6$ \\
\hline
\end{tabular}

As classes de chamadas foram analisadas separadamente e os gráficos das Figuras 3.4 - 3.9 mostram a probabilidade de bloqueio de novas chamadas de cada classe de chamada. As Tabelas 3.5 - 3.10 mostram alguns valores de probabilidade de bloqueio para as classes.

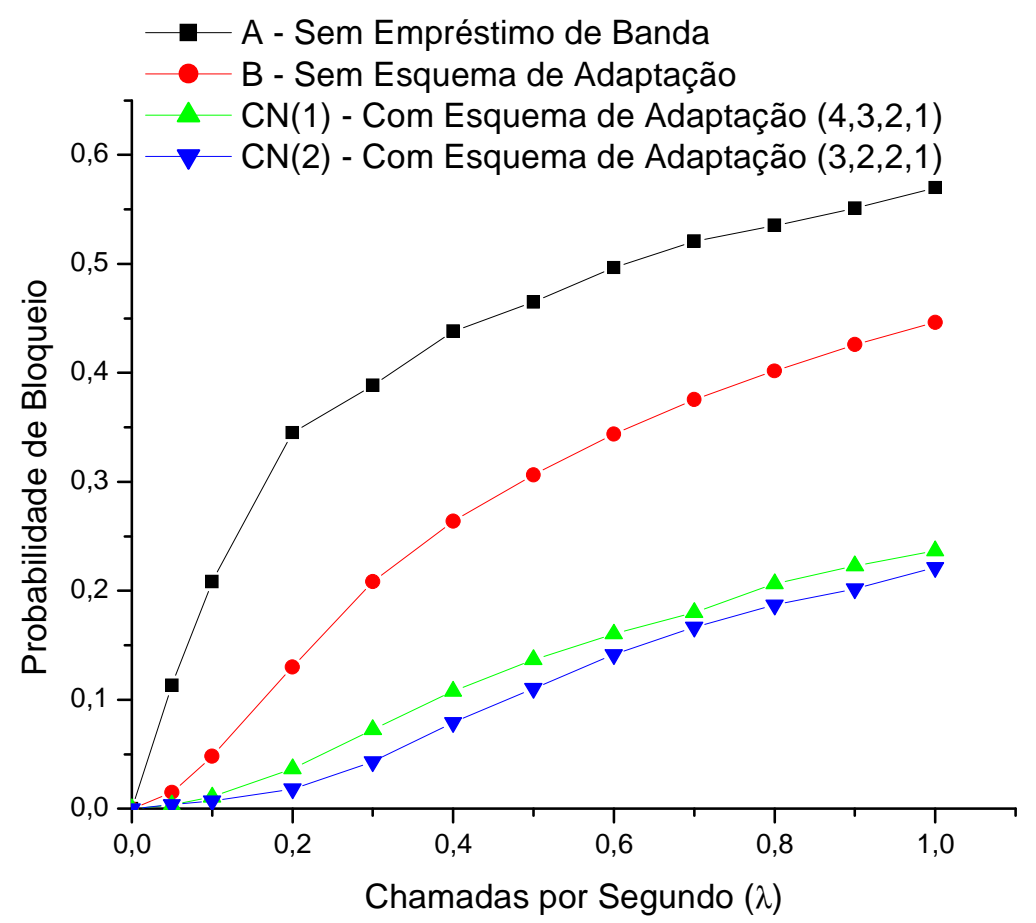

Figura 3.4. Probabilidade de Bloqueio de Novas Chamadas (Classe 1). 


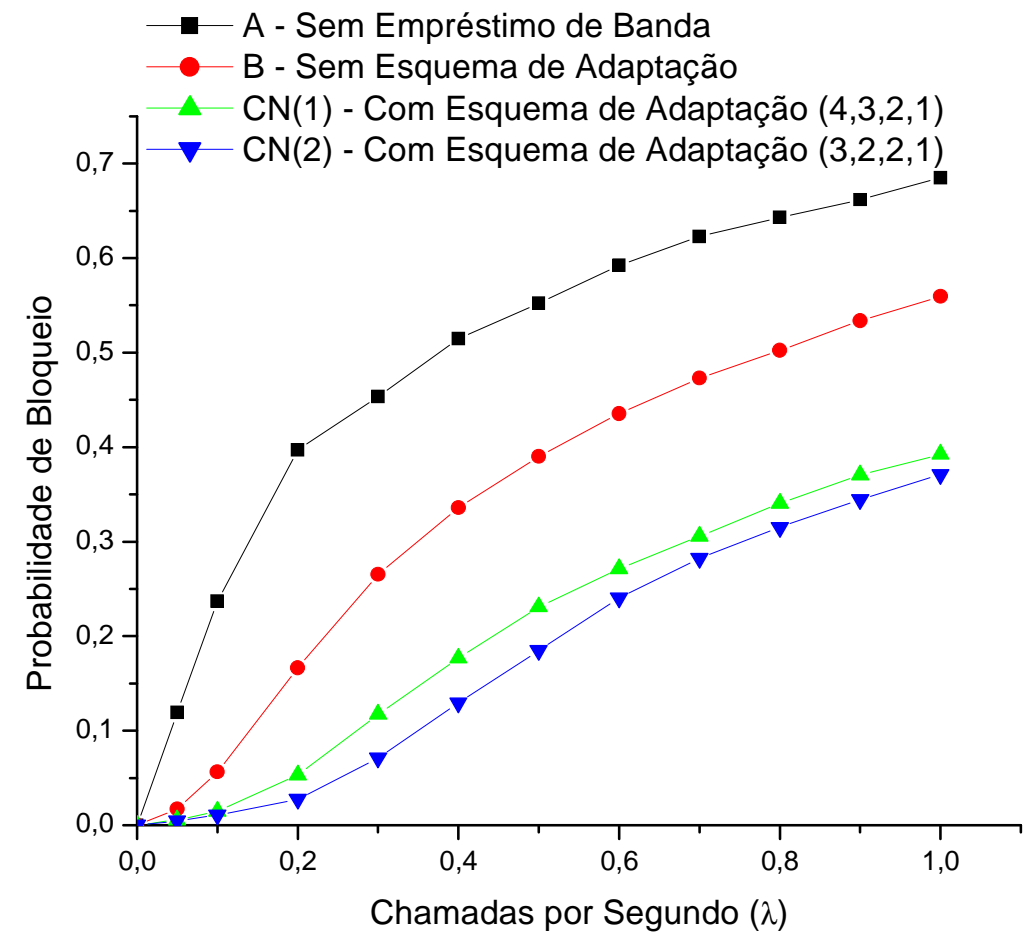

Figura 3.5. Probabilidade de Bloqueio de Novas Chamadas (Classe 2).

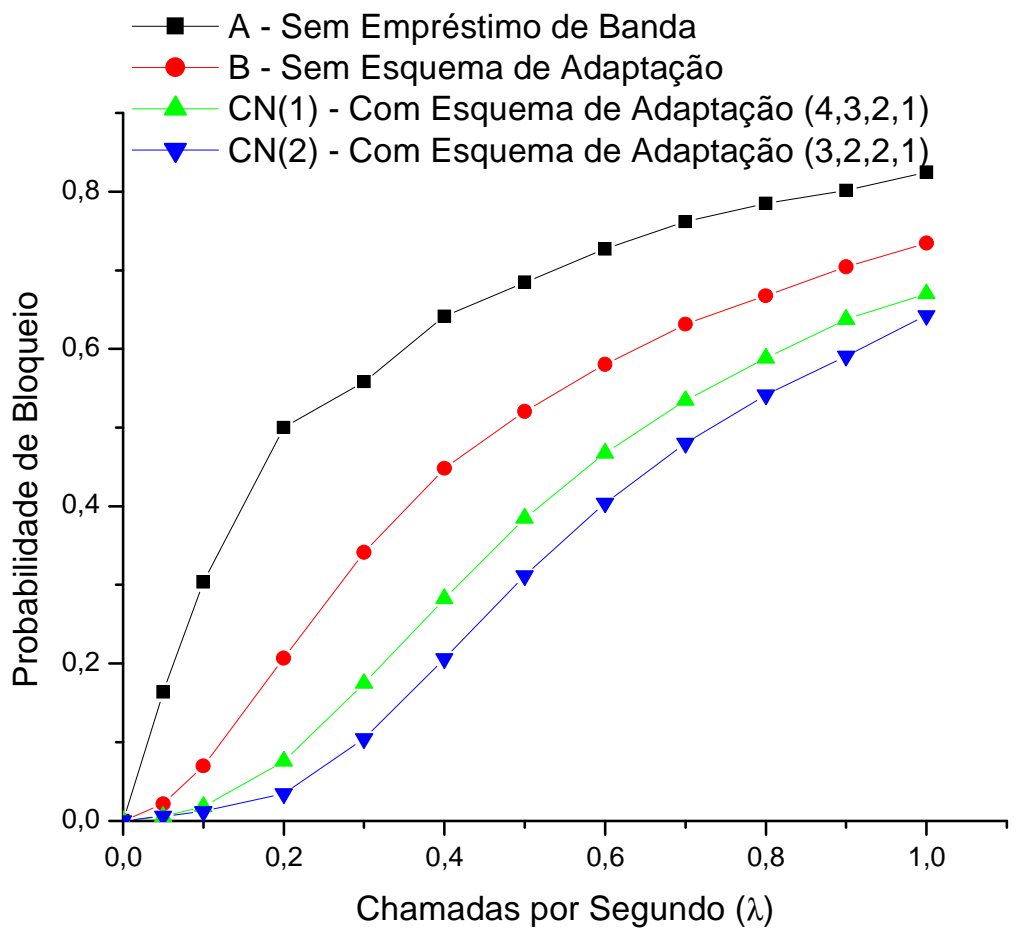

Figura 3.6. Probabilidade de Bloqueio de Novas Chamadas (Classe 3). 


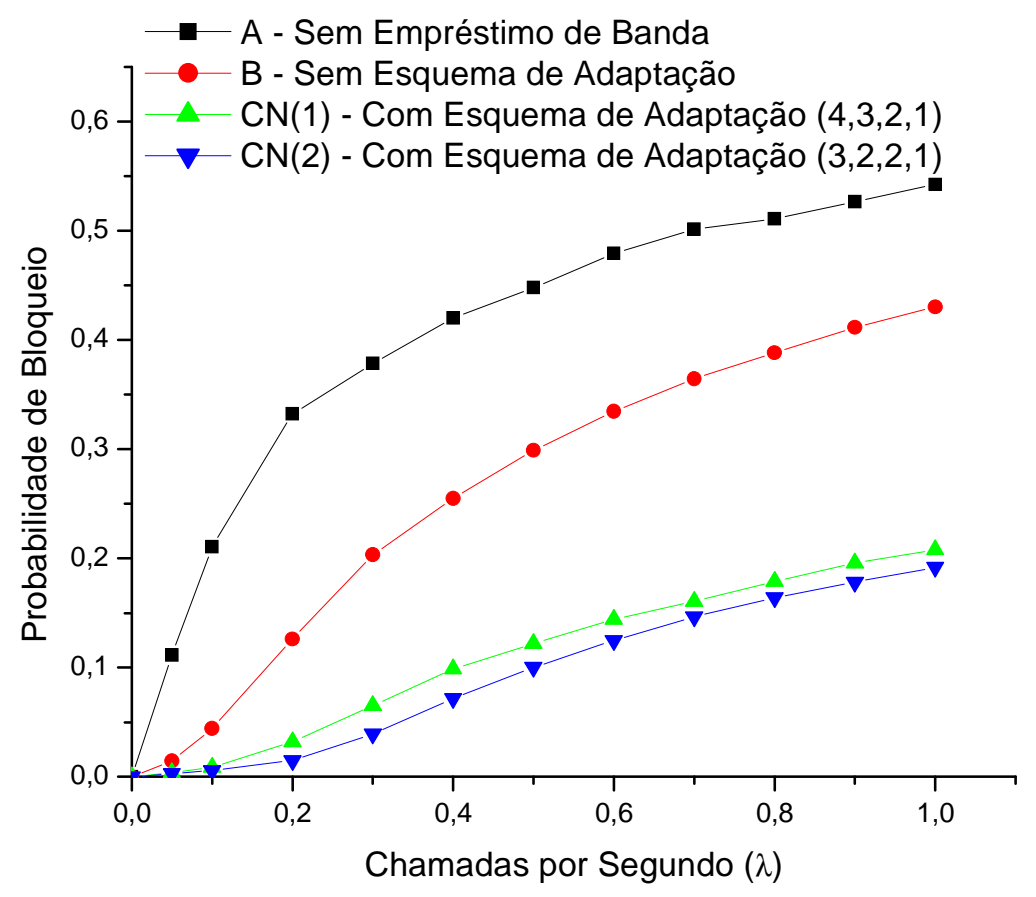

Figura 3.7. Probabilidade de Bloqueio de Novas Chamadas (Classe 4).

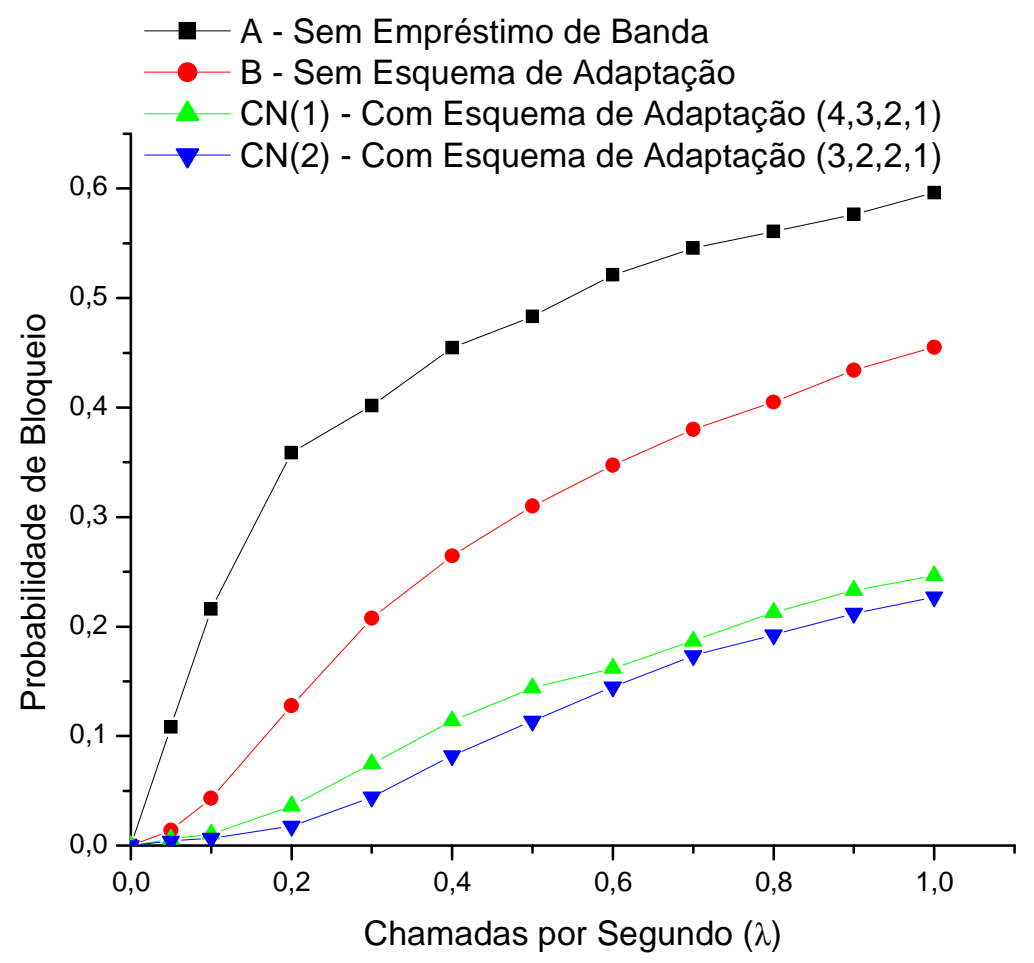

Figura 3.8. Probabilidade de Bloqueio de Novas Chamadas (Classe 5). 


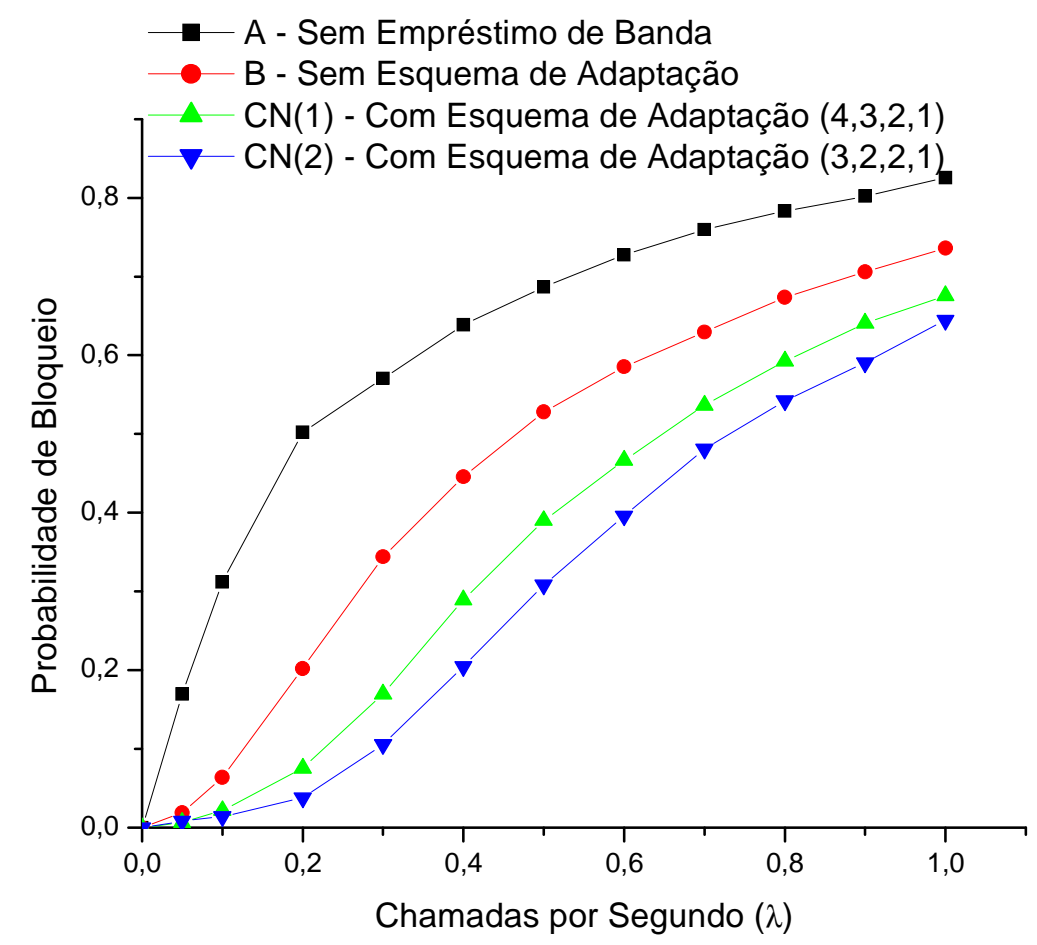

Figura 3.9. Probabilidade de Bloqueio de Novas Chamadas (Classe 6).

Tabela 3.5. Comparação de Valores da Classe 1 (Novas Chamadas).

\begin{tabular}{|c|c|c|c|c|c|}
\hline$\lambda$ & Algoritmo B & Algoritmo CN(1) & Dif.(\%) & Algoritmo CN(2) & Dif.(\%) \\
\hline 0,1 & 0,04808 & 0,01072 & $-77,7$ & 0,00719 & -85 \\
\hline 0,5 & 0,30626 & 0,13683 & $-55,3$ & 0,11032 & $-63,9$ \\
\hline 1,0 & 0,44608 & 0,23667 & $-46,9$ & 0,22126 & $-50,3$ \\
\hline
\end{tabular}

Tabela 3.6. Comparação de Valores da Classe 2 (Novas Chamadas).

\begin{tabular}{|c|c|c|c|c|c|}
\hline$\lambda$ & Algoritmo B & Algoritmo CN(1) & Dif.(\%) & Algoritmo CN(2) & Dif.(\%) \\
\hline 0,1 & 0,05627 & 0,01467 & $-73,9$ & 0,01082 & $-80,7$ \\
\hline 0,5 & 0,39013 & 0,23102 & $-40,7$ & 0,18486 & $-52,6$ \\
\hline 1,0 & 0,55952 & 0,3925 & $-29,8$ & 0,3708 & $-33,7$ \\
\hline
\end{tabular}


Tabela 3.7. Comparação de Valores da Classe 3 (Novas Chamadas).

\begin{tabular}{|c|c|c|c|c|c|}
\hline$\lambda$ & Algoritmo B & Algoritmo CN(1) & Dif.(\%) & Algoritmo CN(2) & Dif.(\%) \\
\hline 0,1 & 0,06971 & 0,01795 & $-74,2$ & 0,012 & $-82,7$ \\
\hline 0,5 & 0,52039 & 0,38467 & -26 & 0,31166 & $-40,1$ \\
\hline 1,0 & 0,73445 & 0,67002 & $-8,7$ & 0,64242 & $-12,5$ \\
\hline
\end{tabular}

Tabela 3.8. Comparação de Valores da Classe 4 (Novas Chamadas).

\begin{tabular}{|c|c|c|c|c|c|}
\hline$\lambda$ & Algoritmo B & Algoritmo CN(1) & Dif.(\%) & Algoritmo CN(2) & Dif.(\%) \\
\hline 0,1 & 0,04431 & 0,00877 & $-80,2$ & 0,0056 & $-87,3$ \\
\hline 0,5 & 0,29887 & 0,12204 & $-59,1$ & 0,10021 & $-66,4$ \\
\hline 1,0 & 0,43021 & 0,20808 & $-51,6$ & 0,19176 & $-55,4$ \\
\hline
\end{tabular}

Tabela 3.9. Comparação de Valores da Classe 5 (Novas Chamadas).

\begin{tabular}{|c|c|c|c|c|c|}
\hline$\lambda$ & Algoritmo B & Algoritmo CN(1) & Dif.(\%) & Algoritmo CN(2) & Dif.(\%) \\
\hline 0,1 & 0,04329 & 0,01065 & -75.3 & 0,00668 & $-84,5$ \\
\hline 0,5 & 0,30988 & 0,14409 & -53 & 0,11379 & $-63,2$ \\
\hline 1,0 & 0,45512 & 0,24646 & $-45,8$ & 0,22703 & $-50,1$ \\
\hline
\end{tabular}

Tabela 3.10. Comparação de Valores da Classe 6 (Novas Chamadas).

\begin{tabular}{|c|c|c|c|c|c|}
\hline$\lambda$ & Algoritmo B & Algoritmo CN(1) & Dif.(\%) & Algoritmo CN(2) & Dif.(\%) \\
\hline 0,1 & 0,0639 & 0,02166 & $-66,1$ & 0,01409 & $-77,9$ \\
\hline 0,5 & 0,52801 & 0,39013 & $-26,1$ & 0,30799 & $-41,6$ \\
\hline 1,0 & 0,73585 & 0,67559 & $-8,1$ & 0,64444 & $-12,4$ \\
\hline
\end{tabular}

As figuras exibem um aumento do desempenho do sistema quando utilizado o algoritmo proposto. A probabilidade de bloqueio da classe 4 apresenta uma melhoria mais significativa, pois se caracteriza pela menor necessidade de banda. 
As classes 3 e 6, apesar de possuírem menores percentuais de geração de chamadas, apresentam a maior probabilidade de bloqueio dentre as outras, como pode ser visualizado pelas Figuras 3.6 e 3.9. Este fato é resultado da maior necessidade de banda desses dois tipos de tráfego. Pelos gráficos destas duas classes também é possível perceber que apresentam a menor diminuição das probabilidades de bloqueio dentre as outras classes com a adoção do algoritmo proposto $(\mathrm{CN})$, o que é atribuído à maior necessidade de banda dessas duas classes. Este fato acarreta uma maior necessidade de acúmulo de banda no sistema de empréstimo do algoritmo para suprir o nível mínimo no caso de uma nova chamada e suprir o nível médio no caso de uma chamada handoff.

As probabilidades de bloqueio de handoff de cada classe de chamada são exibidas nas Figuras $3.10-3.15$.

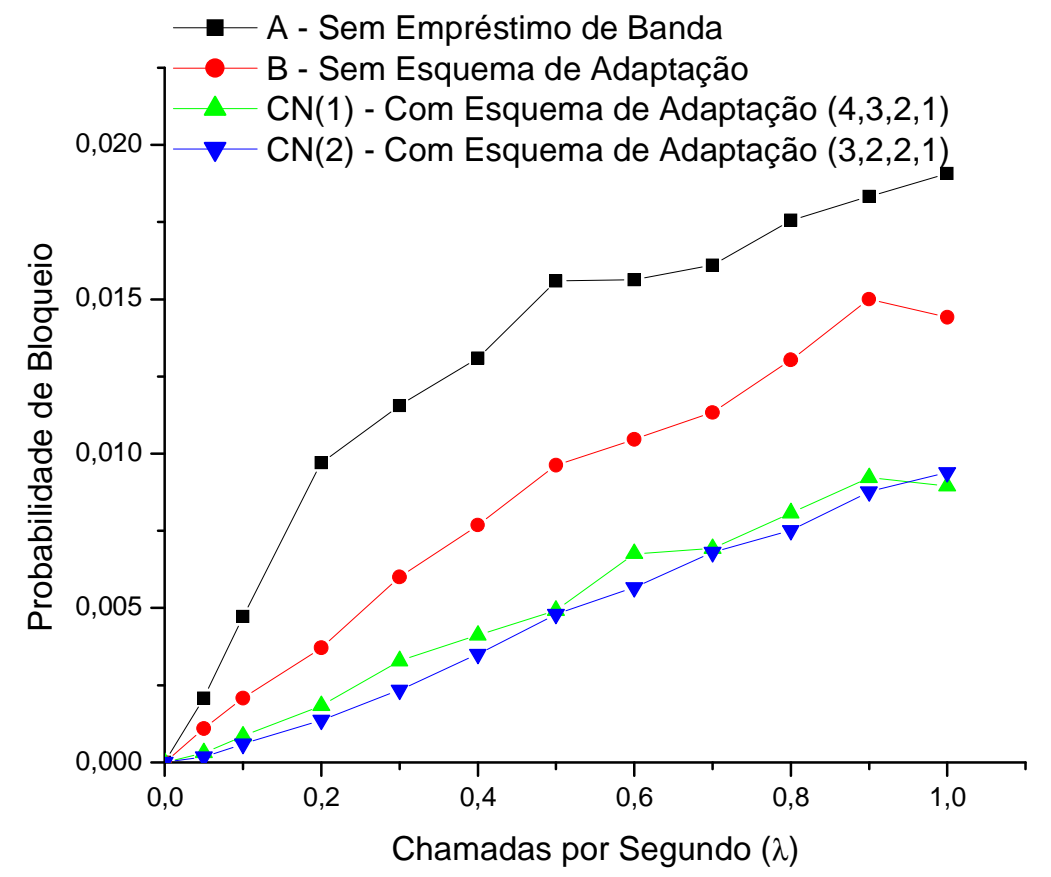

Figura 3.10. Probabilidade de Bloqueio de Handoff (Classe 1). 


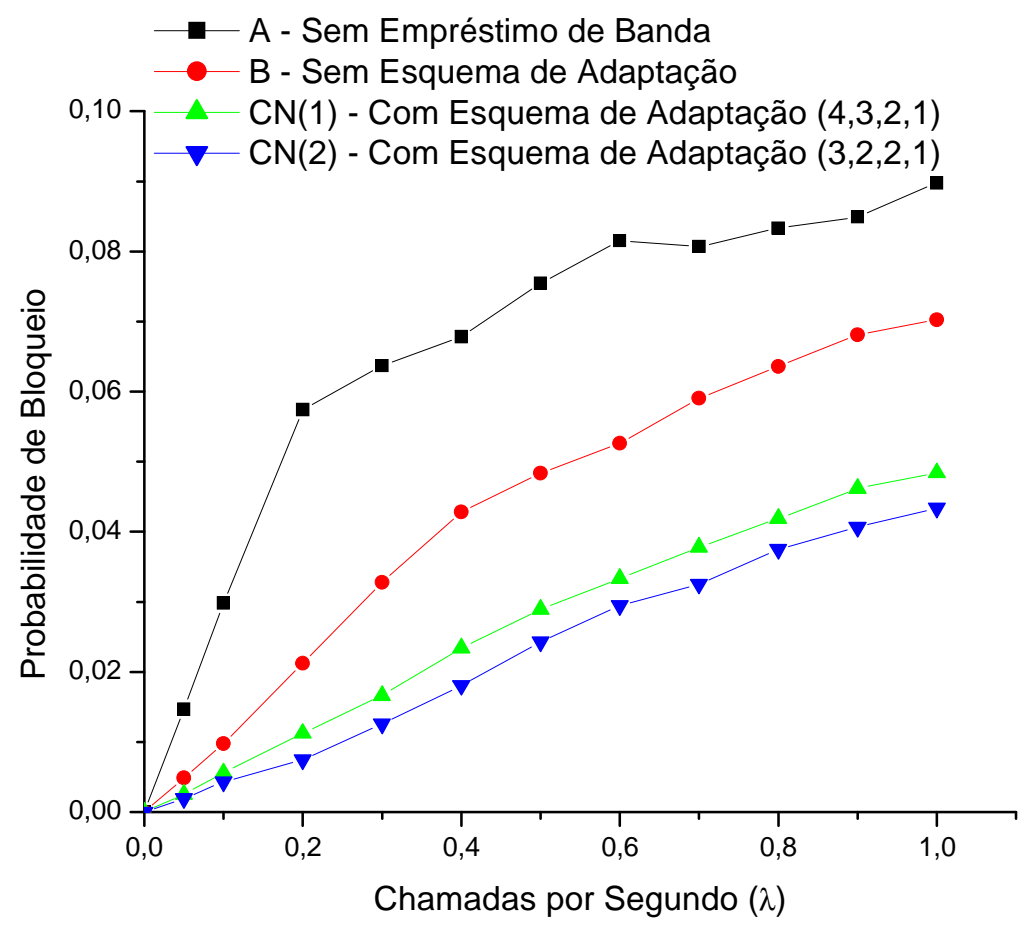

Figura 3.11. Probabilidade de Bloqueio de Handoff (Classe 2).

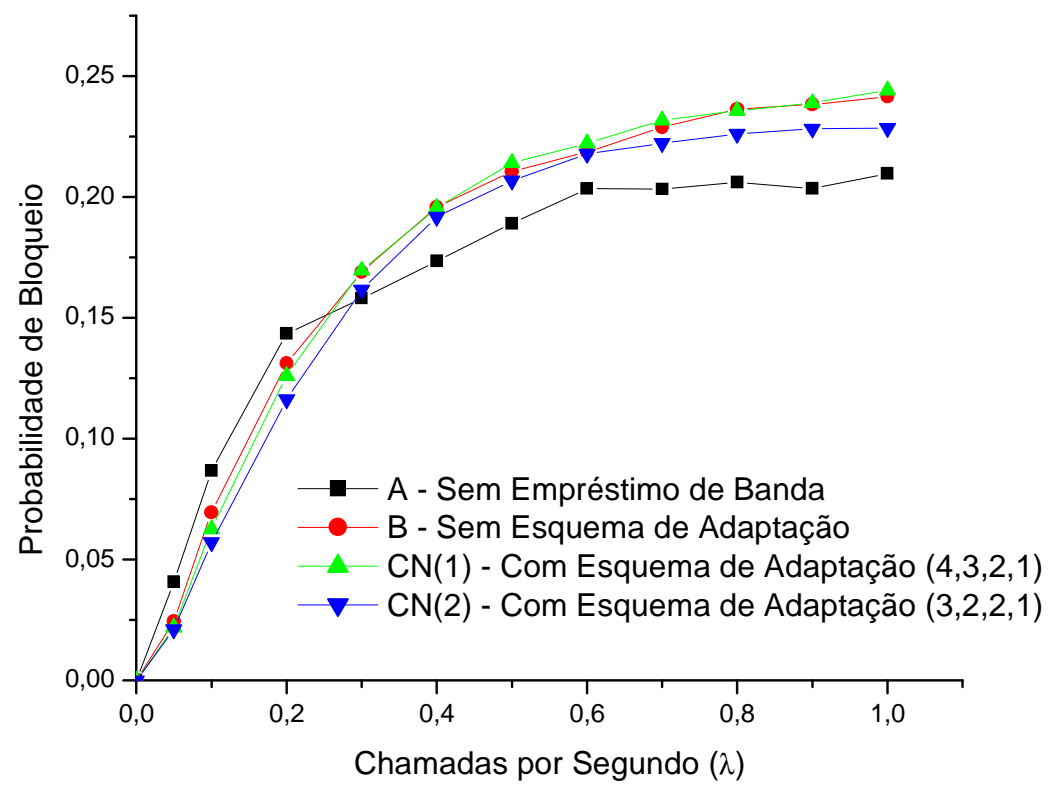

Figura 3.12. Probabilidade de Bloqueio de Handoff (Classe 3). 


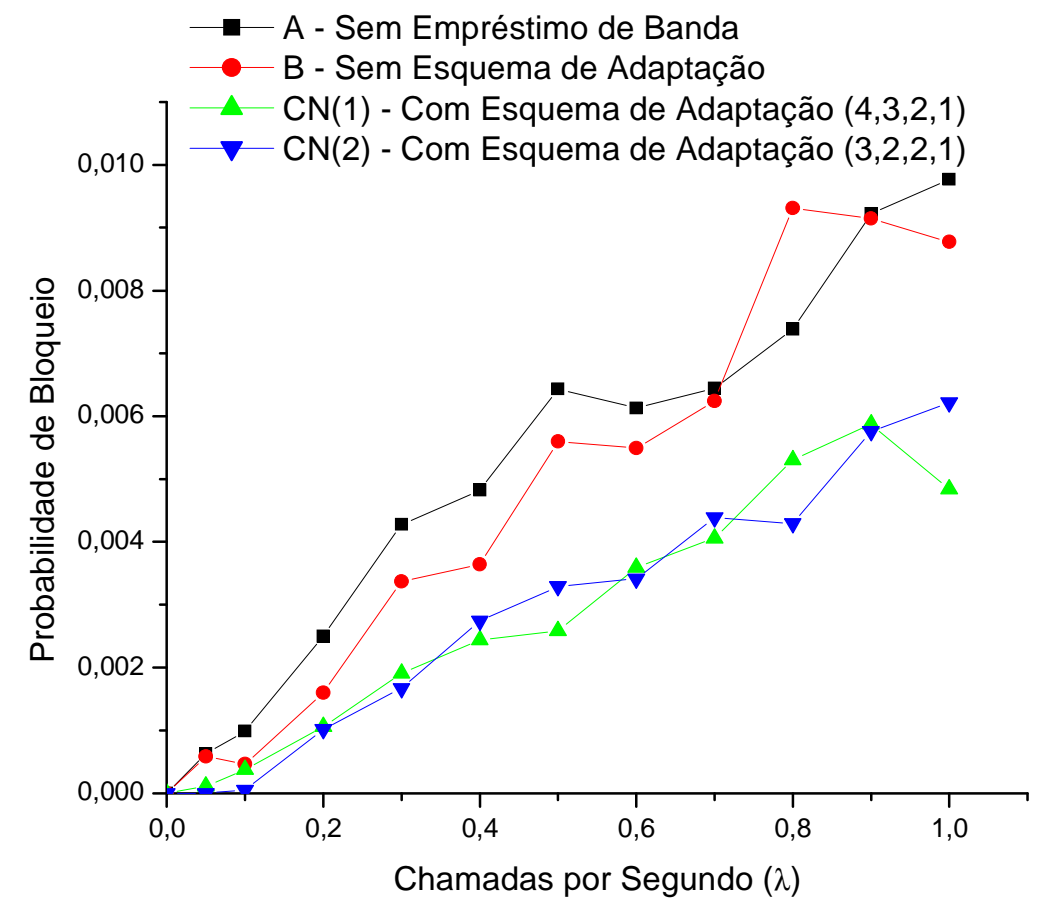

Figura 3.13. Probabilidade de Bloqueio de Handoff (Classe 4).

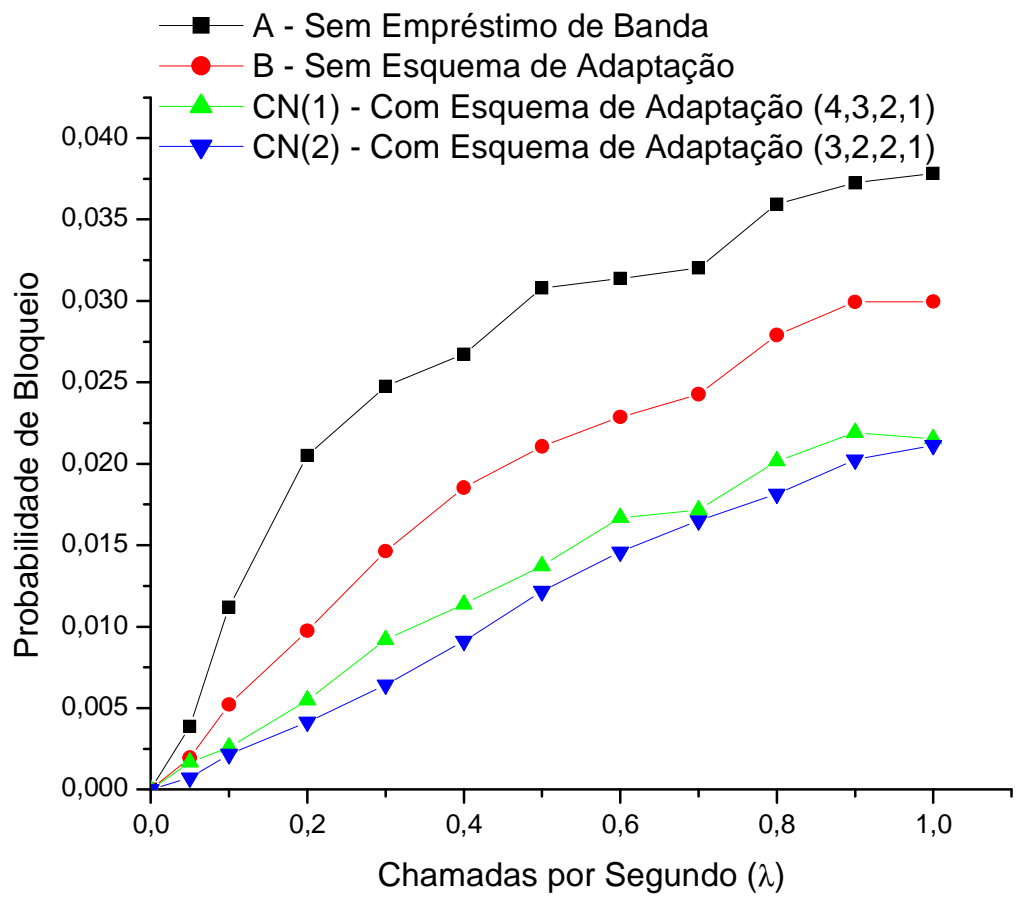

Figura 3.14. Probabilidade de Bloqueio de Handoff (Classe 5). 


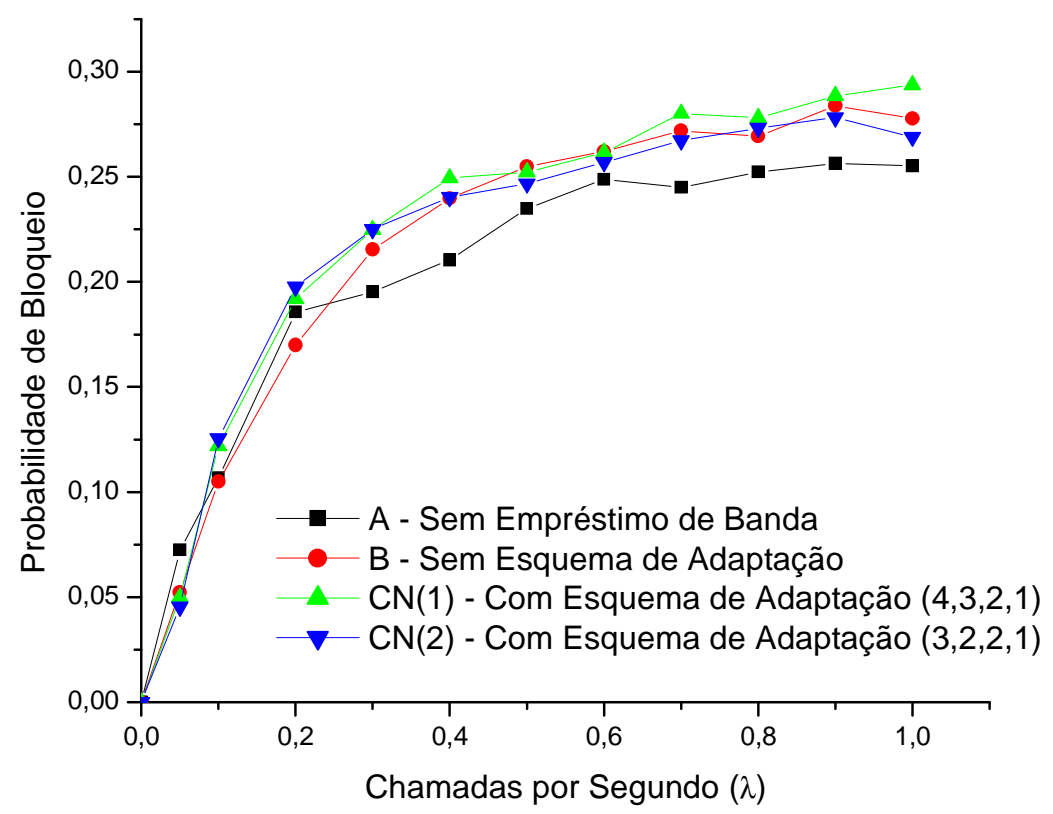

Figura 3.15. Probabilidade de Bloqueio de Handoff (Classe 6).

Tabela 3.11. Comparação de Valores da Classe 1 (Chamadas Handoff).

\begin{tabular}{|c|c|c|c|c|c|}
\hline$\lambda$ & Algoritmo B & Algoritmo CN(1) & Dif.(\%) & Algoritmo CN(2) & Dif.(\%) \\
\hline 0,1 & 0,00207 & 0,000851 & $-58,8$ & 0.000596 & $-71,2$ \\
\hline 0,5 & 0,00963 & 0,00492 & $-48,9$ & 0,0048 & $-50,1$ \\
\hline 1,0 & 0,01442 & 0,00894 & -38 & 0,00939 & $-34,8$ \\
\hline
\end{tabular}

Tabela 3.12. Comparação de Valores da Classe 2 (Chamadas Handoff).

\begin{tabular}{|c|c|c|c|c|c|}
\hline$\lambda$ & Algoritmo B & Algoritmo CN(1) & Dif.(\%) & Algoritmo CN(2) & Dif.(\%) \\
\hline 0,1 & 0,00977 & 0,0056 & $-42,6$ & 0,0043 & $-55,9$ \\
\hline 0,5 & 0,04836 & 0,02891 & $-40,2$ & 0,02428 & $-49,7$ \\
\hline 1,0 & 0,07024 & 0,04842 & -31 & 0,04338 & $-38,2$ \\
\hline
\end{tabular}


Tabela 3.13. Comparação de Valores da Classe 3 (Chamadas Handoff).

\begin{tabular}{|c|c|c|c|c|c|}
\hline$\lambda$ & Algoritmo B & Algoritmo CN(1) & Dif.(\%) & Algoritmo CN(2) & Dif.(\%) \\
\hline 0,1 & 0,06945 & 0,06263 & $-9,8$ & 0,05707 & $-17,8$ \\
\hline 0,5 & 0,2106 & 0,21412 & $+1,6$ & 0,20669 & $-1,8$ \\
\hline 1,0 & 0,24141 & 0,24404 & +1 & 0,2285 & $-5,3$ \\
\hline
\end{tabular}

Tabela 3.14. Comparação de Valores da Classe 4 (Chamadas Handoff).

\begin{tabular}{|c|c|c|c|c|c|}
\hline$\lambda$ & Algoritmo B & Algoritmo CN(1) & Dif.(\%) & Algoritmo CN(2) & Dif.(\%) \\
\hline 0,1 & 0,000464 & 0,000373 & $-19,6$ & 0,000054 & $-88,3$ \\
\hline 0,5 & 0,0056 & 0,00258 & $-53,9$ & 0,00329 & $-41,2$ \\
\hline 1,0 & 0,00877 & 0,00484 & $-44,8$ & 0,00622 & -29 \\
\hline
\end{tabular}

Tabela 3.15. Comparação de Valores da Classe 5 (Chamadas Handoff).

\begin{tabular}{|c|c|c|c|c|c|}
\hline$\lambda$ & Algoritmo B & Algoritmo CN(1) & Dif.(\%) & Algoritmo CN(2) & Dif.(\%) \\
\hline 0,1 & 0,00521 & 0,0026 & -50 & 0,00216 & $-58,5$ \\
\hline 0,5 & 0,02106 & 0,01374 & $-34,7$ & 0,01217 & $-42,2$ \\
\hline 1,0 & 0,02996 & 0,02154 & $-28,1$ & 0,02114 & $-29,4$ \\
\hline
\end{tabular}

Tabela 3.16. Comparação de Valores da Classe 6 (Chamadas Handoff).

\begin{tabular}{|c|c|c|c|c|c|}
\hline$\lambda$ & Algoritmo B & Algoritmo CN(1) & Dif.(\%) & Algoritmo CN(2) & Dif.(\%) \\
\hline 0,1 & 0,105 & 0,12197 & +16 & 0,12553 & $+19,3$ \\
\hline 0,5 & 0,25484 & 0,2522 & -1 & 0,24677 & $-3,1$ \\
\hline 1,0 & 0,27771 & 0,29365 & $+5,7$ & 0,26897 & $-2,8$ \\
\hline
\end{tabular}

A classe 4 (Figura 3.13) apresenta uma maior variação de valores, pois dentre os tráfegos do tipo VBR é que necessita de menor necessidade de banda (10 - $20 \mathrm{kbps})$, sendo mais suscetível às variações da banda disponível que pode alocar a banda média $\left(N_{m e d}\right)$ necessária 
para o handoff. Entre as probabilidades de bloqueio das seis classes de chamadas expostas, é possível perceber que as classes 3 e 6 apresentam uma piora de desempenho em relação ao esquema sem empréstimo de banda (esquema A) em ambiente de maior tráfego. Esse fenômeno ocorre porque as classes 3 e 6 são as que demandam mais banda e, desta maneira, ficam mais suscetíveis à sua escassez. O esquema apresenta um maior aproveitamento de banda e como a alocação de uma chamada de uma classe de maior demanda (classes 3 ou 6) realiza o empréstimo de banda, a banda disponível na ERB será probabilisticamente menor (Figura 3.3). Desta maneira, como a chamada handoff requer uma banda de nível médio $\left(N_{m e d}\right)$, sua alocação experimenta uma situação de escassez de banda especifica para as classes 3 e 6.

As Figuras 3.16 - 3.19 mostram o throughput médio para as classes 3, 4, 5 e 6, respectivamente. Há uma diminuição do throughput médio para as classes 3 e 6 quando utilizados os esquemas de adaptação $(\mathrm{CN})$. Este fato ocorre porque o esquema apresenta uma melhor utilização de banda e, desta maneira, a banda disponível na ERB será estatisticamente menor e distribuída de maneira mais homogênea pelas chamadas do sistema, gerando uma diminuição no throughput médio para as classes de maior banda (classes 3 e 6). Estas classes são mais suscetíveis à diminuição da banda disponível e que probabilisticamente requerem mais o uso do sistema de empréstimo de banda. 


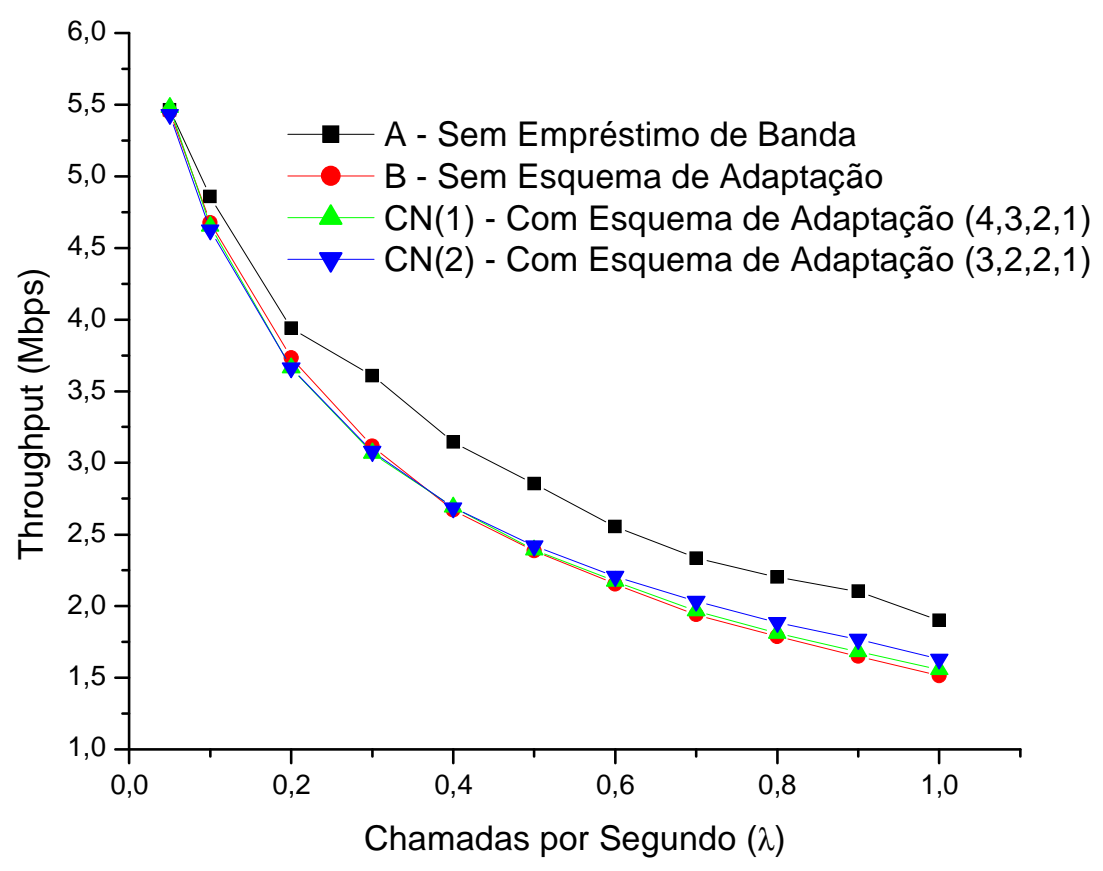

Figura 3.16. Throughput médio para a classe 3.

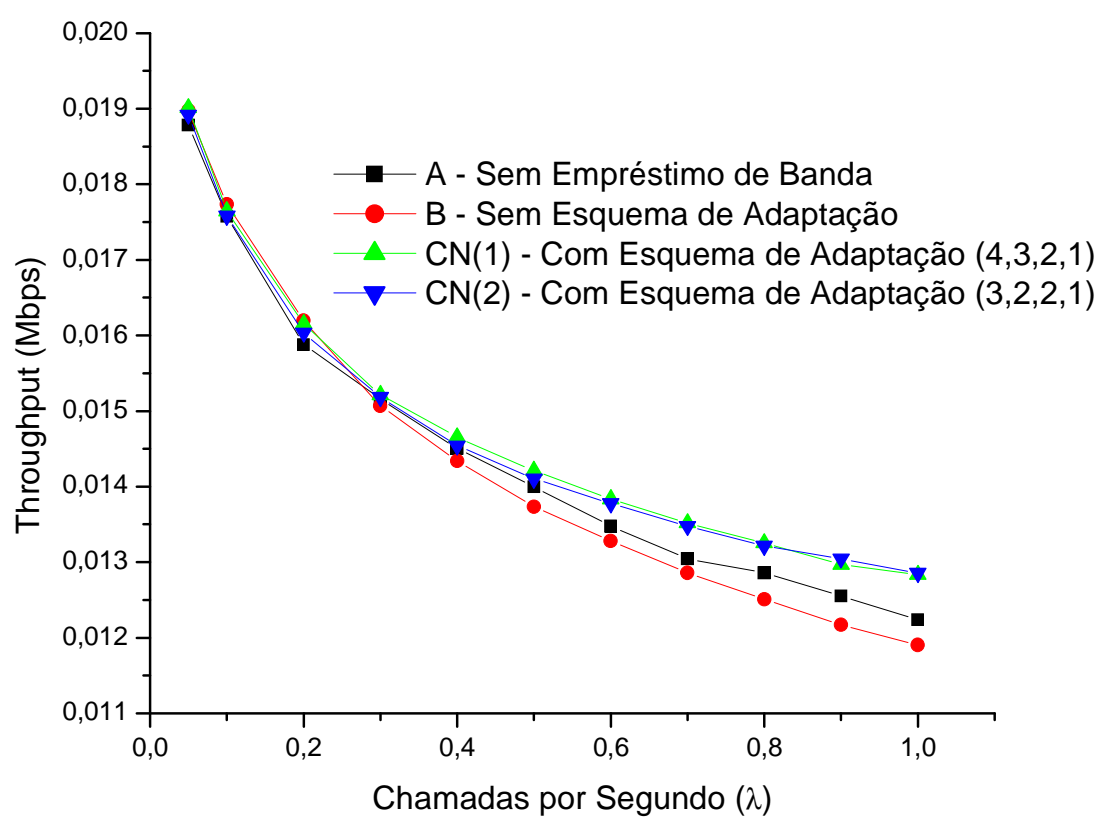

Figura 3.17. Throughput médio para a classe 4. 


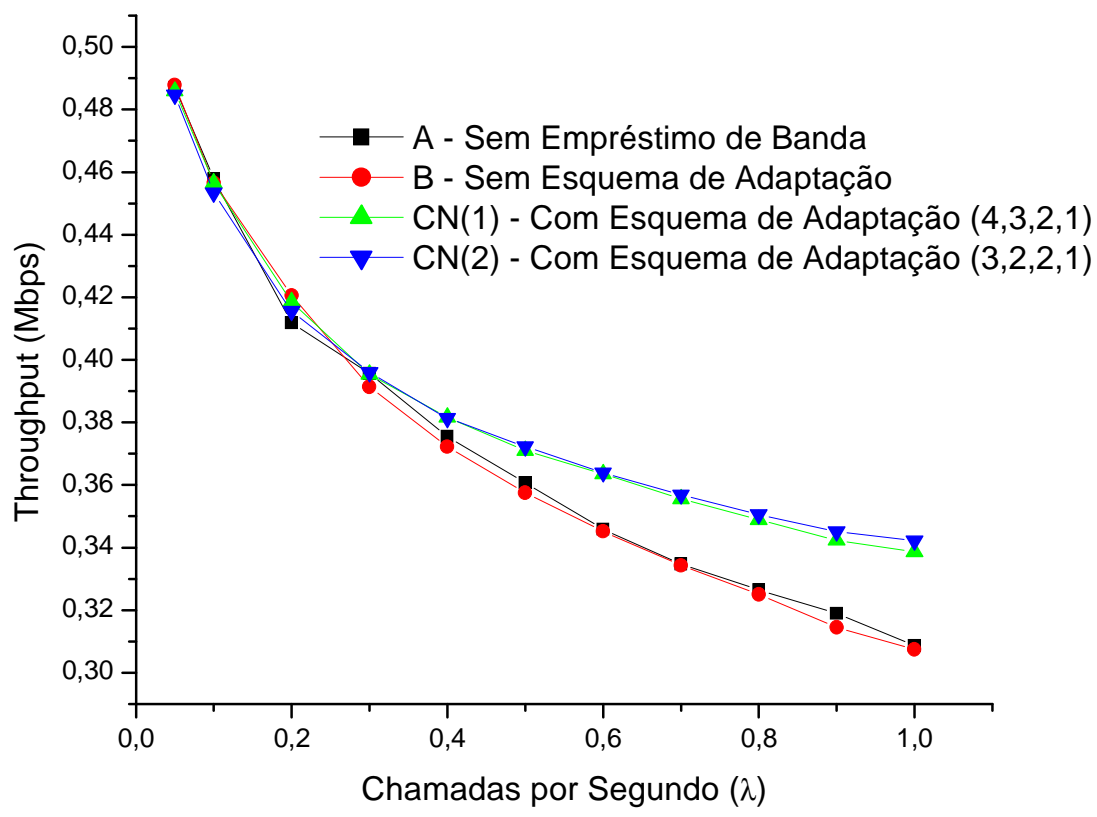

Figura 3.18. Throughput médio para a classe 5.

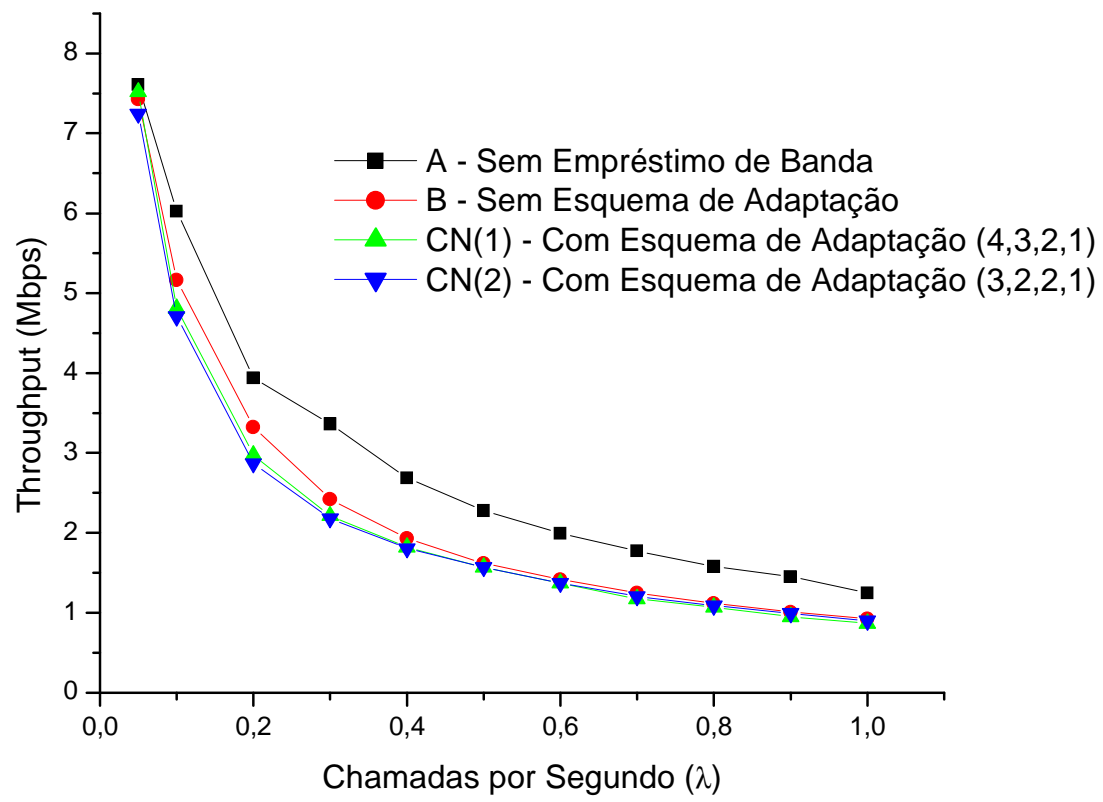

Figura 3.19. Throughput médio para a classe 6. 



\section{Capítulo 4}

\section{Resultados GSM/GPRS}

Este capítulo exibe os resultados da simulação do algoritmo de alocação de banda para uma rede GSM/GPRS. São considerados na simulação os aspectos de banda utilizados pelo padrão GSM, que são baseados nas diferentes bandas utilizadas pelo tráfego de voz (AMR) e pelo GPRS, que utiliza diferentes esquemas de codificação para o tráfego de dados. Na simulação foram considerados os parâmetros mostrados na Tabela 4.1. Cada ponto dos gráficos corresponde à média aritmética de três simulações realizadas.

Tabela 4.1. Parâmetros Utilizados na Rede GSM/GPRS.

\begin{tabular}{|c|c|}
\hline Chamadas por Segundo $(\lambda)$ & 0,$05 ; 0,1 ; 0,2 ; 0,3 ; 0,4 ; 0,5 ; 0,6 ; 0,7 ; 0,8 ; 0,9 ; 1,0$. \\
\hline Limiar $T_{h}$ & 0,05 \\
\hline Limiar $T_{n}$ & $0,05 \lambda$ \\
\hline Limiar $T_{v}$ & 0,85 \\
\hline Probabilidade de Handoff $\left(P_{h}\right)$ & $0,75(75 \%)$ \\
\hline Tempo Simulação $($ Sistema $)$ & 1 hora $(3600$ segundos $)$ \\
\hline Banda ERB & 2 Mbps \\
\hline
\end{tabular}

Foram simuladas três configurações diferentes. Uma (D) refere-se ao esquema com empréstimo de banda, mas que não apresenta a funcionalidade de adaptação dos níveis mínimos de conexão para empréstimo de banda conforme parâmetros da rede (parte azul do fluxograma da Figura 2.11), que é base de [5], [15] - [17].

Por último, foi simulado o sistema de empréstimo de banda com adaptação dos níveis mínimos de empréstimo de banda para cada classe de chamada e também com o sistema de 
agregação da parte da banda reservada à handoff à banda considerada para alocação. Um conjunto de níveis $C_{G 2} 6,5,4$ e 3 (E (1)), ou seja, o algoritmo pode emprestar banda das chamadas com o esquema de codificação CS1 até o nível 7; das chamadas com o esquema de codificação CS2 até o nível 6; das chamadas com o esquema de codificação CS3 até o nível 5 e das chamadas com o esquema de codificação CS4 até o nível 4. Outro cenário simulado (E (2)) é com conjunto de níveis mínimos de empréstimo de banda $C_{G 2}$ de $5,4,3$ e 2 para os esquemas de codificação CS1, CS2, CS3 e CS4, respectivamente. O valor do conjunto de níveis mínimos $C_{G l}$ é 7 para o esquema de codificação CS1; 6 para o esquema de codificação CS2; 5 para o esquema de codificação CS3 e 4 para o esquema de codificação CS4. Os níveis de conexão para cada tipo de esquema de codificação dizem respeito à quantidade de slots. Desta maneira, o nível mínimo 7 indica que o algoritmo poderá emprestar banda de uma chamada com o esquema de codificação CS1 referente a um slot de sua atual conexão, ou seja, um nível acima (nível 8), o que corresponde a 8 kbps desta chamada.

A Figura 4.1 exibe a probabilidade de bloqueio de novas chamadas. Percebe-se uma probabilidade de bloqueio menor com o uso do esquema E, que adota a adaptação dos níveis mínimos de empréstimo de banda. Com o aumento da banda emprestada das chamadas em andamento, a probabilidade de bloqueio tem uma queda em relação ao esquema sem adaptação. A Tabela 4.2 exibe alguns valores de probabilidade de bloqueio para três valores de $\lambda: 0,4 ; 0,7$ e 1,0 .

A probabilidade de bloqueio de handoff exibe o mesmo comportamento, como pode ser visualizado pela Figura 4.2 e pela Tabela 4.3. A necessidade de se alocar pelo menos o nível médio de conexão $\left(N_{\text {med }}\right)$ para o handoff reduz a diminuição da probabilidade de bloqueio para um alto tráfego, pois o aumento do tráfego aumenta a escassez de banda do sistema o que leva a uma maior dificuldade para alocar o nível médio de conexão para as chamadas handoff. 


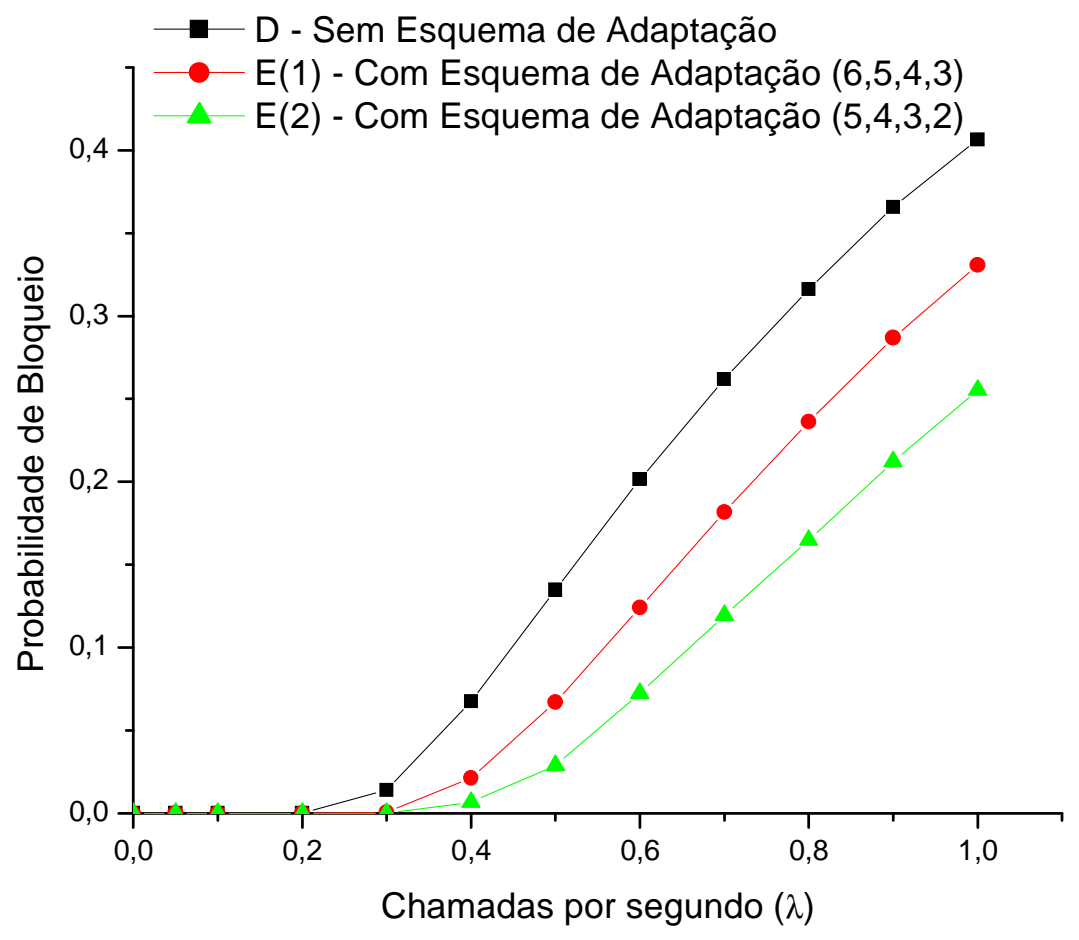

Figura 4.1. Probabilidade de Bloqueio de Novas Chamadas.

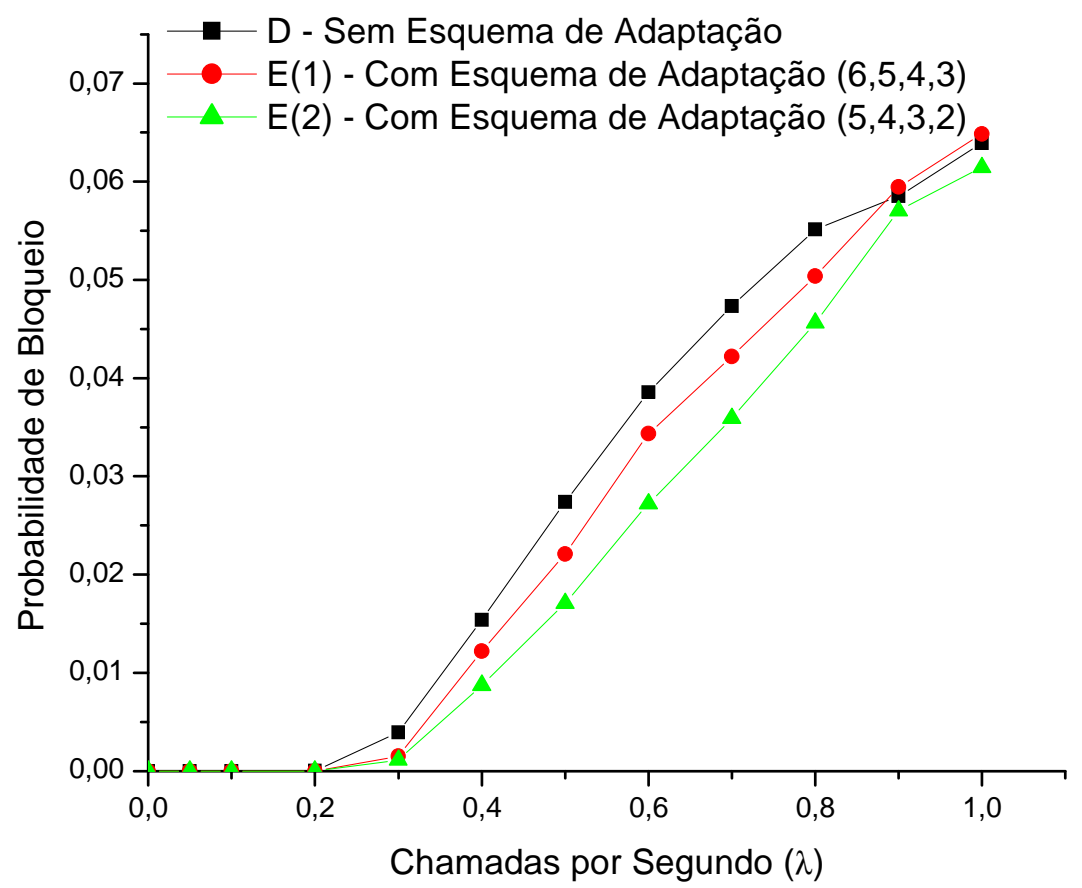

Figura 4.2. Probabilidade de Bloqueio de Handoff. 
Tabela 4.2. Comparação valores entre os esquemas para novas chamadas.

\begin{tabular}{|c|c|c|c|c|c|}
\hline$\lambda$ & Algoritmo D & Algoritmo E(1) & Dif.(\%) & Algoritmo E(2) & Dif.(\%) \\
\hline 0,4 & 0,06749 & 0,0213 & $-68,4$ & 0,00663 & $-90,1$ \\
\hline 0,7 & 0,26188 & 0,18177 & $-30,5$ & 0,11933 & $-54,4$ \\
\hline 1,0 & 0,40655 & 0,33071 & $-18,6$ & 0,25529 & $-37,2$ \\
\hline
\end{tabular}

Tabela 4.3. Comparação de valores entre os esquemas para chamadas Handoff.

\begin{tabular}{|c|c|c|c|c|c|}
\hline$\lambda$ & Algoritmo D & Algoritmo E(1) & Dif.(\%) & Algoritmo E(2) & Dif.(\%) \\
\hline 0,4 & 0,01538 & 0,0122 & $-20,6$ & 0,00873 & $-43,2$ \\
\hline 0,7 & 0,04734 & 0,04219 & $-10,8$ & 0,03591 & $-24,1$ \\
\hline 1,0 & 0,06393 & 0,06485 & $+1,4$ & 0,06146 & $-3,8$ \\
\hline
\end{tabular}

A Figura 4.3 mostra a utilização de banda do sistema. É possível perceber que não há uma diferenciação clara no desempenho deste parâmetro em um ambiente de grande tráfego, como pode ser visualizado pela Tabela 4.4. Este fato é relacionado às diferenças de divisão de banda em níveis de conexão do sistema GSM/GPRS em relação ao sistema 3G.

O trabalho também estuda as probabilidades de bloqueio de novas chamadas que se iniciam com um tipo especifico de esquema de codificação (CS1, CS2, CS3 ou CS4) atribuído às chamadas e também das chamadas de voz, mostradas nas Figuras de 4.4 a 4.8. Nas Tabelas de 4.5 a 4.9 são exibidos alguns valores da probabilidade de bloqueio de novas chamadas para diferentes tipos de tráfego. 


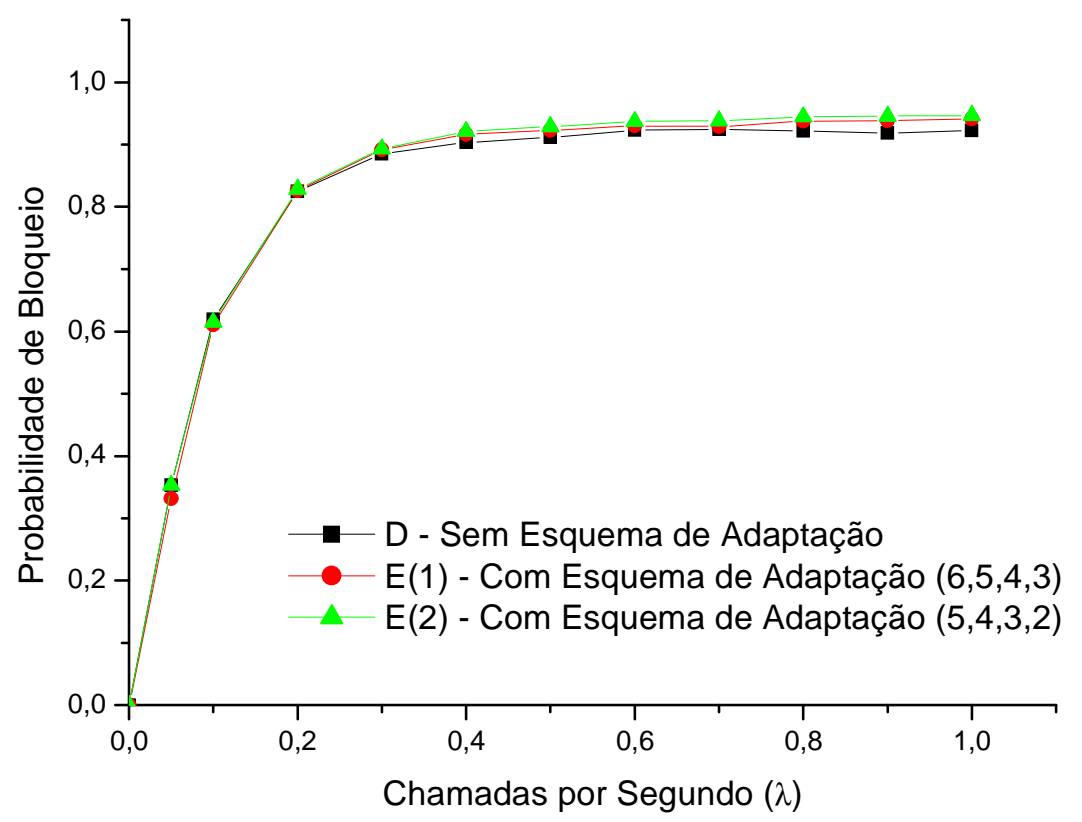

Figura 4.3. Utilização de Banda.

Tabela 4.4. Comparação da utilização de banda entre os esquemas.

\begin{tabular}{|c|c|c|c|c|c|}
\hline$\lambda$ & Algoritmo D & Algoritmo E(1) & Dif.(\%) & Algoritmo E(2) & Dif.(\%) \\
\hline 0,4 & 0,90358 & 0,91671 & $+1,4$ & 0,92096 & $+1,9$ \\
\hline 0,7 & 0,92426 & 0,92885 & $+0,4$ & 0,93824 & $+1,5$ \\
\hline 1,0 & 0,92282 & 0,94143 & +2 & 0,94697 & $+2,6$ \\
\hline
\end{tabular}




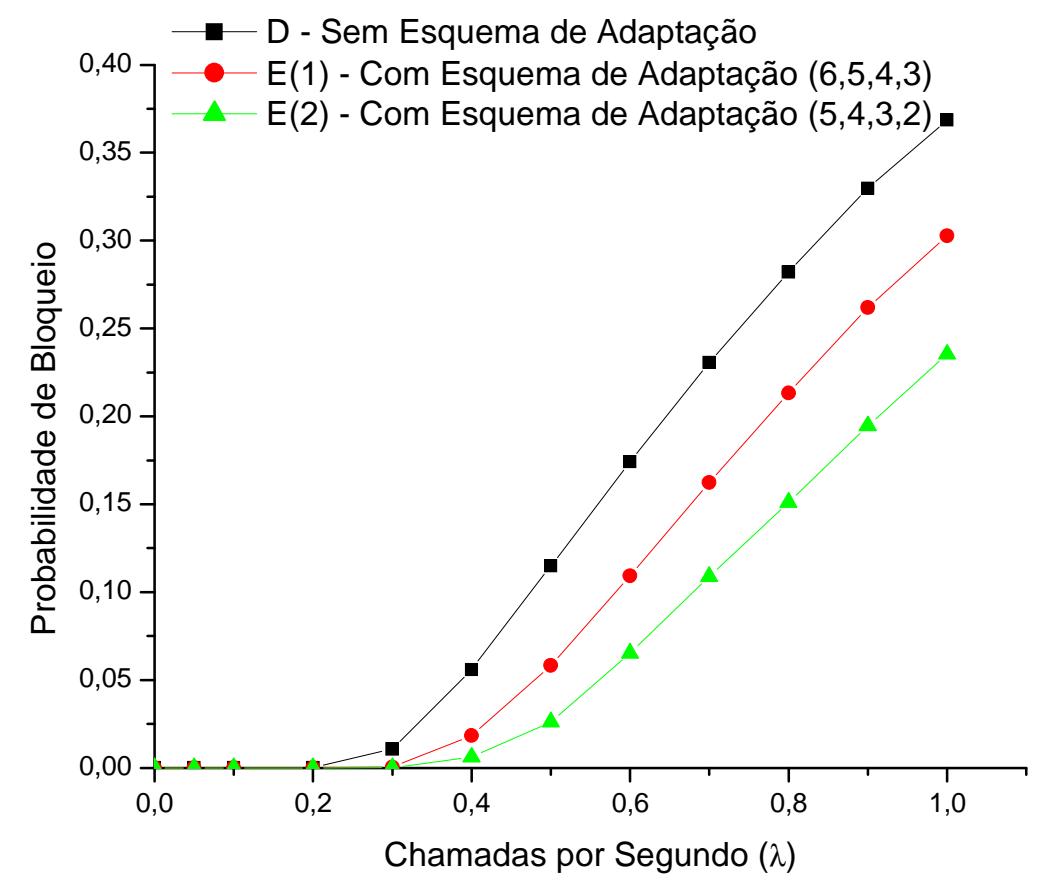

Figura 4.4. Probabilidade de Bloqueio de Novas Chamadas (Voz).

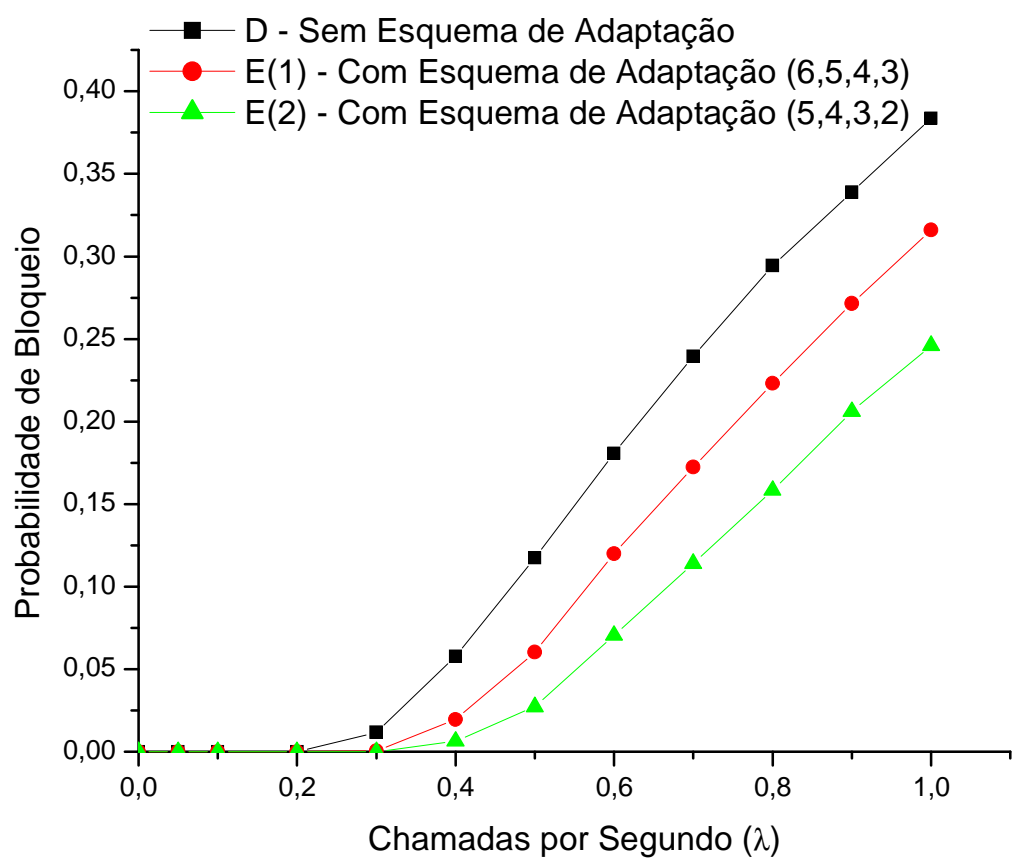

Figura 4.5. Probabilidade de Bloqueio de Novas Chamadas (Chamadas CS1). 


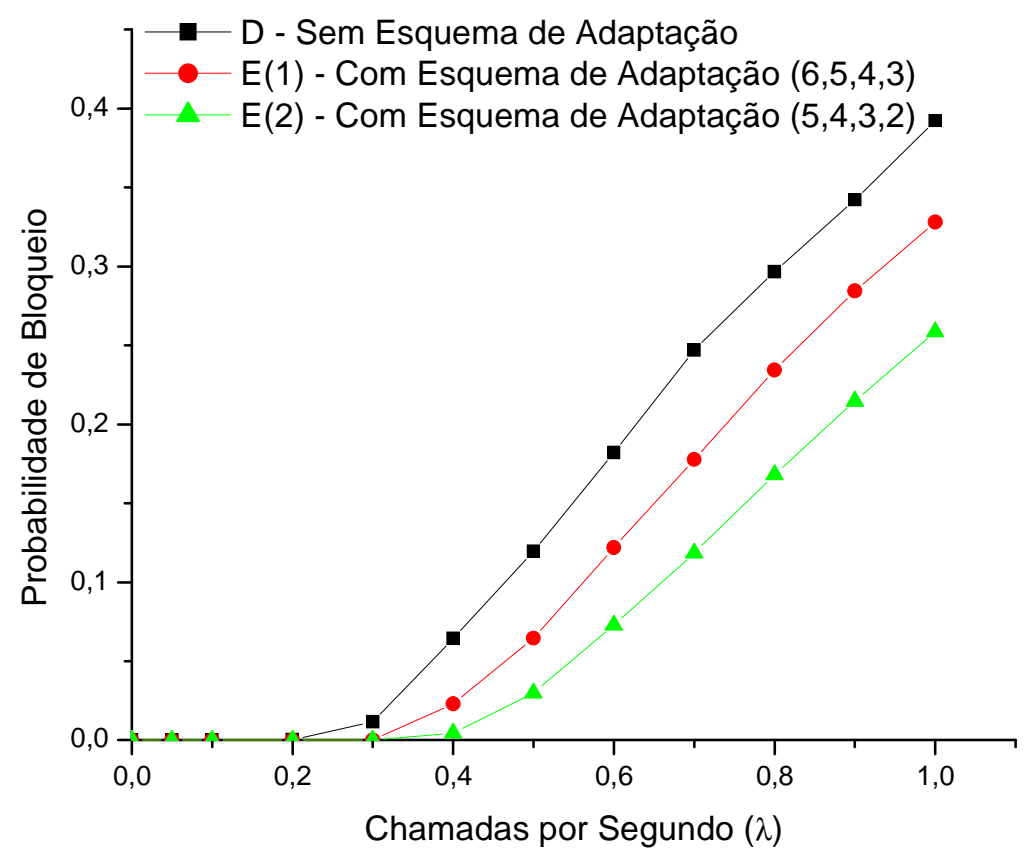

Figura 4.6. Probabilidade de Bloqueio de Novas Chamadas (Chamadas CS2).

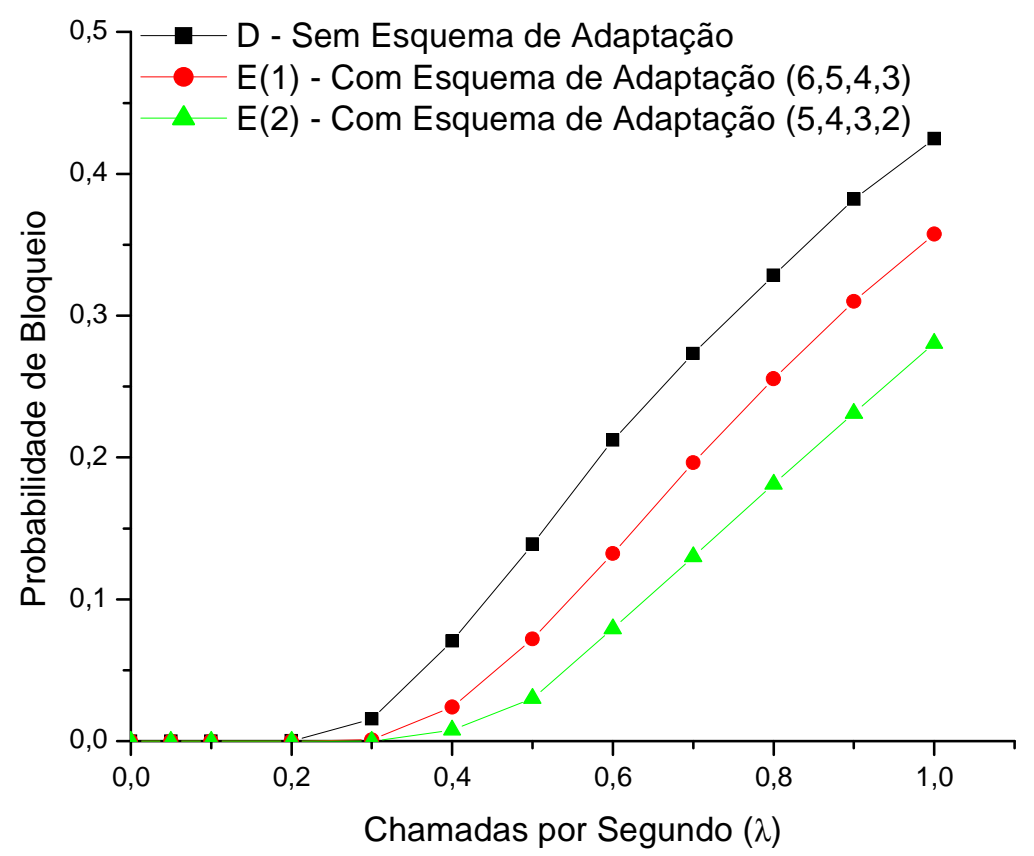

Figura 4.7. Probabilidade de Bloqueio de Novas Chamadas (Chamadas CS3). 


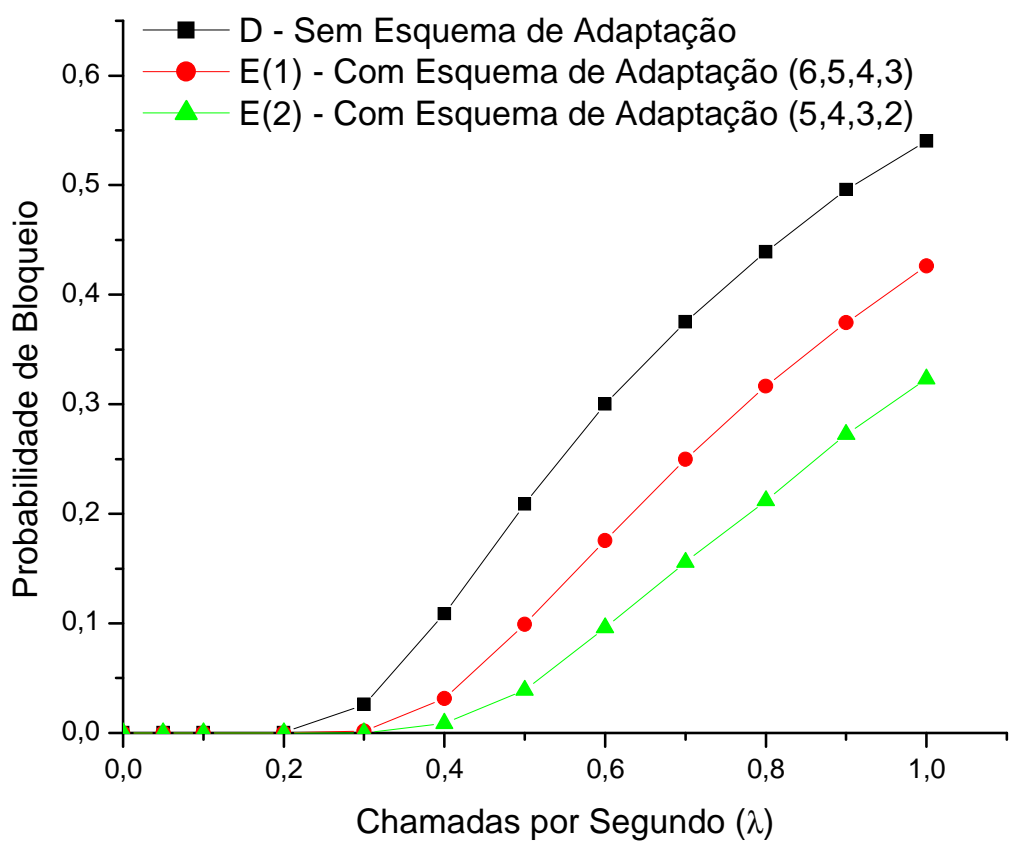

Figura 4.8. Probabilidade de Bloqueio de Novas Chamadas (Chamadas CS4).

Tabela 4.5. Comparação de probabilidade de bloqueio (Voz).

\begin{tabular}{|c|c|c|c|c|c|}
\hline$\lambda$ & Algoritmo D & Algoritmo E(1) & Dif.(\%) & Algoritmo E(2) & Dif.(\%) \\
\hline 0,4 & 0,05597 & 0,01831 & -67 & 0,00605 & $-89,1$ \\
\hline 0,7 & 0,23052 & 0,16236 & $-29,5$ & 0,1089 & $-52,7$ \\
\hline 1,0 & 0,36856 & 0,30283 & $-17,8$ & 0,23539 & $-36,1$ \\
\hline
\end{tabular}

Tabela 4.6. Comparação de probabilidade de bloqueio (Chamadas CS1).

\begin{tabular}{|c|c|c|c|c|c|}
\hline$\lambda$ & Algoritmo D & Algoritmo E(1) & Dif.(\%) & Algoritmo E(2) & Dif.(\%) \\
\hline 0,4 & 0,0578 & 0,01952 & $-66,2$ & 0,00631 & -89 \\
\hline 0,7 & 0,23949 & 0,17239 & -28 & 0,11397 & $-52,4$ \\
\hline 1,0 & 0,38373 & 0,31591 & $-17,6$ & 0,24603 & $-35,8$ \\
\hline
\end{tabular}


Tabela 4.7. Comparação de probabilidade de bloqueio (Chamadas CS2).

\begin{tabular}{|c|c|c|c|c|c|}
\hline$\lambda$ & Algoritmo D & Algoritmo E(1) & Dif.(\%) & Algoritmo E(2) & Dif.(\%) \\
\hline 0,4 & 0,06446 & 0,02294 & $-64,4$ & 0,0044 & $-93,1$ \\
\hline 0,7 & 0,24692 & 0,17769 & -28 & 0,11854 & $-51,9$ \\
\hline 1,0 & 0,39224 & 0,32816 & $-16,3$ & 0,25858 & $-34,1$ \\
\hline
\end{tabular}

Tabela 4.8. Comparação de probabilidade de bloqueio (Chamadas CS3).

\begin{tabular}{|c|c|c|c|c|c|}
\hline$\lambda$ & Algoritmo D & Algoritmo E(1) & Dif.(\%) & Algoritmo E(2) & Dif.(\%) \\
\hline 0,4 & 0,07065 & 0,02399 & -66 & 0,00789 & $-88,8$ \\
\hline 0,7 & 0,27322 & 0,19634 & $-28,1$ & 0,13004 & $-52,4$ \\
\hline 1,0 & 0,42474 & 0,35732 & $-15,8$ & 0,28064 & $-33,9$ \\
\hline
\end{tabular}

Tabela 4.9. Comparação de probabilidade de bloqueio (Chamadas CS4).

\begin{tabular}{|c|c|c|c|c|c|}
\hline$\lambda$ & Algoritmo D & Algoritmo E(1) & Dif.(\%) & Algoritmo E(2) & Dif.(\%) \\
\hline 0,4 & 0,10882 & 0,03123 & $-71,3$ & 0,00858 & $-92,1$ \\
\hline 0,7 & 0,37528 & 0,24975 & $-33,4$ & 0,15574 & -84 \\
\hline 1,0 & 0,54052 & 0,42623 & $-21,1$ & 0,32311 & $-40,2$ \\
\hline
\end{tabular}

Pelos gráficos das probabilidades de bloqueio das chamadas que se iniciam com um tipo específico de esquema de codificação é possível perceber uma clara diferenciação entre os esquemas. Com a adoção dos esquemas $\mathrm{E}(1)$ e $\mathrm{E}(2)$, o algoritmo realiza o empréstimo de banda até os níveis mínimos especificados. Desta maneira, uma diminuição destes níveis acarreta menores probabilidades de bloqueio, já que a banda acumulada é estatisticamente maior, atendendo maior número de chamadas.

Os resultados das probabilidades de bloqueio de handoff para cada tipo de esquema de codificação das chamadas são exibidos nas Figuras de 4.9 a 4.13 e alguns de seus valores são 
apresentados nas Tabelas de 4.10 a 4.14 .

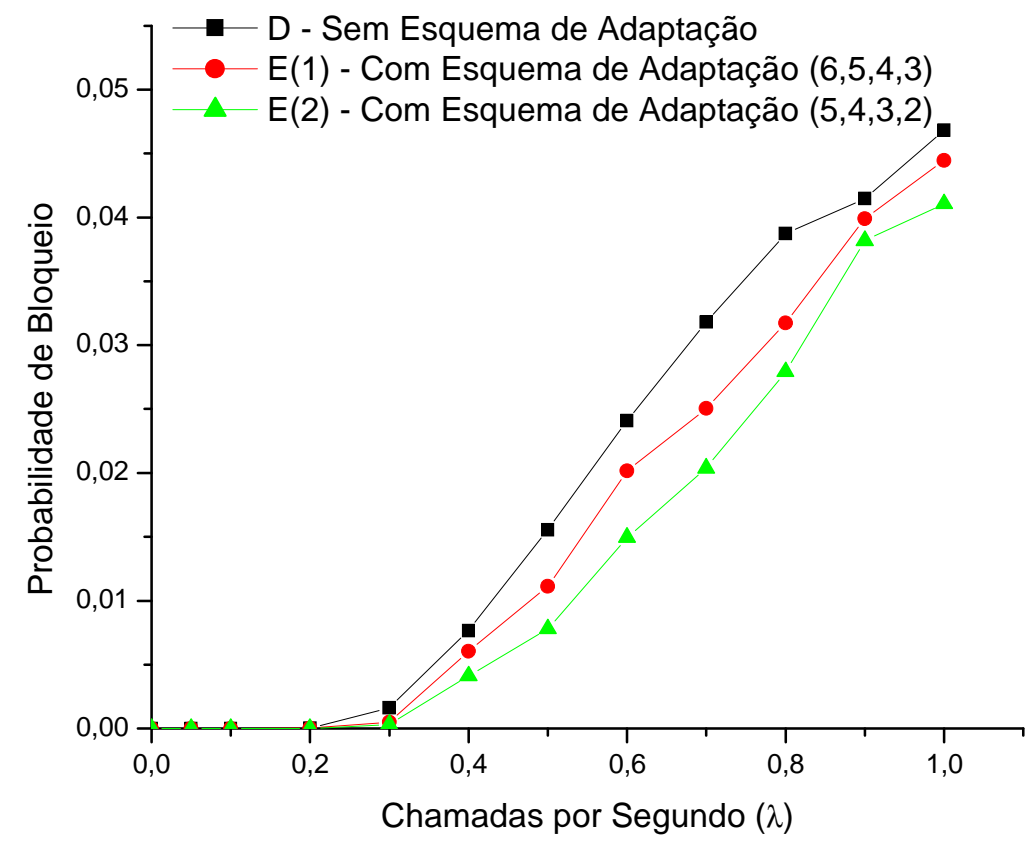

Figura 4.9. Probabilidade de Bloqueio de Handoff(Voz).

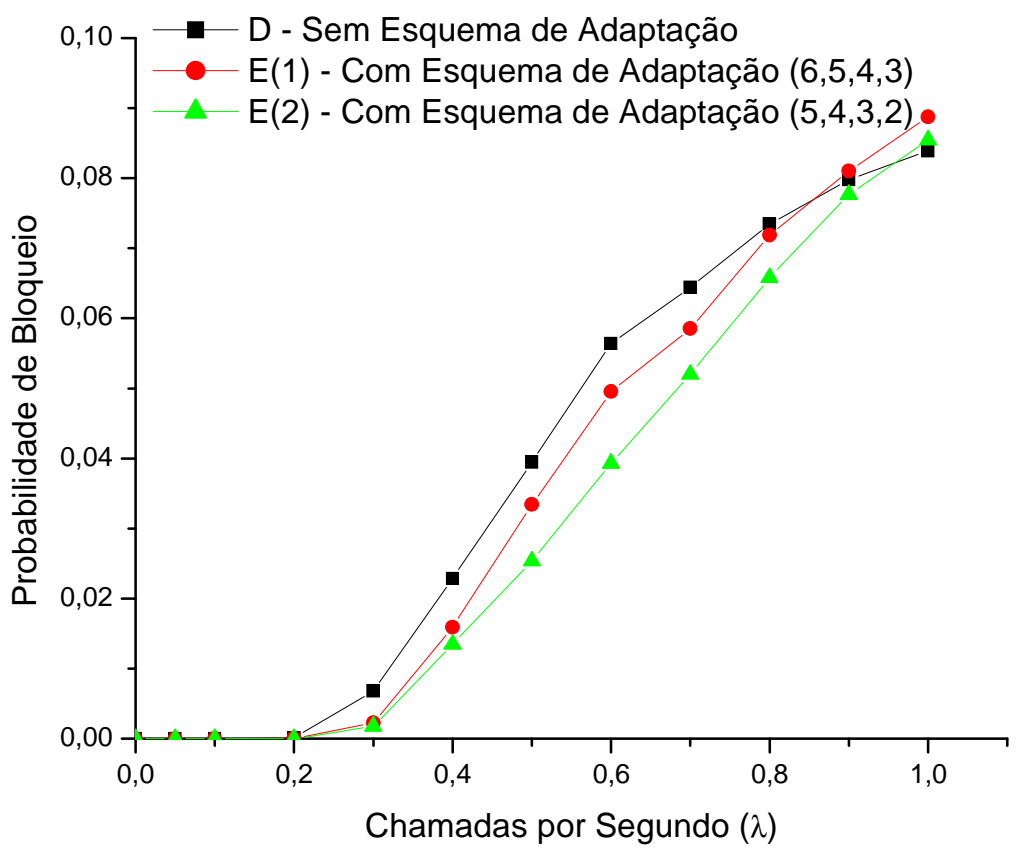

Figura 4.10. Probabilidade de Bloqueio de Handoff (Chamadas CS1). 


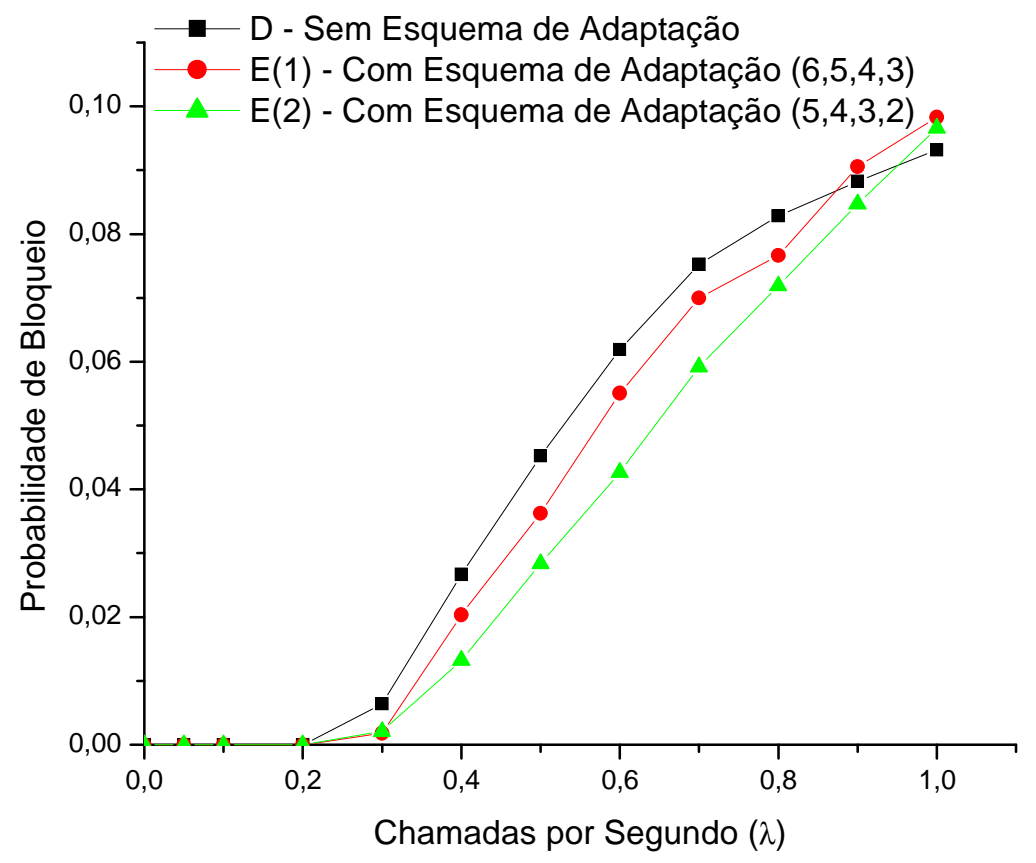

Figura 4.11. Probabilidade de Bloqueio de Handoff (Chamadas CS2).

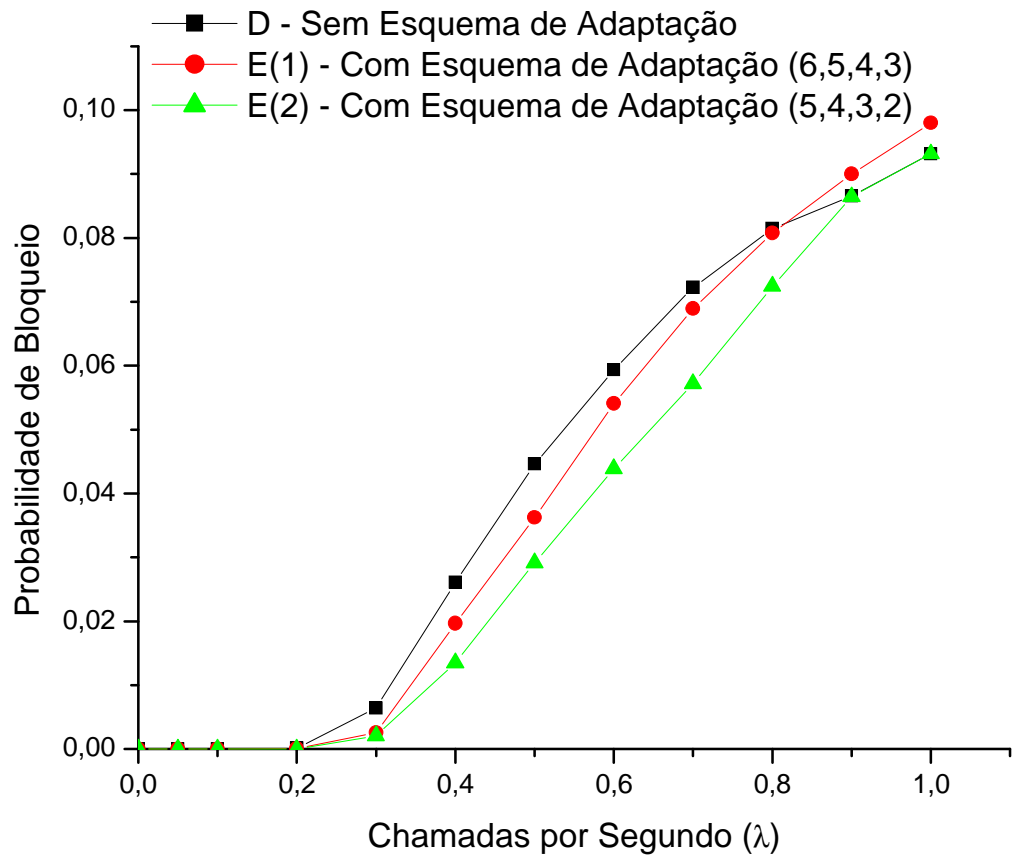

Figura 4.12. Probabilidade de Bloqueio de Handoff (Chamadas CS3). 


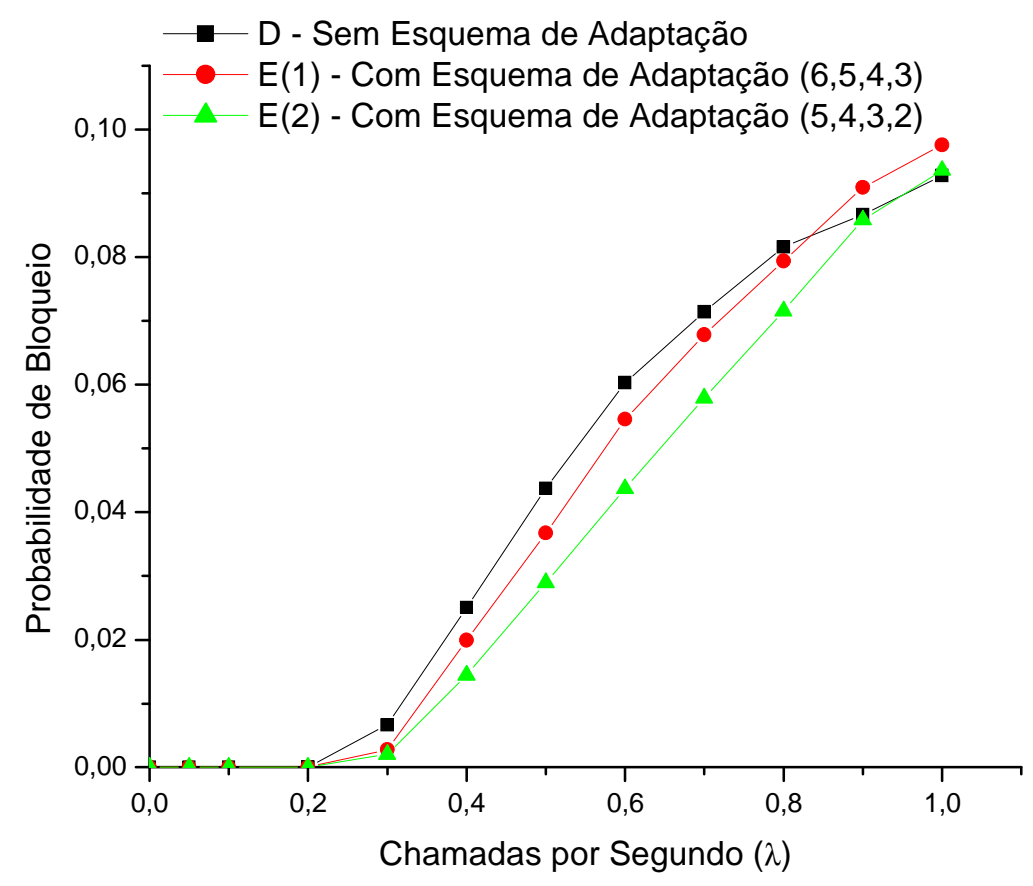

Figura 4.13. Probabilidade de Bloqueio de Handoff (Chamadas CS4).

Tabela 4.10. Comparação de probabilidade de bloqueio (Handoff - Voz).

\begin{tabular}{|c|c|c|c|c|c|}
\hline$\lambda$ & Algoritmo B & Algoritmo C (1) & Dif.(\%) & Algoritmo C (2) & Dif.(\%) \\
\hline 0,4 & 0,00766 & 0,00605 & -21 & 0,00412 & $-46,2$ \\
\hline 0,7 & 0,03179 & 0,02505 & $-21,2$ & 0,02038 & $-35,8$ \\
\hline 1,0 & 0,04682 & 0,04445 & -5 & 0,04106 & $-12,3$ \\
\hline
\end{tabular}

Tabela 4.11. Comparação de probabilidade de bloqueio (Chamadas handoff CS1).

\begin{tabular}{|c|c|c|c|c|c|}
\hline$\lambda$ & Algoritmo B & Algoritmo C (1) & Dif.(\%) & Algoritmo C(2) & Dif.(\%) \\
\hline 0,4 & 0,02286 & 0,01593 & $-30,3$ & 0,01347 & -41 \\
\hline 0,7 & 0,06442 & 0,05854 & $-9,1$ & 0,05199 & $-19,2$ \\
\hline 1,0 & 0,08389 & 0,08871 & $+5,7$ & 0,08545 & $+1,8$ \\
\hline
\end{tabular}


Tabela 4.12. Comparação de probabilidade de bloqueio (Chamadas handoff CS2).

\begin{tabular}{|c|c|c|c|c|c|}
\hline$\lambda$ & Algoritmo B & Algoritmo C (1) & Dif.(\%) & Algoritmo C (2) & Dif.(\%) \\
\hline 0,4 & 0,02666 & 0,02037 & $-23,5$ & 0,01324 & $-50,3$ \\
\hline 0,7 & 0,07525 & 0,06995 & -7 & 0,0592 & $-30,8$ \\
\hline 1,0 & 0,09316 & 0,09827 & $+5,4$ & 0,09657 & +3.6 \\
\hline
\end{tabular}

Tabela 4.13. Comparação de probabilidade de bloqueio (Chamadas handoff CS3).

\begin{tabular}{|c|c|c|c|c|c|}
\hline$\lambda$ & Algoritmo B & Algoritmo C (1) & Dif.(\%) & Algoritmo C (2) & Dif.(\%) \\
\hline 0,4 & 0,02605 & 0,01965 & $-24,5$ & 0,0135 & $-48,1$ \\
\hline 0,7 & 0,07221 & 0,0689 & $-4,5$ & 0,05719 & $-20,8$ \\
\hline 1,0 & 0,09315 & 0,09799 & $+5,1$ & 0,09316 & 0 \\
\hline
\end{tabular}

Tabela 4.14. Comparação de probabilidade de bloqueio (Chamadas handoff CS4).

\begin{tabular}{|c|c|c|c|c|c|}
\hline$\lambda$ & Algoritmo B & Algoritmo C (1) & Dif.(\%) & Algoritmo C (2) & Dif.(\%) \\
\hline 0,4 & 0,02505 & 0,01991 & $-20,5$ & 0,01446 & $-42,2$ \\
\hline 0,7 & 0,07143 & 0,06783 & -5 & 0,05789 & $-18,9$ \\
\hline 1,0 & 0,09281 & 0,0976 & $+5,1$ & 0,0936 & $+0,8$ \\
\hline
\end{tabular}

É possível perceber, também para o caso de handoff, que todos os tipos de chamadas apresentaram comportamento semelhante. Conforme também ocorre com a Figura 4.2, com um tráfego maior ocorre uma aproximação das curvas. Este fato é decorrente da necessidade de alocação do nível médio das chamadas handoff $\left(N_{m e d}\right)$ e de que em um ambiente de alto tráfego gera escassez de banda para a alocação das chamadas.

Não há uma diferenciação significativa entre o comportamento das probabilidades de bloqueio das diferentes esquemas de codificação (CS1, CS2, CS3 e CS4). Como suas conexões contam igualmente com oito níveis, variando de 1 a oito slots, o funcionamento do 
algoritmo produz resultados semelhantes devido ao processo de escolha do nível de conexão possível para uma determinada situação da rede.

As Figuras 4.14 - 4.17 mostram o throughput médio para os esquemas de codificação possíveis (CS1, CS2, CS3 ou CS4) de cada chamada. Há uma pequena diminuição do throughput para tráfegos maiores em relação ao esquema sem adaptação (D) para os esquemas de codificação CS2, CS3 e CS4, pois como apresentam uma demanda de banda maior, sua alocação vai depender de maior banda disponível na célula, o que implica em necessidade de alocação em níveis menores de banda.

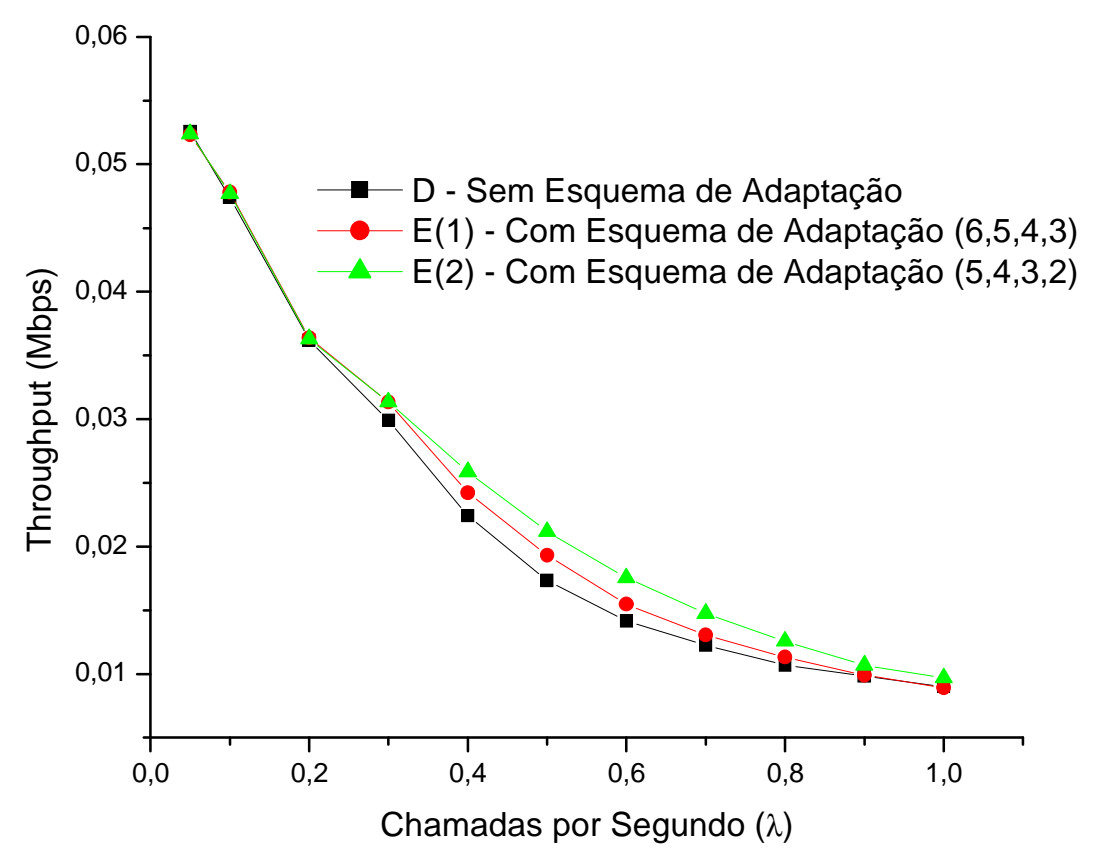

Figura 4.14. Throughput médio (Chamadas CS1). 


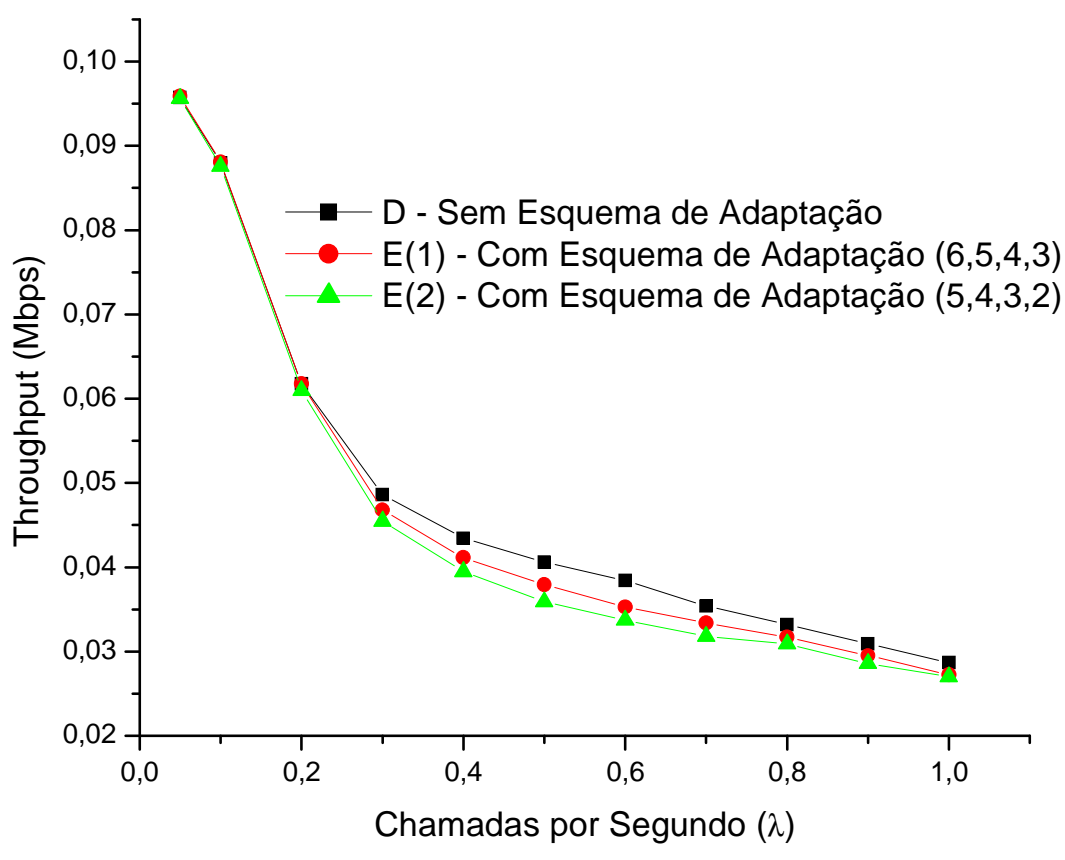

Figura 4.15. Throughput médio (Chamadas CS2).

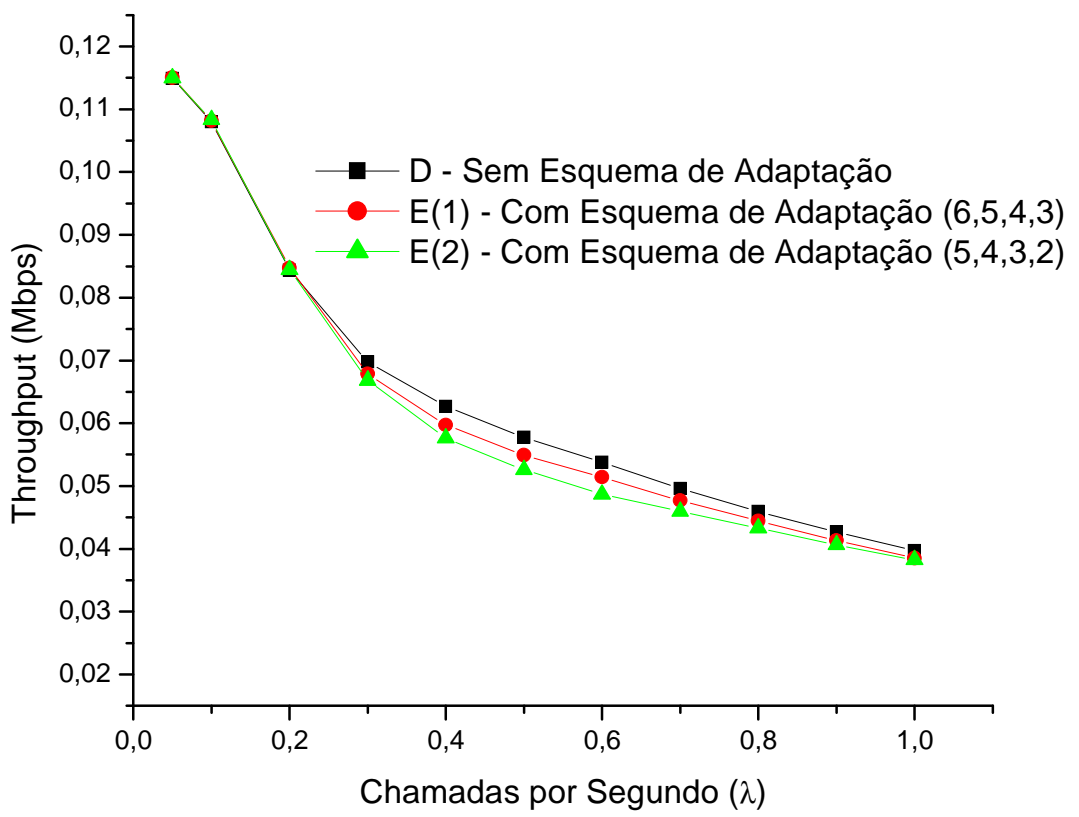

Figura 4.16. Throughput médio (Chamadas CS3). 


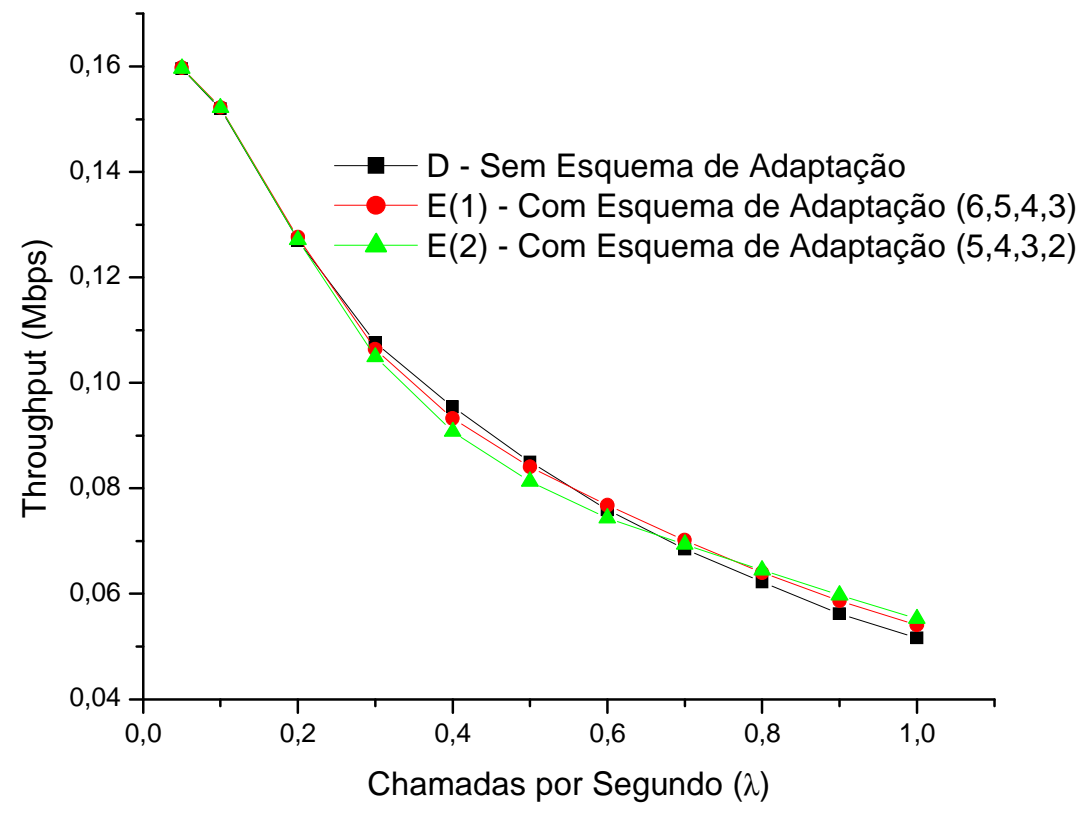

Figura 4.17. Throughput médio (Chamadas CS4). 


\section{Capítulo 5}

\section{Conclusões}

As redes de comunicação móvel celular vêm ganhando grande importância no modo de vida da população mundial. O oferecimento de um serviço de comunicação móvel com uma boa qualidade torna mister o investimento em tecnologia e infra-estrutura por parte das diversas operadoras.

O bom aproveitamento da infra-estrutura instalada aliado ao oferecimento de uma boa prestação de serviços tem importância fundamental para o sistema. Como centro de decisão de qualquer controle de um sistema de comunicação móvel celular, o controle de admissão de chamadas (CAC) atua para melhorar o desempenho global da rede.

Este trabalho está centrado justamente nestes fatores para as abordagens propostas, que exibem melhorias na probabilidade de bloqueio de novas chamadas com a adição de um mecanismo que utiliza uma maneira mais eficiente a banda reservada para as chamadas handoff e que realiza o empréstimo de banda de chamadas em andamento na célula até níveis de banda mínimos estabelecidos. O algoritmo proposto foi simulado para uma rede de comunicação móvel celular de terceira geração (3G) (esquema $\mathrm{CN}$ ) e também para uma rede GSM/GPRS (esquema E). A simulação levou em conta as bandas típicas utilizadas nestes sistemas e, no caso da rede GSM, foram consideradas as restrições físicas de C/I para a escolha do esquema de codificação adequado para uma determinada chamada.

Para a rede de terceira geração (3G), os resultados mostram uma melhoria significativa num determinado cenário de até $83 \%$ para a probabilidade de bloqueio de novas chamadas e de até $23 \%$ na probabilidade de bloqueio de chamadas handoff num cenário específico (Tabelas 3.2 
e 3.3). Para a probabilidade de bloqueio de classes de novas chamadas, percebe-se uma melhora significativa em seus valores, sendo que as classes 3 e 6 apresentam as maiores probabilidades de bloqueio, o que é consequiência de suas altas demandas por banda (Tabelas 3.7 e 3.10). A classe 4 exibe a menor probabilidade de bloqueio e apresenta a melhoria mais significativa, por apresentar uma baixa demanda de banda e ser do tipo VBR, o que facilita sua conexão.

Quanto à probabilidade de bloqueio de classes de chamadas handoff, ocorrem melhorias entre o esquema proposto $(\mathrm{CN})$ em relação ao esquema B. Para as classes 3 e 6 há um aumento na probabilidade de bloqueio pelos motivos explicados no Capítulo 3.

No caso da rede GSM/GPRS, há melhorias significativas de até $90 \%$ para a probabilidade de bloqueio de novas chamadas e de até $43 \%$ para a probabilidade de bloqueio de chamadas handoff. Para as probabilidades de bloqueio dos esquemas de codificação CS1, CS2, CS3 e CS4 há uma melhoria de desempenho do esquema E em relação ao esquema sem adaptação (D). O mesmo ocorre para as probabilidades de bloqueio dos esquemas de codificação para chamadas handoff.

A simulação das redes de terceira geração mostrou-se interessante no contexto atual, pois essa tecnologia ainda está em ascensão na maior parte do mundo e, no Brasil, suas respectivas freqüências de operação foram recentemente licitadas pela Anatel (Agência Nacional de Telecomunicações).

A simulação do algoritmo de controle de admissão de chamadas em uma rede GSM/GPRS teve como objetivo a sua avaliação no que tange as suas bandas típicas para voz e dados. Como a tecnologia GSM detém a maioria do mercado mundial, o estudo de seu desempenho em nível de rede torna-se igualmente interessante.

Como trabalho futuro sugere-se o estudo da integração das redes de comunicação móvel celular com as redes de satélites, com o objetivo de estudar algoritmos para a alocação de 
banda em chamadas para esta rede híbrida. O mesmo estudo pode ser estendido para a integração de redes de comunicação móvel celular com redes ópticas. 



\section{Referências Bibliográficas}

[1] GSA - The Global mobile Suppliers Association, http://www.gsacom.com/, Último Acesso: Março 2008.

[2] Agência Nacional de Telecomunicações - Anatel http://sistemas.anatel.gov.br/smp/administracao/consulta/acompanhamento_estacoes/tela.asp? CodTopico $=2440 \&$ CodArea $=31 \&$ CodTemplate $=413 \&$ CodMenuServico=43, Último Acesso: Janeiro 2008.

[3] Agência Nacional de Telecomunicações - $\quad$ Anatel http://www.anatel.gov.br/Tools/frame.asp?link=/biblioteca/releases/2006/release_22_12_200 6mm.pdf, Último Acesso: Outubro 2007.

[4] Faruque, Saleh. Cellular Systems Engineering, Artech House, 1996.

[5] M. Sanabani, S. Shamala, M. Othman e J. Desa, "Adaptive Call Admission Control for Prioritized Adaptive services in Wireless/Mobile Multimedia Cellular Networks", International Journal of Computer Science and Network Security, pp.114-214, 2006.

[6] GSA - The Global mobile Suppliers Association, http://www.gsacom.com/downloads/pdf/GSM_3G_Market_Update.php4/, Último Acesso: Março 2008.

[7] Teleco - http://www.teleco.com.br/3g_brasil.asp, Ultimo Acesso: Outubro 2007.

[8] Q. Ren, e G. Ramamurthy, “A real-time dynamic connection admission controller based on traffic modeling, measurement, and fuzzy logic control”. IEEE Journal on Select. Areas Comm., Volume 18, pp. 268-282, Fevereiro, 2000.

[9] C. Oliveira, J. Kim, e T. Suda. "Quality-of-Service Guarantee in High-Speed Multimedia Wireless Networks", Technical Report, University of California, Irvine, CA, pp. 95-41, 1995.

[10] Ghaderi, Majid e Boutaba, Raouf, "Call admission control in mobile cellular networks: a comprehensive survey", Wireless Communications \& Mobile Computing, pp. 69-93, Fevereiro. 2006.

[11] Katzela e M. Naghshineh, "Channel Assignment Schemes for Cellular Mobile Telecommunication Systems: A Comprehensive Survey", IEEE Personal Communications, pp. 10-21, 1996. 
[12] K. Jun, S. Kang, "Call Admission Control for Next Generation Cellular Networks Using on Demand Round Robin Bandwidth Sharing", Lecture Notes in Computer Science, Volume 3421, pp. 543 - 550, Janeiro, 2005.

[13] Koo-Min Ahn e Sehun Kim, "Optimal bandwidth allocation for bandwidth adaptation in wireless multimedia networks", Computers and Operations Research, Volume 30, nro.13, pp. 1917-1929, Novembro, 2003.

[14] Marcos A. C. de Lima, Alocação de recursos e roteamento de tráfego em telecomunicações por meio de algoritmo genético: rede óptica WDM e rede de comunicação móvel celular, Tese de Doutorado, Escola de Engenharia de São Carlos - Universidade de São Paulo, 2005.

[15] M. El-Kadi, S. Olariu, e H. Abdel-Wahab, "A rate-based borrowing scheme for QoS provisioning in multimedia wireless networks," IEEE Trans. Parallel Distrib. Syst., Volume13, nro.2, pp.156-166, Janeiro, 2002.

[16] Malla, A., El-Kadi, M., Olariu, S., e Todorova, P., "A Fair Resource Allocation Protocol for Multimedia Wireless Networks". IEEE Trans. Parallel Distrib. Syst. 14, pp. 6371, Janeiro, 2003.

[17] Mokhtar Aboelazel, Ayman Elnaggar e Maan Musleh, "A Priority Based Call Admission Control Protocol with Call Degradation for Cellular Networks", Proceedings of the 1st International Symposium on Wireless Communication Systems ISWC, Mauritius, pp. 20-22, Setembro, 2004.

[18] Nidal Nasser e Hossam Hassanein, "Optimized Bandwidth Allocation with Fairness and Service Differentiation in Multimedia Wireless Networks", International Journal of Wireless Communications and Mobile Computing, Wiley, 2006.

[19] N. Nasser e H. S. Hassanein, "Combined Admission Control Algorithm and Bandwidth Adaptation Algorithm in Multimedia Cellular Networks with QoS Provisioning," IEEE Canadian Conference on Electrical and Computer Engineering, Maio, 2004.

[20] Jamal R., "Development and Comparison Between Resource Allocation Strategies Based on Intelligent Scheme and Traditional Distributed Dynamic Resource Allocation Strategies in Mobile Communication Networks", Wireless Personal Communications: An International Journal, Volume 40, pp. 495 - 509, Março, 2007.

[21] Maneesh T. e H. S. Jamadagni, "A New Call Admission Control scheme for Realtime traffic in Wireless Networks". In Proceedings IEEE TENCON, Bangalore, Índia, pp. 1585-1589, 2003.

[22] Y. Zhang e D. Liu, "An adaptive algorithm for call admission control in wireless networks", in: Proc. IEEE Globecom, San Antonio, Texas, pp. 3628-3632, 2001. 
[23] Y.C. Kim, D.E. Lee, Y.S. Kim e B. Mukherjee, "Dynamic channel reservation based on mobility in wireless ATM networks", IEEE Communications Magazine, pp. 47-51, 1999.

[24] Tanembaum, A. S., "Redes de Computadores", Editora Campus, 2003.

[25] P.J.A. Gutierrez, J. Wigard, P.N. Andersen, H.C. Damgaard, P. Mogensen, "Performance of link adaptation in GPRS Networks" Vehicular Technology Conference, 2000. IEEE VTS-Fall VTC 2000. Volume 2, pp. 492 - 499, 2000.

[26] J. C. Wu, W. Chen, H. Liu, "Radio Resource Allocation in GSM/GPRS Networks" International Conference on Information Networking - ICOIN, pp. 457-468, 2002.

[27] W. Featherstone, D. Molkdar, "System level performance evaluation of GPRS for various traffic models" Vehicular Technology Conference, 2000. IEEE VTS-Fall VTC 2000. Volume 6, pp. 2648 - 2652, 2000.

[28] P. Stuckmann, F. Muller, "GPRS radio network capacity and quality of service using fixed andon-demand channel allocation techniques", Vehicular Technology Conference Proceedings, IEEE Volume 1, pp.440 - 444, 2000.

[29] O. Queseth, F. Gessler, M. Frodigh, "Algorithms for link adaptation in GPRS" Vehicular Technology Conference, 1999 IEEE Volume 2, pp. 943 - 947, Julho 1999.

[30] T. Lundberg, P. de Bruin, S. Bruhn, S. Hakansson, S. Craig, "Adaptive Thresholds for AMR Codec Mode Selection", Vehicular Technology Conference, Volume 4, pp. 2325 2329, Junho 2005.

[31] H. Holma, J. Melero, J. Vainio, T. Halonen, J. Makinen, "Performance of Adaptive Multirate (AMR) Voice in GSM and WCDMA", Vehicular Technology Conference, Volume 4, pp. 2177 - 2181, Abril 2003.

[32] Alan Olivré, "Call Admission Control and Dynamic Pricing in a GSM/GPRS Cellular Network", Master of Science in Computer Science, University of Dublin, Trinity College, Setembro 2004.

[33] Timo, H, Romero, J., Melero, J., "GSM, GPRS and EDGE Performance - Evolution Towards 3G/UMTS", Editora John Wiley \& Sons, 2002.

[34] Anatel - http://www.anatel.gov.br/Portal/exibirPortalInternet.do, Último Acesso: Outubro, 2007.

[35] Ed. Nowicki, "Resource Allocation for Multimedia Messaging Services over EGPRS", Master of of Engineering in Electronic Engineering, Dublin City University, Setembro 2003. 

Artigos Resultantes do Trabalho:

Eduardo M. G. de Queiroz, Helvécio M. A. Neto e Amílcar C. César, "Algoritmo de Alocação Dinâmica de Largura de Faixa para Redes Sem Fio”, XXV Simpósio Brasileiro de Telecomunicações - SBrT'07, pp. 1-6 (CD-ROM), Recife, PE, 3 a 6 de setembro de 2007. 